\title{
Recent synthesis of thietanes
}

\author{
Jiaxi Xu
}

\author{
Review \\ Address: \\ State Key Laboratory of Chemical Resource Engineering, Department \\ of Organic Chemistry, College of Chemistry, Beijing University of \\ Chemical Technology, Beijing 100029, People's Republic of China \\ Email: \\ Jiaxi Xu - jxxu@mail.buct.edu.cn \\ Keywords: \\ cycloaddition; cyclization; ring contraction; ring expansion; thietane; \\ thiotherification
}

Beilstein J. Org. Chem. 2020, 16, 1357-1410.

doi:10.3762/bjoc.16.116

Received: 29 March 2020

Accepted: 26 May 2020

Published: 22 June 2020

Associate Editor: B. Nay

(C) 2020 Xu; licensee Beilstein-Institut.

License and terms: see end of document.

\section{Abstract}

Thietanes are important aliphatic four-membered thiaheterocycles that are found in the pharmaceutical core and structural motifs of some biological compounds. They are also useful intermediates in organic synthesis. Various synthetic methods of thietanes have been developed, including inter- and intramolecular nucleophilic thioetherifications, photochemical [2+2] cycloadditions, ring expansions and contractions, nucleophilic cyclizations, and some miscellaneous methods. The recently developed methods provide some new strategies for the efficient preparation of thietanes and their derivatives. This review focuses on the synthetic methods to construct thietane backbones developed during 1966 to 2019.

\section{Review}

\section{Introduction}

Thietanes are a class of important aliphatic four-membered thiaheterocycles. Some simple alkyl and dialkyl thietanes are components of anal gland secretions of the stoat [1] and the ferret [2]. Some pharmaceutical and biological thietane-containing compounds include thiaanalogue thietanose nucleosides $\mathbf{1}$ and $\mathbf{2}$ $[3,4]$, and the spiroannulated glyco-thietane nucleoside 3 [5] of the antiviral (anti-HIV and HSV) drug oxetanocin A, the D-ring-modified thia derivatives $\mathbf{4}$ and $\mathbf{5}$ of the anticancer drug taxoids and docetaxels [6], thiathromboxane A2 6 [7], pesticide 7 [8], and the sweetener 8 [9] (Figure 1). Thietanes also serve as important and useful intermediates and versatile building blocks in organic synthesis for the preparation of sulfur-containing

acyclic and heterocyclic compounds [10,11]. Several synthetic methods for thietanes have been developed and reviewed [1214]. One traditional route is the intermolecular double substitution (cyclic thioetherification) of 1,3-dihaloalkanes, sulfonates of 3-haloalkan-1-ols, or disulfonates of alkane-1,3-diols with sodium sulfide. The intramolecular substitution of 3-mercaptoalkyl halides or sulfonates is a similar strategy for the preparation of thietanes [12-14]. Alternatively, inter- and intramolecular photochemical [2+2] cycloadditions (thia-Paternò-Büchi reactions) of alkenes and thiocarbonyl compounds are another important route for the synthesis of thietanes [15,16], especially, spirothietanes $[17,18]$. The formal $[2+2]$ cycloadditions 
<smiles>Cc1cn(C23COCC2CC3O)c(=O)[nH]c1=O</smiles>

1<smiles>CCCCC[C@H](O)/C=C/[C@H]1C[C@H]2CC[C@H]1[C@@H]2C/C=C/CCCC(=O)O</smiles>

(+)-thiathromboxane A2<smiles>O=c1ccn([C@H]2OC3(CSC3)[C@H](O)[C@H]2O)c(=O)[nH]1</smiles>

3<smiles>Cc1cc(Cl)cc(C2(C(F)(F)F)CC(c3ccc(C(=O)NC4CSC4)c(C)c3)=NO2)c1</smiles>

7

pesticide

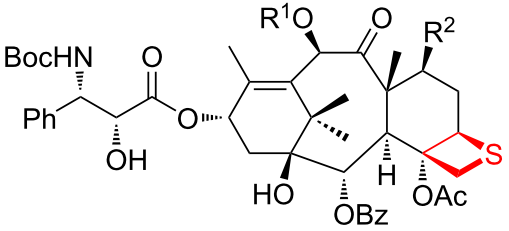

thiadocetaxel $\left(\mathrm{R}^{1}=\mathrm{H}, \mathrm{R}^{2}=\mathrm{OH}\right) \mathbf{4}$

7-deoxythiadocetaxel $\left(R^{1}=A c, R^{2}=H\right) 5$<smiles>C[C@H](NC(=O)[C@H](N)CC(=O)O)C(=O)NC1C(C)(C)SC1(C)C</smiles>

8

sweetener

Figure 1: Examples of biologically active thietane-containing molecules.

of hexafluorothioacetone and olefins are also applied in the preparation of bis(trifluoromethyl)-containing thietanes [19]. The ring-contractions of five and six-membered aliphatic thiaheterocycles have been seldom applied in the preparation of thiatetraoses [20,21]. In contrast, both nucleophilic and electrophilic ring expansions of thiiranes have been developed to synthesize thietanes [22,23]. Phosphorodithioate has been applied in the synthesis of thietanes as a nucleophile and generated phosphorothioate as a leaving group [24]. Some other cyclization methods have been reported in the synthesis of thietanes as well [25] (Figure 2).
This review covers the methods outlined in Figure 2 and also some miscellaneous methods for the synthesis of various thietane derivatives. A special focus is on the construction of the thietane ring, excluding methods for the simple modifications of the thietane rings and their side chains [26-31].

\section{Synthesis via cyclic thioetherifications}

2.1 Synthesis via double nucleophilic displacements 2.1.1 Synthesis via double nucleophilic displacements of 1,3dihaloalkanes: Although the double nucleophilic displacements of 1,3-dihaloalkanes with sodium sulfide are the oldest

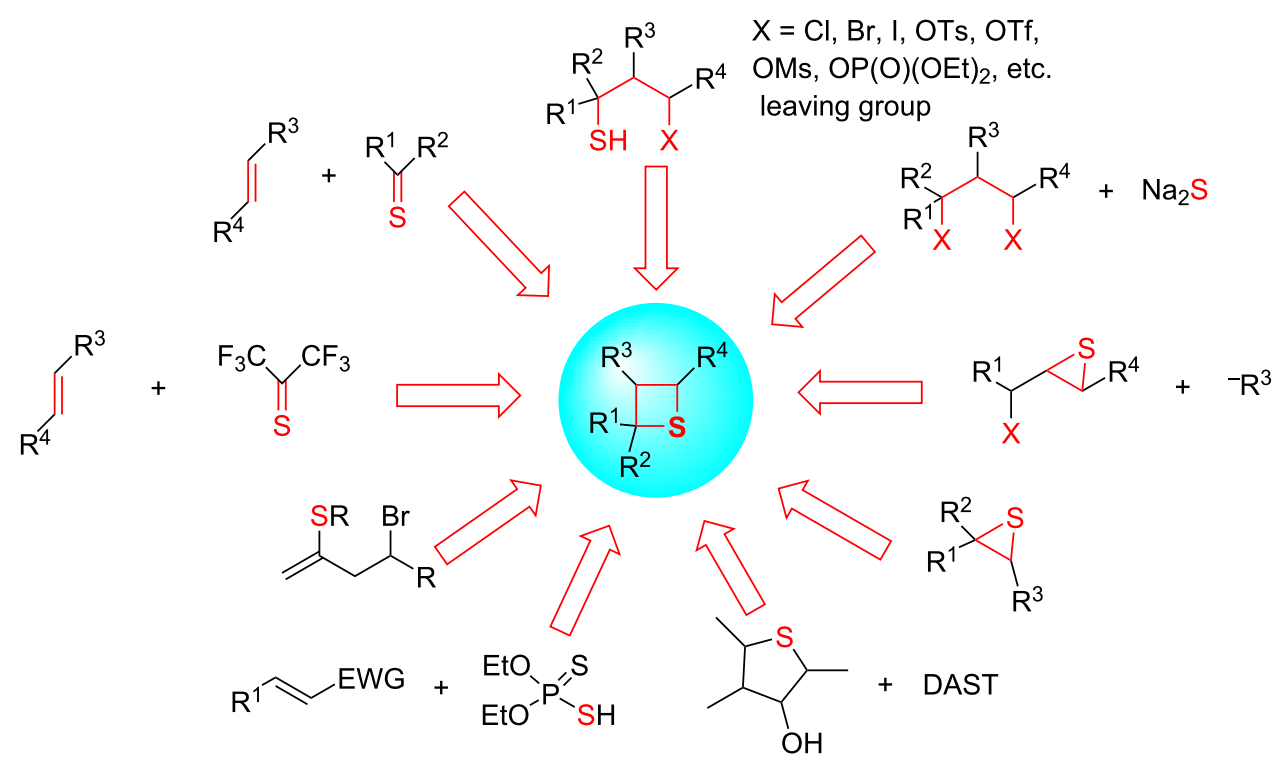

Figure 2: The diverse methods for the synthesis of thietanes. 
methods for the preparation of thietane derivatives and have well been studied, they are widely applied till now. The development of this method before 1965 was reviewed by Sander [12] and this review contains new advances since 1965.

After Sander's review [12], Cerny and Polacek reported the synthesis of a thietane derivative via the double nucleophilic displacement of 1,3-dichloroalkane in 1966 [32]. They treated 3,5-dichloropentan-2-ol (9) with $\mathrm{K}_{2} \mathrm{~S}$ to produce 1-(thietan-2yl)ethan-1-ol (10) in 65\% yield (Scheme 1).

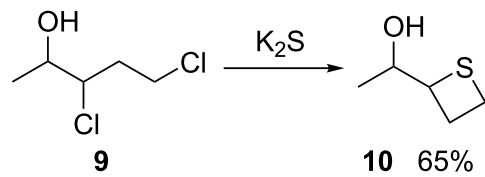

Scheme 1: Synthesis of 1-(thietan-2-yl)ethan-1-ol (10) from 3,5dichloropentan-2-ol (9).

In 2007, Nishizono and co-workers used 2,2-bis(bromomethyl)propane-1,3-diol (11) as starting material to prepare thietanose nucleosides $\mathbf{2}$ and $\mathbf{1 4}$. They first carried out a double displacement with sodium sulfide to obtain thietane-3,3diyldimethanol (13), which was further converted into two different thietanose nucleosides $\mathbf{2}$ and $\mathbf{1 4}$ [33] (Scheme 2).
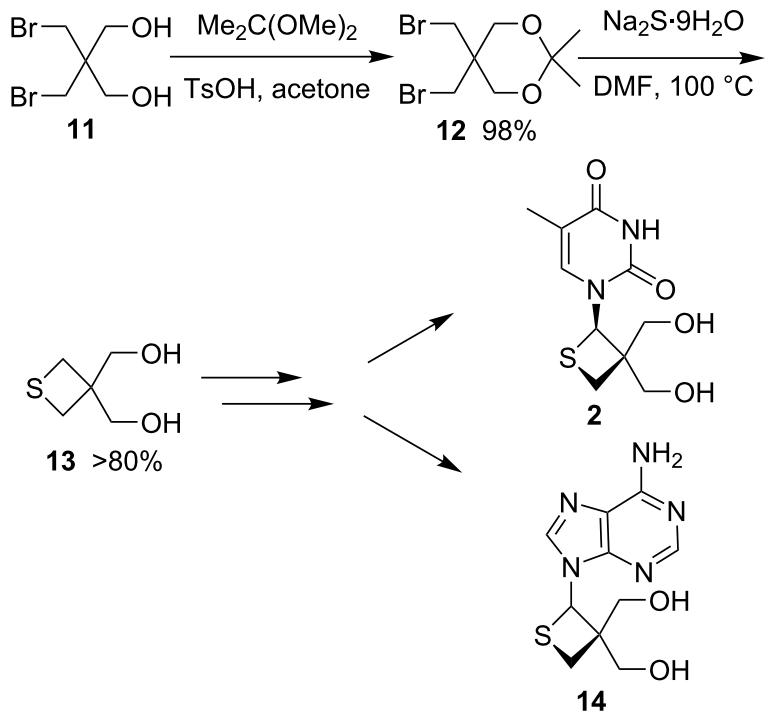

Scheme 2: Synthesis of thietanose nucleosides 2,14 from 2,2 bis(bromo-methyl)propane-1,3-diol (11).

In the synthesis of sesquiterpene thioalkaloids, the method also was utilized. A double-aldol condensation of methyl crotonate (15) with 1-hydroxymethylbenzotriazole (16) generated methyl 2,2-dihydroxymethylbut-3-enoate (17) in 58\% yield. Iodination and subsequent double displacement with sodium sulfide afforded methyl 1-vinylthietane-1-carboxylate (19) in 51\% yield over two steps [34]. Compound 19 was used as an intermediate for the total synthesis of sesquiterpene thioalkaloids (Scheme 3).

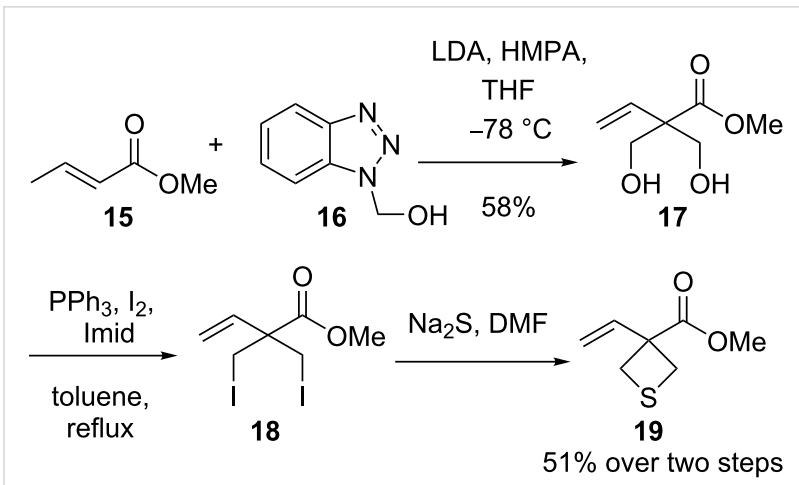

Scheme 3: Synthesis of methyl 3-vinylthietane-3-carboxylate (19).

Spiro[3.3] heptane derivatives were recently used as the surrogates of piperazines, piperidines, morpholines, and thiomorpholines, which display pharmacological activities [35]. 1,6Thiazaspiro[3.3] heptane (24) was synthesized for discovery of pan-CDK inhibitors. For this, 3-bromo-2,2-bis(bromomethyl)propan-1-ol (20) was transformed into 3-bromomethyl3-hydroxymethyl-1-tosylazetidine (21), which was treated with $\mathrm{Ph}_{3} \mathrm{P} / \mathrm{CBr}_{4}$ to yield 3,3-bis(bromomethyl)-1-tosylazetidine (22) in $52 \%$ yield. The double displacement of 3,3bis(bromomethyl)-1-tosylazetidine (22) with sodium sulfide followed by the detosylation with $\mathrm{Mg}$ in $\mathrm{MeOH}$ afforded 1,6thiazaspiro[3.3] heptane (24) [36] (Scheme 4).
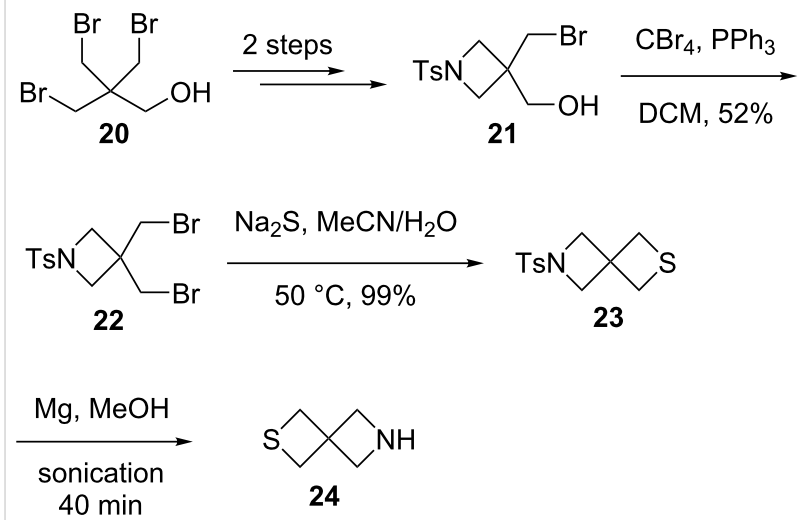

Scheme 4: Synthesis of 1,6-thiazaspiro[3.3]heptane (24).

2.1.2 Synthesis via double nucleophilic displacements of disulfonates of alkane-1,3-diols: Considering that 6-amino-3- 
azaspiro[3.3] heptane was evaluated as inhibitor of kinases, insecticides, and acaricides, its sulfur analogue, 6-amino-2thiaspiro[3,3]heptane (28) was prepared from the cheap starting material 2,2-bis(bromo-methyl)propane-1,3-diol (11). Compound 11 was converted into 3-(tert-butoxycarbonyl)-1,1bis(hydroxymethyl)aminocyclobutane (25) in 6 steps. After the treatment of $\mathbf{2 5}$ with methanesulfonyl chloride, the obtained dimethanesulfonate $\mathbf{2 6}$ was reacted with sodium sulfide giving rise to 6-(tert-butoxycarbonyl)amino-2-thiaspiro[3.3] heptane (27), which was further transformed into the desired 6-amino-2thiaspiro[3,3]heptane $(\mathbf{2 8})$ hydrogen chloride salt after the acidic deprotection [37] (Scheme 5).

During recent decades, the cyclic thioetherification strategy was widely applied in the synthesis of thietane-based square sugurs (thietanoses), and sulfur-containing glycomimetics of furanoses and pyranoses [38]. The first thietanose was synthesized from vitamin C (29) in 1996 (Scheme 6). Vitamin C (29) was converted first into 1,3-dimesylate $\mathbf{3 0}$ of 2,4-di- $O$-protected 1,2,3,4butane-tetraol in 6 steps. The subsequent treatment with $\mathrm{Na}_{2} \mathrm{~S}$ in refluxing ethanol then gave rise to the protected thietanose $\mathbf{3 1}$ in $62 \%$ yield [3] (Scheme 6 ).

Following similar protocols, $(S, S)$-2,3-bis(benzoyloxymethyl)thietane (34) was synthesized from diethyl L-tartrate

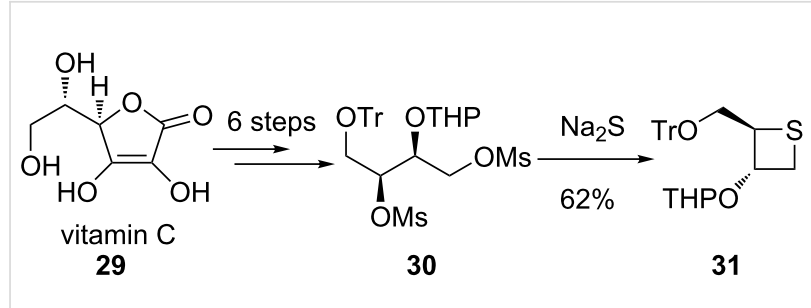

Scheme 6: Synthesis of optically active thietane $\mathbf{3 1}$ from vitamin C.

(32), which was further converted into thietanocin A (35), a sulfur analogue of oxetanocin A [39] (Scheme 7).

The double displacement cyclic thioetherification strategy was also utilized for the synthesis of thietane-containing spironucleosides. The easily available 5-aldo-3-O-benzyl-1,2-O-isopropylidene- $\alpha$-D-glucofuranose (36) was first treated with formaldehyde in the presence of $\mathrm{NaOH}$ followed by $\mathrm{MsCl}$, affording the dimesylate derivative $\mathbf{3 8}$, which was reacted with $\mathrm{Na}_{2} \mathrm{~S}$ to afford the spirothietane 39. The latter was further converted into the thietane-containing spironucleoside 40 [40] (Scheme 8).

The same research group synthesized the optically active 2-methylthietane-containing spironucleoside $\mathbf{4 3}$ by following a similar synthetic method [40] (Scheme 9).
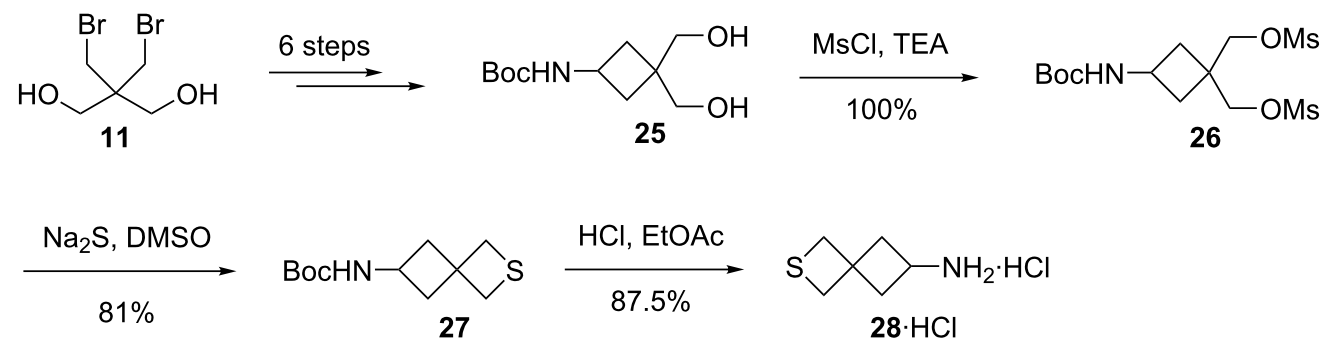

Scheme 5: Synthesis of 6-amino-2-thiaspiro[3.3]heptane hydrochloride (28).

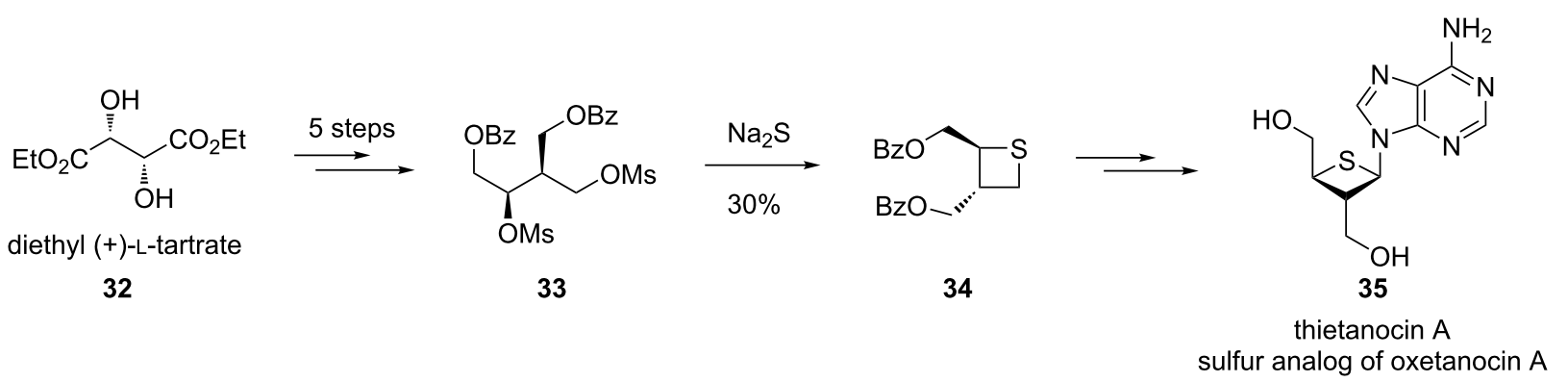


<smiles>CC1(C)O[C@@H]2O[C@H](C=O)[C@@H](OCc3ccccc3)[C@H]2O1</smiles>

36<smiles>CC1(C)OC2C(O)C(CO)(CO)O[C@@H]2O1</smiles>

$3765 \%$

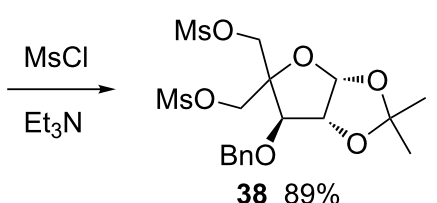

$3889 \%$

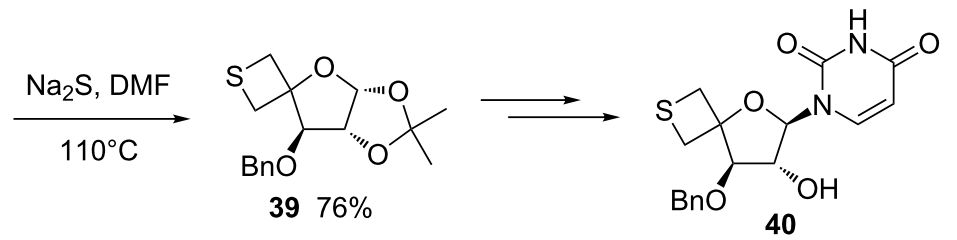<smiles>CC#CC1(C)OC2OC(CO)(CO)C(O)C2O1</smiles>

37

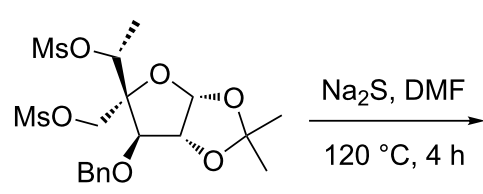

41<smiles>CC1SCC12O[C@@H]1OC(C)(C)O[C@H]1C2OCc1ccccc1</smiles>

$4277 \%$<smiles>CC1SC[C@]12O[C@@H](n1ccc(=O)[nH]c1=O)[C@H](O)[C@H]2OCc1ccccc1</smiles>

43

Scheme 9: Synthesis of optically active 2-methylthietane-containing spironucleoside 43.

In 2009, Da Silva and co-worker succeeded in the synthesis of a 4',4'-spirothietane-2', $N^{3}$-cycloadenosine 46 as a highly constrained analogue of 5'-deoxy-5'-methylthioadenosine. They first prepared tritosylate derivative $\mathbf{4 4}$ from D-glucose which was treated with KSAc to give the spirothietane derivative $\mathbf{4 5}$. The latter compound was further converted to the final thietanecontaining spironucleoside 46 [41] (Scheme 10).

In 2011, Nishizono and co-worker synthesized two anomeric thietanose nucleosides with (Z)-but-2-ene-1,4-diol (47) as the starting material. They first converted the diol $\mathbf{4 7}$ into dimethanesulfonates 48 of 1,5-dibenzyloxypentane-2,4-diol and treated it with sodium sulfide to afford 2,4-di(benzyloxymethyl)thietane (49). Compound 49 was then further trans- formed into two different anomeric thietanose nucleosides $\mathbf{1}$ and 50 [4] (Scheme 11).

In the development of novel class I phosphoinositide 3-kinase (PI3k) inhibitors, 6-bromo-3,3-bis(hydroxymethyl)indolin-2one (51) was reacted first with mesyl chloride and then treated with sodium sulfide to afford 6-bromospiro[indoline-3,3'thietan]-2-one (53), which was further converted into the target inhibitor candidate 54 [42] (Scheme 12).

2-Methylene- $\gamma$-butyrolactone (55) as the initial starting material was converted into bis(hydroxymethyl)quinolizidinone $\mathbf{5 6}$. After mesylation and the double displacement with sodium sulfide, spirothietane-quinolizidine $\mathbf{5 7}$ was obtained as a key

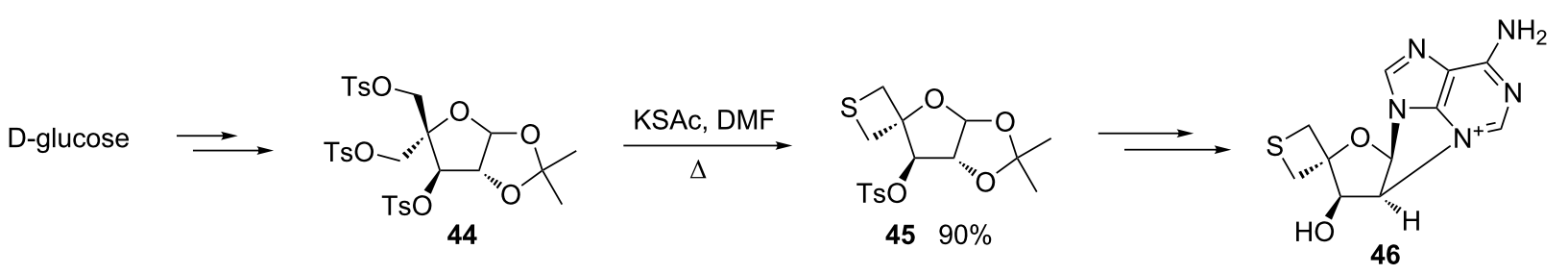



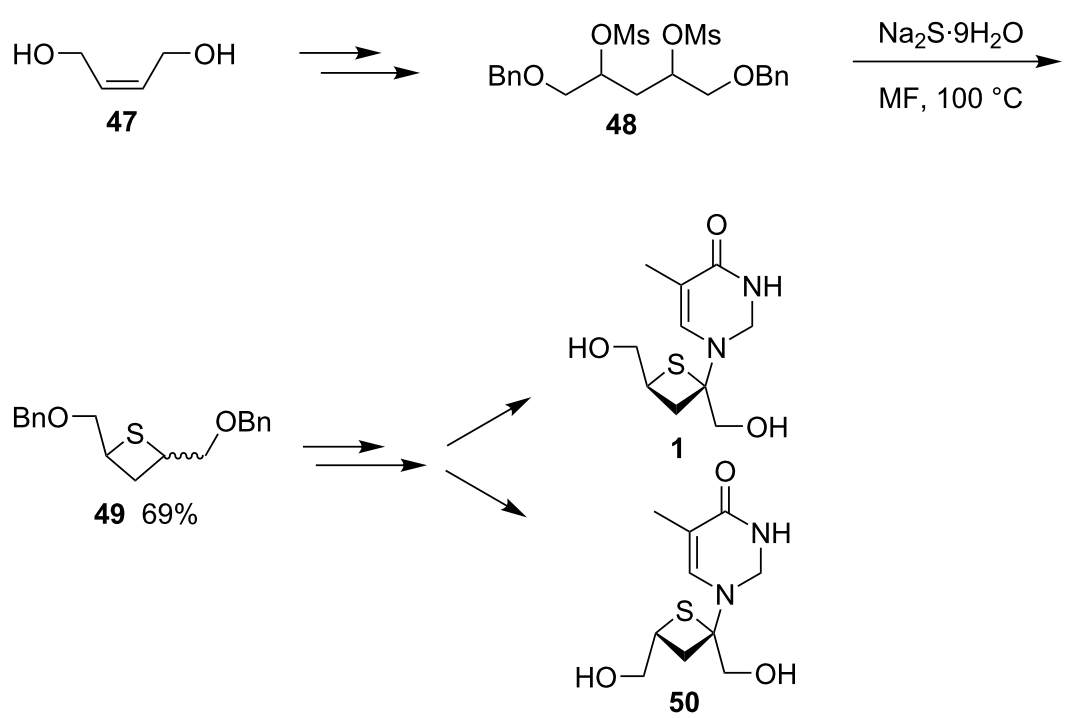

Scheme 11: Synthesis of two diastereomeric thietanose nucleosides via 2,4-di(benzyloxymethyl)thietane (49).

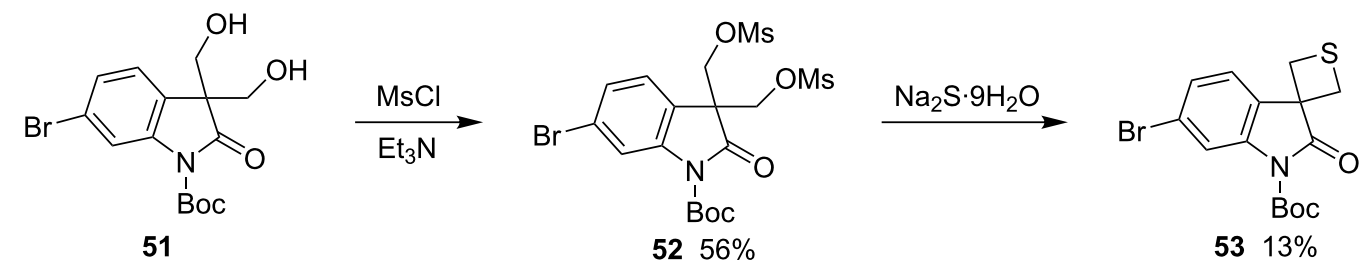<smiles>Cc1c(-c2ccccn2)nc2cc(F)ccc2c1N1C(=O)C2(CS(=O)(=O)C2)c2ccc(N3CCOCC3)cc21</smiles>

Scheme 12: Synthesis of the thietane-containing PI3k inhibitor candidate 54.

intermediate. It was further applied in the total synthesis of four different natural products of Nuphar sesquiterpene thioalkaloids 58 and 59 [43] (Scheme 13).

\subsection{Synthesis via intramolecular nucleophilic dis- placements}

2.2.1 Synthesis via the direct cyclic thioetherification of $\gamma$-mercaptoalkanols: The direct cyclic thioetherification of $\gamma$-mercaptoalkanols was regarded as an efficient route to synthesize thietanes. Indeed, the direct cyclization of the 3-mercapto- propan-1-ol unit in 60 with $\mathrm{Ph}_{3} \mathrm{P}(\mathrm{OEt})_{2}$ as a reagent was realized in the synthesis of the spirothietane derivative 61 [44] (Scheme 14).

Also, 1,3-diols were considered as precursors of $\gamma$-mercaptoalkanols. A Japanese group developed a new method to transform 1,3-diols 62 into the precursors of $\gamma$-mercaptoalkanols with dibenzoxazol-2-yl disulfide (63) and phosphines. They reacted primary or secondary 1,3-diols 62 with disulfide 63 in the presence of $\mathrm{Bu}_{3} \mathrm{P}$ or $\mathrm{Ph}_{3} \mathrm{P}$ to selectively synthesize 2-(3- 


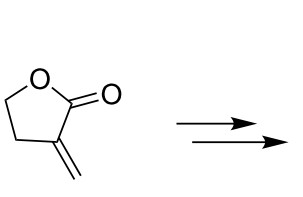

55<smiles>CC1CC[C@@H](c2ccoc2)N2C(=O)C(CO)(CO)CC[C@H]12</smiles>

56
1) $\mathrm{MsCl}$, DIPEA $\mathrm{DCM}, 0{ }^{\circ} \mathrm{C}$

2) $\mathrm{Na}_{2} \mathrm{~S} \cdot 9 \mathrm{H}_{2} \mathrm{O}, \mathrm{DMF}$ $\mathrm{Bu}_{4} \mathrm{NI}, 50^{\circ} \mathrm{C}$<smiles>CC1CC[C@@H](c2ccoc2)N2C(=O)C3(CC[C@H]12)CSC3</smiles>

57

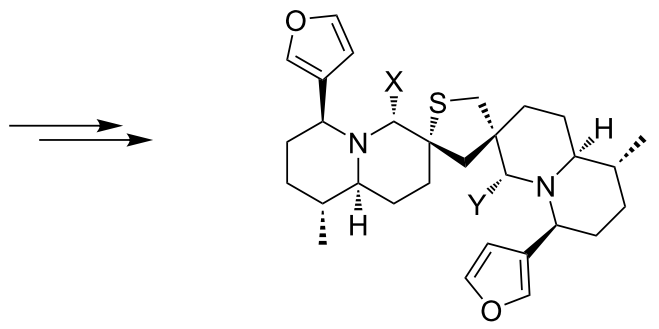

(+)-6-hydroxythiobinupharidine $\mathrm{X}=\mathrm{OH}, \mathrm{Y}=\mathrm{H}$ 58a $(-)$-thiobinupharidine $\mathrm{X}, \mathrm{Y}=\mathrm{H} \mathbf{5 8 b}$

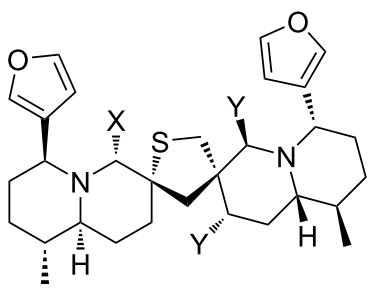

(-)-6-hydroxythionuphlutine $\mathrm{X}=\mathrm{OH}, \mathrm{Y}=\mathrm{H}$ 59a (+)-thionuphlutine $\mathrm{X}, \mathrm{Y}=\mathrm{H}$ 59b

Scheme 13: Synthesis of the spirothietane 57 as the key intermediate to Nuphar sesquiterpene thioalkaloids.

$\stackrel{\mathrm{BocN}}{\mathrm{X}_{\mathrm{SH}} \mathrm{OH}} \stackrel{\mathrm{Ph}_{3} \mathrm{P}(\mathrm{OEt})_{2}}{\mathrm{PhMe}}$

60

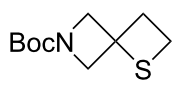

$6196 \%$
Scheme 14: Synthesis of spirothietane 61 through a direct cyclic thioetherification of 3-mercaptopropan-1-ol. hydroxyalkylthio)benzoxazoles $\mathbf{6 4}$. These were treated with $\mathrm{KH}$ to afford the corresponding thietanes 66 . The subsequent introduction of nucleobases then gave the corresponding thietanose nucleosides 68 [45] (Scheme 15).

The treatment of 2-(allylthio)benzimidazole 69 with iodine in $\mathrm{CHCl}_{3}$ followed by aq. $\mathrm{KOH}$ gave (iodomethyl)thiazolobenzimidazole $\mathbf{7 0}$ which was converted to thiazolobenzimidazolium

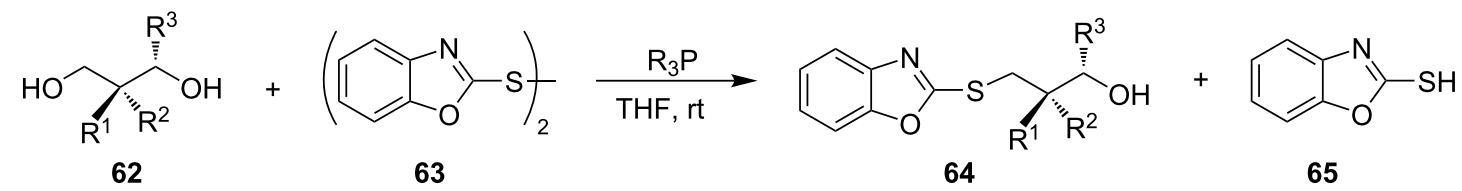<smiles>[R3]C(O)C([R])([R])CSc1nc2ccccc2o1</smiles><smiles>[R]C1SCC1([R])[R]</smiles>

$6632-72 \%$

a: $R^{1}=H, M e, E t, B n$

b: $R^{2}=H, E t, B n$

c: $\mathrm{R}^{3}=\mathrm{H}, \mathrm{Ph}$

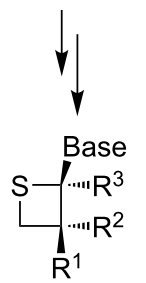

68 
perchlorate 71 by methylation with dimethyl sulfate and addition of $\mathrm{HClO}_{4}$. After the treatment with $\mathrm{KOH}$ powder in $\mathrm{MeCN}$ and subsequent hydrolysis it gave thietanylbenzimidazolone $\mathbf{7 5}$ In the last step, the hydroxide ion first nucleophilically added to the iminium 71 to generate an $O, S$-hemiacetal $\mathbf{7 2}$. Under the basic conditions, the hemiacetal $\mathbf{7 2}$ converted to the thiolate $\mathbf{7 4}$, which underwent an intramolecular substitution to give the final product thietanylbenzimidazolone 75 [46] (Scheme 16).

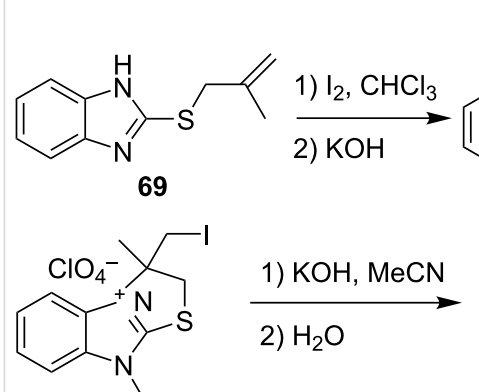

71<smiles></smiles><smiles>CN1c2ccccc2N2C(C)(CI)CSC12O</smiles>

72<smiles>CC1(CI)CSc2nc3ccccc3n2C1(C)CO</smiles>

70<smiles>CC1(n2c(=O)[nH]c3ccccc32)CSC1</smiles>

75

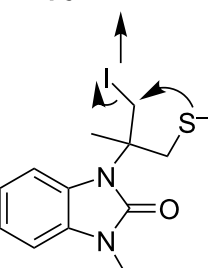

74
Scheme 16: Synthesis of thietanylbenzimidazolone 75 from (iodomethyl)thiazolobenzimidazole $\mathbf{7 0}$.

2.2.2 Synthesis via the stepwise nucleophilic displacements: Besides the double displacements of 1,3-dihaloalkanes with different sulfide salts, thiourea was also used as a nucleophile in the double displacements, actually following the preparation procedure of thiols, affording thietane derivatives. Thiourea reacted with 3,3-bis(chloromethyl)oxetane (76) in the presence of $\mathrm{HClO}_{4}$ to yield $S$-[2-(3-chloro-2-(chloromethyl)-2-hydroxymethyl)propyl]isothiouronium perchlorate (77). Heating compound 77 with $\mathrm{KOH}$ in ethanol for 40 min yielded 3-chloromethyl-3-hydroxymethylthietane (79) through a thiolate intermediate (78). Further reflux for $16 \mathrm{~h}$ gave rise to 2-oxa-6thiaspiro[3.3]heptane (80) [47] (Scheme 17).

In 1985, Miljkovic and co-workers reported the synthesis of thioanhydrohexopyranosides starting from bromodeoxyglucopyranoside 81. Compound $\mathbf{8 1}$ was reacted with $p$ - $\mathrm{MeC}_{6} \mathrm{H}_{4} \mathrm{SO}_{2} \mathrm{Cl}$ and $\mathrm{KSAc}$ to yield thioacetate 83, that upon treatment with excess $\mathrm{NaOMe}$, gave methyl 2-O-p-toluenesulfonyl-4,6-thioanhydro- $\alpha$-D-gulopyranoside (84), the thietane-containing gulopyranoside [48] (Scheme 18).

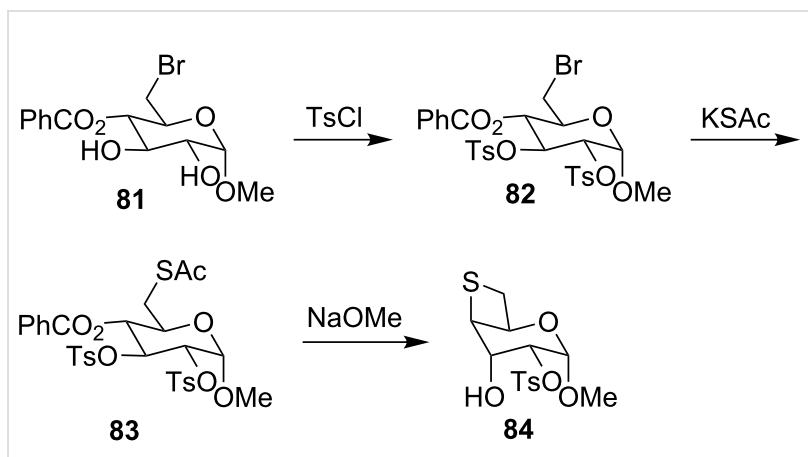

Scheme 18: Synthesis of the thietane-containing glycoside, 2-O-ptoluenesulfonyl-4,6-thioanhydro- $\alpha$-D-gulopyranoside (84).

For the preparation of thioanhydro sugar derivatives, Cubero and co-workers treated methyl 6-S-acetyl-2,4-di- $O$-benzoyl-3$O$-methanesulfonyl-6-thio- $\alpha$-D-galactopyranoside (85) with methanolic sodium methoxide to generate methyl 4,6-thioanhydro- $\alpha$-D-glucopyranoside (89), the thietane-fused pyranoside, in $30 \%$ yield [49] (Scheme 19).<smiles>NC(=S)N[14C](=O)[C@H](O)[14CH2]O</smiles> 


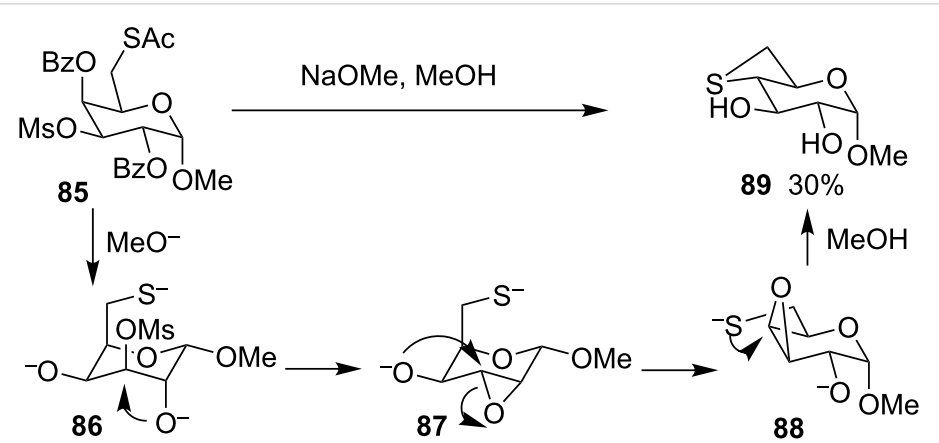

Scheme 19: Synthesis of methyl 4,6-thioanhydro- $\alpha-D-$ glucopyranoside (89).

Since 2000, a lot of thietane-derived carbohydates were reported. Voss and co-workers prepared the 2-oxo-7thiabicyclo[4.2.0]octane derivative (methyl 2,3-di- $O$-mesyl-4,6thio-anhydro- $\alpha$-D-galactopyranoside (93)) from methyl $\alpha$-Dglucopyranoside (90) through a Mitsunobu thioacetylation, mesylation, thioacetate hydrolysis with the treatment of sodium bicarbonate, and a subsequent intramolecular nucleophilic displacement. In the displacement step, the formation of the fourmembered thietane ring is strongly favored over the ring closure between the thiolate and the 2-position, since the $\mathrm{S}_{\mathrm{N}} 2$ displacement of a mesylate leaving group adjacent to the anomeric center is known to be restricted [50] (Scheme 20).
The same group synthesized a thietane-fused gulopyranoside starting from methyl 4,6- $O$-isopropylidene- $\alpha$-D-glucopyranoside (94). Compound 94 first was mesylated and then hydrolyzed to afford 2,3-dimesylated methyl $\alpha$-D-glucopyranoside 96. After thioacetylation and treatment with sodium bicarbonate compound 96 was converted into the thietane-fused $\alpha$-Dgulopyranoside 100. The thioacetate derivative 97 was first converted to the oxirane-fused derivative $\mathbf{9 8}$ through an intramolecular substitution. After hydrolysis, the thiolate underwent an intramolecular nucleophilic displacement to generate the final thietane-fused $\alpha$-D-gulopyranoside 100 [50] (Scheme 21).

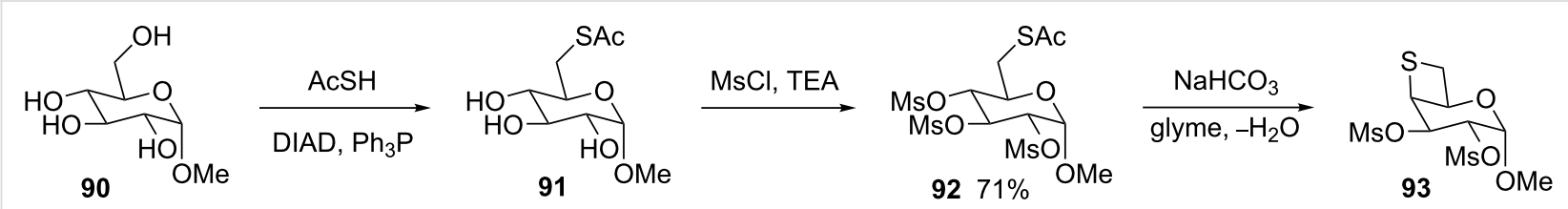

Scheme 20: Synthesis of thietane-fused $\alpha$-D-galactopyranoside 93 .

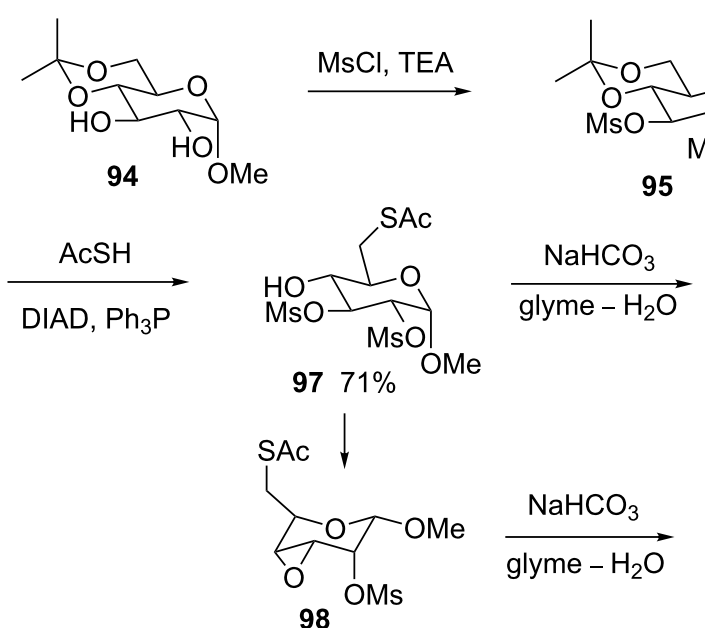

98
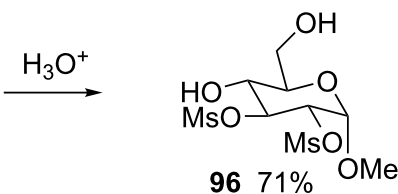

$9671 \%$ OMe 
In 2004, Schulze and co-workers synthesized 3,5-anhydro-3thiopentofuranosides 104 from methyl $\alpha$ - and $\beta$-arabinosides 101 through a Mitsunobu reaction, mesylation, and hydrolysis sequence followed by an intramolecular displacement. The in situ generated thiolate nucleophilically attacked the mesylate to form the thietane ring [51] (Scheme 22).<smiles>[R]C1([R])OC2OC(CO)C1O2</smiles>
101

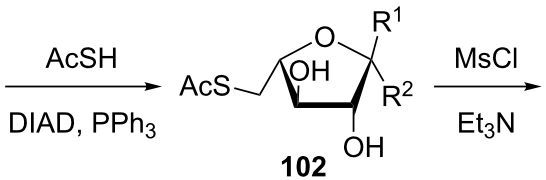
a: $R^{1}=O M e, R^{2}=H \quad 91 \%$ b: $R^{1}=H, R^{2}=$ OMe $87 \%$

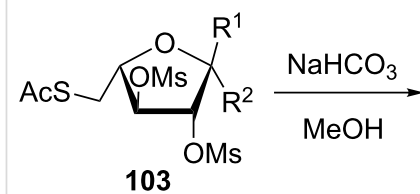
103<smiles>[R14]C1OC2([R])C1OC1CSC2C1[R]</smiles>
104 a: $R^{1}=\mathrm{OMe}, \mathrm{R}^{2}=\mathrm{H} 100 \%$ b: $R^{1}=H, R^{2}=$ OMe $85 \%$

a: $R^{1}=O M e, R^{2}=H \quad 81 \%$ b: $R^{1}=H, R^{2}=$ OMe $45 \%$

Scheme 22: Synthesis of 3,5-anhydro-3-thiopentofuranosides 104

Following the similar synthetic route, Polchow and Voss synthesized 4,6-anhydro-4-thiofuranoside 110, 1,3:4,6-dianhydro1,4-dithio- $\beta$-D-sorbofuranoside 112, and 1,3-anhydro-6- $S$ methyl-1,6-dithio-D-psicofuranoside 113 from 1,2:4,5-di- $O$-isopropylidene D-fructose (105) [52] (Scheme 23).
In an alternative approach, the thietane ring was constructed more efficiently through a two-step displacement sequence from the D-xylose-derived dimesylate 114 (Scheme 24). The first step displacement involved the selective $S_{N} 2$ reaction of the primary mesylate with KSAc to yield a monothioacetate 115 in $80 \%$ yield. The second displacement was an intramolecular $\mathrm{S}_{\mathrm{N}} 2$ process performed under mild basic conditions, affording the desired thietane $\mathbf{1 1 6}$ in $92 \%$ yield. After deprotection, oxidative cleavage, and reduction, a thietanose 117 was obtained in 63\% overall yield. The thietanose 117 was further applied to synthesize a series of thietanose nucleosides 118 [53]. Similarly, enatiomeric thietanose nucleosides $\mathbf{1 2 3}$ were prepared from L-xylose [53] (Scheme 24).

In 2010, Takahata and co-workers designed and synthesized thietane-fused nucleosides. They first prepared a key intermediate spiro acetal $\mathbf{1 2 5}$, which was converted into two different dimesylated nucleosides. After the deprotection with $\mathrm{Hg}(\mathrm{OAc})_{2}$ in the presence of TFA, the dimesylated thiols 127 and $\mathbf{1 3 0}$ generated companied with the thietane-fused nucleoside $\mathbf{1 2 8}$ in one case. Further the treatment of the dimesylated thiols $\mathbf{1 2 7}$ and 130 with DBU gave rise to the corresponding mesylated thietane-fused nucleosides 128 and 131, which generated the final thietane-fused nucleosides $\mathbf{1 2 9}$ and $\mathbf{1 3 2}$ after the reactions with benzoic acid and $\mathrm{CsF}$ and subsequent aminolysis [54] (Scheme 25).

The methyl 2,3-anhydro- $\alpha$ - and $\beta$-D-ribofuranosides 133 were used as starting materials and converted into 3,5-anhydro-3-

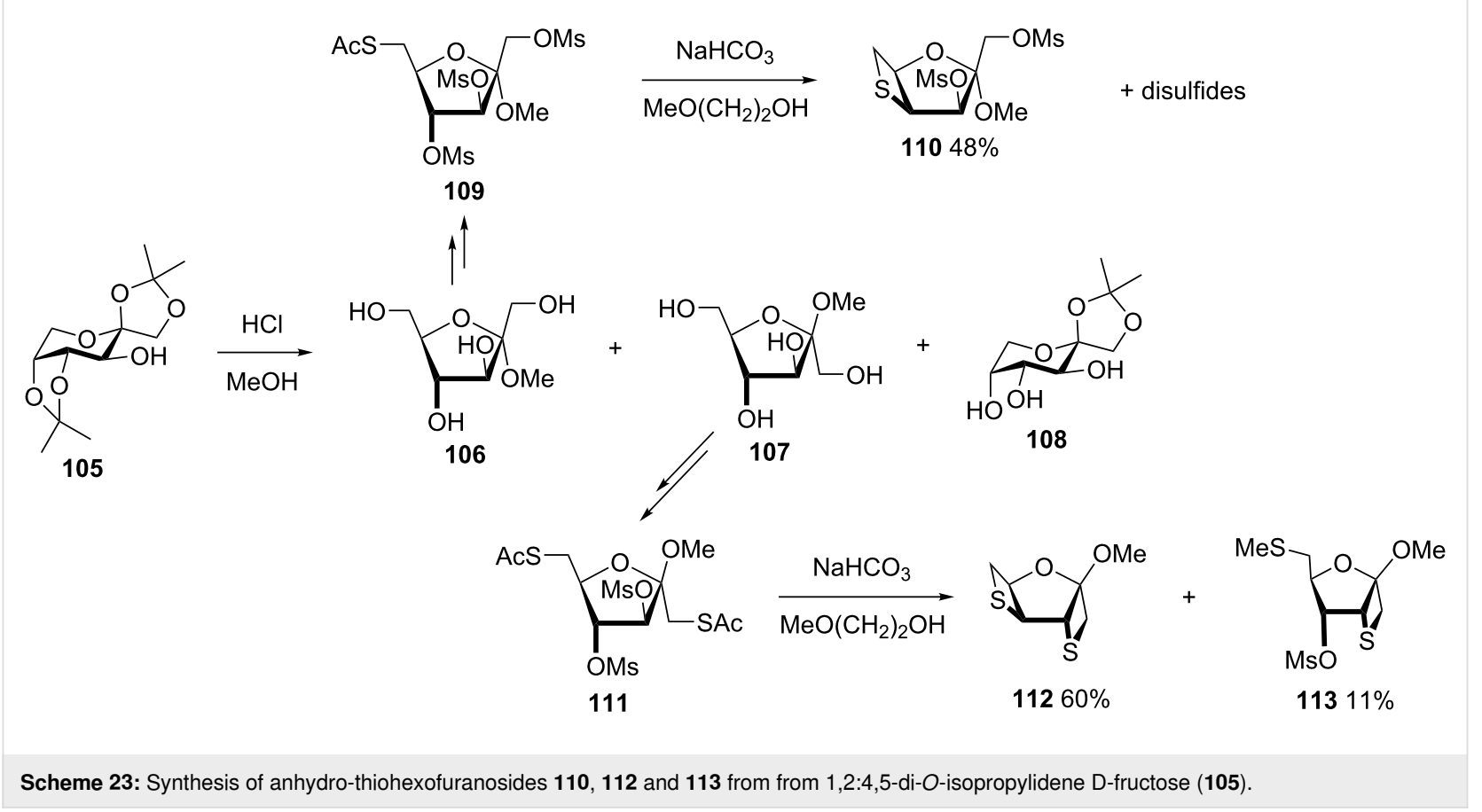



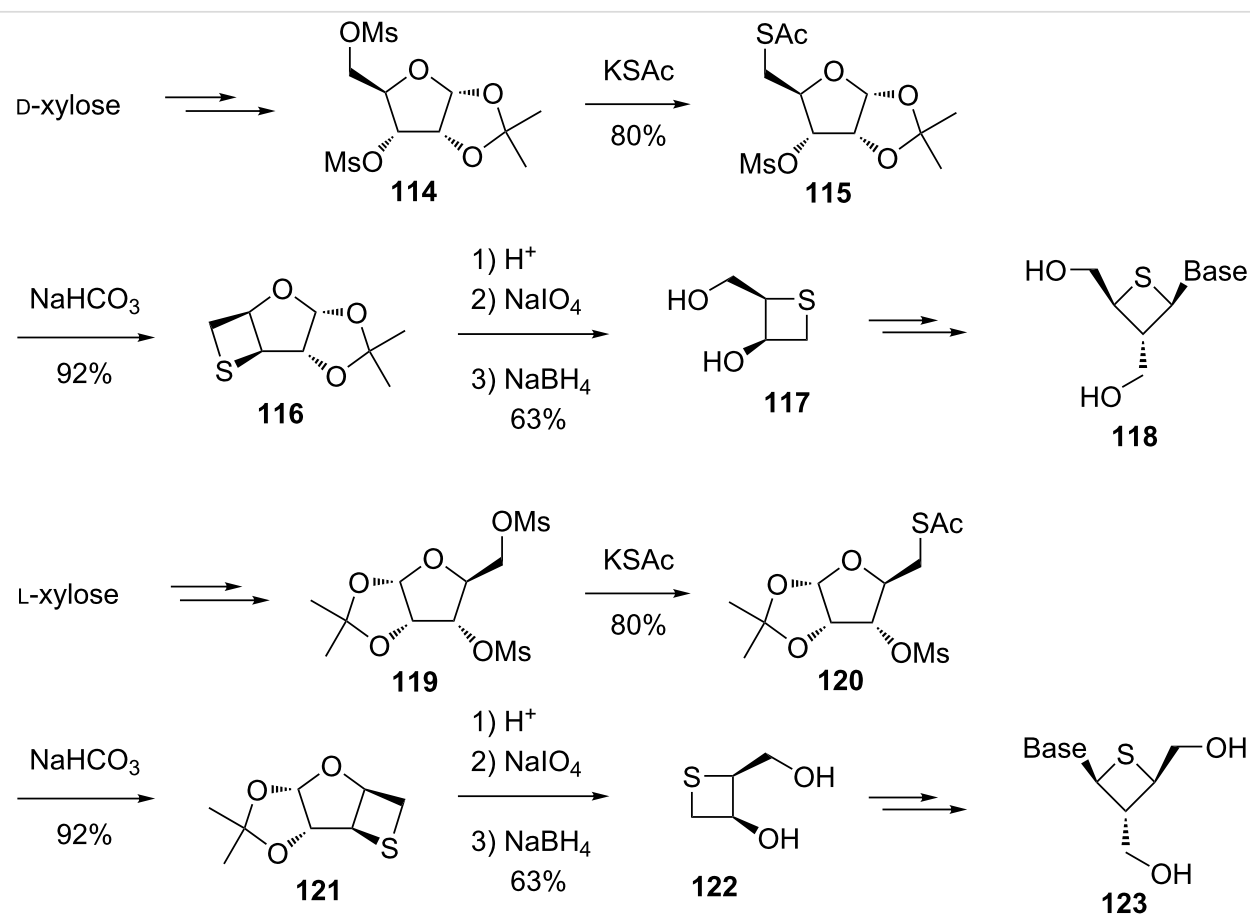

Scheme 24: Synthesis of optically active thietanose nucleosides from D- and L-xyloses.<smiles>CC1(C)OCC(=O)CO1</smiles><smiles>C=CC1CC(CO)(CO)CO1</smiles><smiles>[AlH]I</smiles>

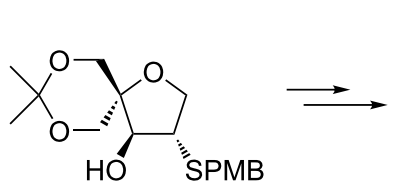
125<smiles>COCC1(COC)OCC(n2cnc3c(Cl)ncnc32)C1C(=O)O</smiles><smiles>[AlH][V]</smiles><smiles>COCC1(COC)OCC(n2cnc3c(Cl)ncnc32)C1O</smiles>

127 63\%<smiles>COCC12COC3(n4cnc5c(Cl)ncnc54)C1SC23</smiles>

$12825 \%$<smiles>C=CN1C(=O)C(S)C2C1COC2(COC)COC</smiles>

130

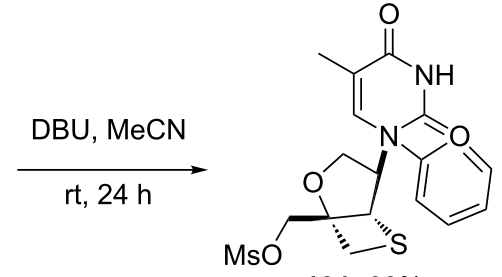

$13160 \%$
$\mathrm{PhCO}_{2} \mathrm{H}, \mathrm{CsF}$ $\mathrm{DMF}, 60^{\circ} \mathrm{C}, 36 \mathrm{~h}$ $56 \%$ $\mathrm{NH}_{4} \mathrm{OH}$ $\mathrm{MeOH}, \mathrm{rt}, 6 \mathrm{~h}$ $\stackrel{93 \%}{\longrightarrow}$

$50 \%$

Scheme 25: Synthesis of thietane-fused nucleosides. 
thiopentofuranosides 135 through a Mitsunobu reaction with thiolacetic acid and hydrolysis followed by an intramolecular nucleophilic ring-opening of the oxirane ring. The newly generated thiolate underwent a nucleophilic ring-opening of the oxirane to generate the thietane ring [55] (Scheme 26).

After the ring-opening of methyl 2,3-anhydro- $\alpha$-D-ribofuranoside (133a) with $\mathrm{NaOMe}$, following a sequence of a Mitsunobu reaction, mesylation, and treatment with sodium bicarbonate, another 3,5-anhydro-3-thiopentofuranoside 138 was prepared [51] (Scheme 26).

The 2-amino-3,5-anhydro-3-thiofuranoside 141 was prepared from methyl 2,3-anhydro- $\alpha$-D-ribofuranoside (133a), which was first reacted with sodium azide followed by the similar synthetic route as described above, affording 3,5-anhydro-2-azido3-thiofuranoside 139. The azido derivative 139 generated the final product 2-amino-3,5-anhydro-3-thiofuranoside 141 by reduction with triphenylphosphine [55] (Scheme 27).

2.2.3 Synthesis via the nucleophilic ring-opening of threemembered heterocycles and subsequent displacement from halomethyloxirane derivatives: Chloromethyloxirane (142a) and its 2 and 3-phenyl derivatives $142 \mathrm{~b}$ and $\mathbf{1 4 2 c}$ reacted with $\mathrm{H}_{2} \mathrm{~S}$ in the presence of $\mathrm{Ba}(\mathrm{OH})_{2}$ to give the corresponding thietane-3-ols 145. In this reaction $\mathrm{H}_{2} \mathrm{~S}$ first was deprotonated to the hydrogensulfide anion $\left({ }^{-} \mathrm{SH}\right)$ by $\mathrm{Ba}(\mathrm{OH})_{2}$. The obtained anion nucleophilically attacked the less steric or benzylic ring carbon atom of the oxirane ring, giving mercaptoalkanolates 143. A proton transfer generated hydroxyalkanethiolates 144 because the acidity of the thiols is higher than that of alcohols, the newly generated thiolates 144 underwent an intramolecularly nucleophilic displacement to give thietane-3-ols 145 [56] (Scheme 28).
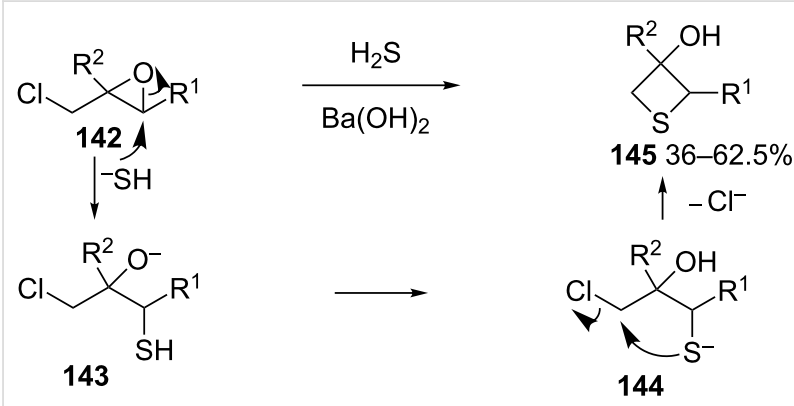

a: $R^{1}=R^{2}=H ; \mathbf{b}: R^{1}=P h, R^{2}=H ; c^{1}: R^{1}=H, R^{2}=P h$

Scheme 28: Synthesis of thietane-3-ols 145 from (1-chloromethyl)oxiranes 142 and hydrogen sulfide.

In a similar approach, chloromethyloxirane (142a) was first converted into a thietan-3-ol 145a by treatment with $\mathrm{H}_{2} \mathrm{~S}$ and $\mathrm{Ba}(\mathrm{OH})_{2}$. Compound 145a was further transformed to<smiles>[R]C1([R])OC(CO)C2OC21</smiles>

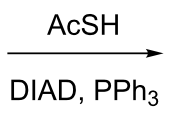

\begin{tabular}{l|l}
$\mathrm{R}^{1}$ & $=\mathrm{H}$ \\
$\mathrm{R}^{2}$ & $=\mathrm{OMe}$
\end{tabular} \mid $\mathrm{NaOMe}$<smiles>CO[C@H]1O[C@@H](CO)[C@H](O)[C@H]1O</smiles>

136

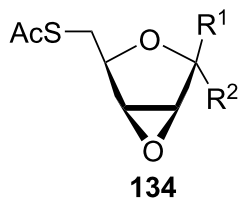<smiles>COCCOO</smiles>

a: $\mathrm{R}^{1}=\mathrm{H}, \mathrm{R}^{2}=\mathrm{OMe} 73 \%$

b: $R^{1}=O M e, R^{2}=H \quad 85 \%$
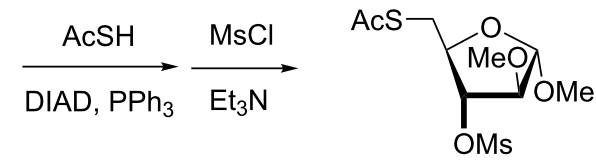

137

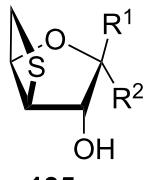

135

a: $R^{1}=H, R^{2}=$ OMe $89 \%$

b: $R^{1}=O M e, R^{2}=H \quad 82 \%$

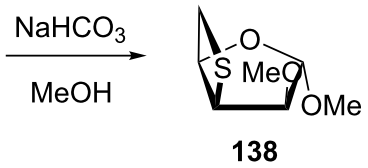

Scheme 26: Synthesis of 3,5-anhydro-3-thiopentofuranosides.
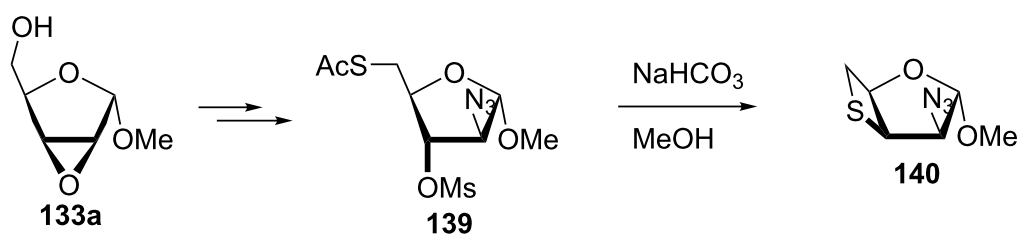
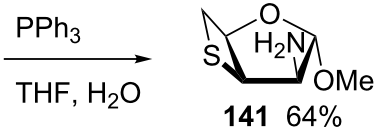
3-aminothietane-3-carboxylic acid (146), a modulator of the $N$-methyl-D-aspartate (NMDA) receptor [57] (Scheme 29).

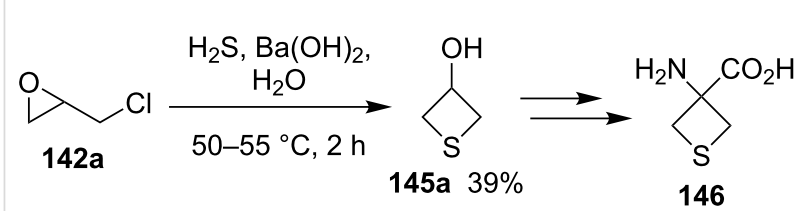

Scheme 29: Synthesis of thietane-3-ol 145a from chloromethyloxirane (142a).

Several thietane-3-ol derivatives $\mathbf{1 4 5}$ were synthesized in low to good yields by the reaction of 2-(1-haloalkyl)oxiranes 142 and 147 with ammonium monothiocarbamates 148 as the sulfur nucleophiles. First, a nucleophilic ring-opening of the oxiranes 142 and 147 by monothiocarbamates 148 gave rise to the $S$ - $(\gamma$ halo- $\beta$-hydroxyalkyl)carbamates $\mathbf{1 4 9}$ with release of amines. The latter then aminolyzed the carbamates 149 to generate ureas 151 and $\gamma$-halo- $\beta$-hydroxyalkanethiols 150. The intermediates 150 further underwent an intramolecular cyclization to produce the thietane-3-ols $\mathbf{1 4 5}$ in low to good yields [58] (Scheme 30).

Paclitaxel $\left(\right.$ Taxol $\left.^{\circledR}\right)$ and docetaxel $\left(\right.$ Taxotere $\left.{ }^{\circledR}\right)$ both are anticancer drugs of the taxoid series. They inhibit cell growth through the interaction with microtubules. In order to study the structure-activity relationships, the D-ring-modified deoxythiataxoid 154a was synthesized. For this, the iodomethyloxirane derivative $\mathbf{1 5 2}$ was first treated with lithium sulfide followed by reaction with carbonyldiimazole (CDI), yielding the thietane derivative 153 and byproduct. The thietane derivative 153 was then converted into 7-deoxy-5(20)-thiapaclitaxel 154a in a three steps sequence [59] (Scheme 31).

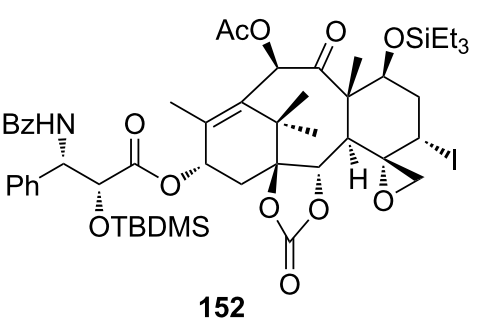

1) $\mathrm{Li}_{2} \mathrm{~S}, \mathrm{THF}, \mathrm{rt}, 28 \mathrm{~h}$

2) CDI, imidazole, $\mathrm{rt}, 12 \mathrm{~h}$

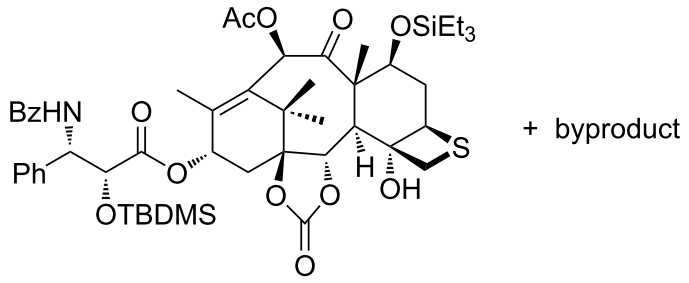

$15356 \%$

1) $\mathrm{ClCO}_{2} \mathrm{Me}$, LHMDS,

THF, $-78^{\circ} \mathrm{C}, 7 \mathrm{~min}, \mathrm{rt}, 1 \mathrm{~min}, 39 \%$

2) $\mathrm{PhLi}, \mathrm{THF},-78^{\circ} \mathrm{C}, 3 \mathrm{~min}, 61 \%$

3) Py.HF, rt, 9 h, $76 \%$

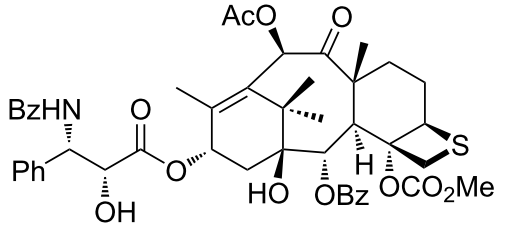

7-deoxy-5(20)-thiapaclitaxel 154a

Scheme 31: Synthesis of 7-deoxy-5(20)thiapaclitaxel 154a, a thietane derivative of taxoids.<smiles>[R]C([X])C1([R])CO1</smiles>

$142 \mathrm{X}=\mathrm{Cl}$

$147 \mathrm{X}=\mathrm{Br}$<smiles>[R]C([X])C([R])(O)CSC(=O)N([R])[R]</smiles><smiles>[R]N([R])C(=O)S[NH+]([R])[R]</smiles>

148<smiles>C1CCC1</smiles><smiles>[R]C1SCC1([R])O</smiles>

$145 \quad 13-84 \%$<smiles>[R]N([R])C(=O)N([R])[R]</smiles><smiles>[X][Te]</smiles><smiles>[R]C([X])C([R])(O)CS</smiles><smiles>[R]N([R])C(=O)N([R])[R]</smiles>

150

$\mathrm{R}^{1}=\mathrm{H}, \mathrm{Me}, \mathrm{Pr}, \mathrm{Ph} ; \mathrm{R}^{2}=\mathrm{H}, \mathrm{Me}$;

$\mathrm{HNR}^{3} \mathrm{R}^{4}=\mathrm{PrNH}_{2}, \mathrm{iPrNH}_{2}, \mathrm{CHexNH}_{2}, \mathrm{PhCH}_{2} \mathrm{CH}_{2} \mathrm{NH}_{2}, \mathrm{Et}_{2} \mathrm{NH}, 4-\mathrm{MeC}_{6} \mathrm{H}_{4} \mathrm{NH}_{2}, \mathrm{Py}$ 
Another member of taxoids, 10-deacetylbaccatin III (155) was isolated from the leaves of the European yew tree Taxus baccata $L$. in a significant yield and was applied as starting material for the semisynthesis of 5(20)-thiadocetaxel 158. First, the compound was converted into the corresponding bromomethyloxirane derivative 156, which generated the corresponding thietane-fused product 157 by the treatment with KSAc. Product $\mathbf{1 5 7}$ was finally transformed to 5(20)-thiadocetaxel 158 [6] (Scheme 32).
2.2.4 Synthesis via the nucleophilic ring-opening of threemembered heterocycles and subsequent displacement from oxirane-2-methyl sulfonates: Similar as for the halomethyloxirane derivatives, oxiranemethyl mesylate derivatives were also used as precursors for the synthesis of the corresponding thietane derivatives. After various protection-deprotection steps and mesylation, the oxiranemethyl mesylate derivatives $\mathbf{1 6 0}$ were prepared (Scheme 33). Following treatments with KSAc and $\mathrm{NaOMe}$ in methanol, respectively, the corresponding

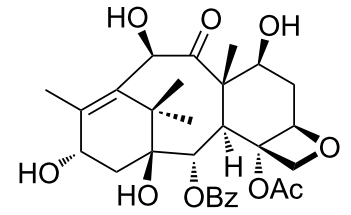

10-deacetylbaccatin III 155

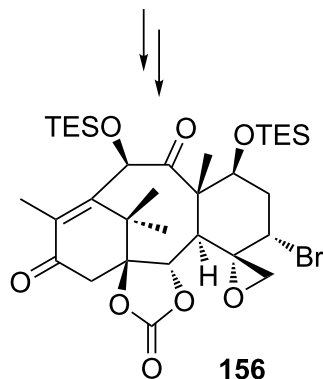

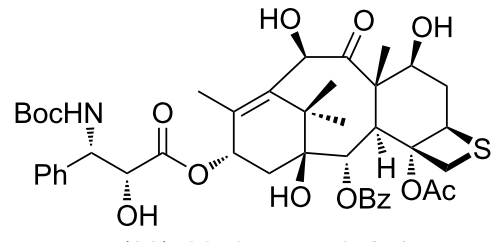

5(20)-thiadocetaxel 158

$\underset{\mathrm{DMF}}{\stackrel{\text { AcSK }}{60^{\circ} \mathrm{C}}}$

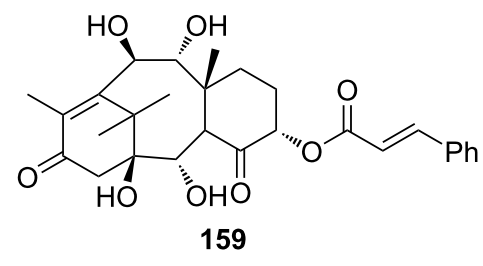

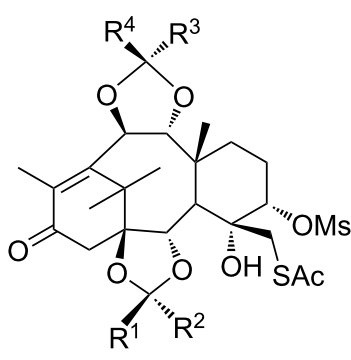

161
$\mathrm{MeONa}, \mathrm{MeOH}$

$60{ }^{\circ} \mathrm{C}, 1 \mathrm{~h}$

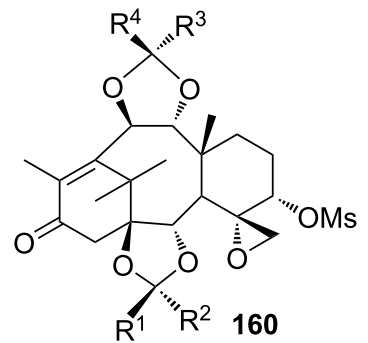

$\mathrm{AcSH}, \mathrm{NaH}$

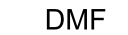

$60^{\circ} \mathrm{C}, 5 \mathrm{~h}$ 
thietane-fused products $\mathbf{1 6 2}$ were obtained as the intermediates for the synthesis of deoxythiataxoids [60] (Scheme 33).

Taxine B (163a) and isotaxine B (163b) were obtained from the leaves of the European yew tree Taxus baccata $L$. in significant yields as well. The compounds were used for the semisynthesis of further sulfur derivatives of taxoids by first converting them into the acetal-protected oxiranemethyl mesylate derivative 164 . After the treatment of compound $\mathbf{1 6 4}$ with KSAc, the mesylate 165 generated the corresponding thietane-fused product $\mathbf{1 6 6}$, which was finally converted into the D-ring-modified 7-deoxy 5(20)-thiadocetaxel 154b [6] (Scheme 34).

The mechanism for the formation of thietane rings $\mathbf{1 7 1}$ from oxiranes $\mathbf{1 6 7}$ with vicinal leaving groups was suggested as a nucleophilic ring-opening and intramolecular transesterification followed by an intramolecular displacement [6] (Scheme 35).

2.2.5 Synthesis via the nucleophilic ring-opening of threemembered heterocycles and subsequent displacement from thiirane-2-methanol derivatives: Gay and Scherowsky prepared thietane derivatives from a thiirane-2-methanol when they worked on the synthesis of liquid crystal materials. They synthesized a chiral thietane $\mathbf{1 7 5}$ from the chiral thiirane-2-methanol 172 with 3-nitrophenol (173) under Mitsunobu conditions (Scheme 36). In the synthesis, the alcohol 172 first reacted with triphenylphosphine to generate thiirane 174, which underwent nucleophile ring-opening followed by an intramolecular substitution to afford chiral thietane 175 [61].

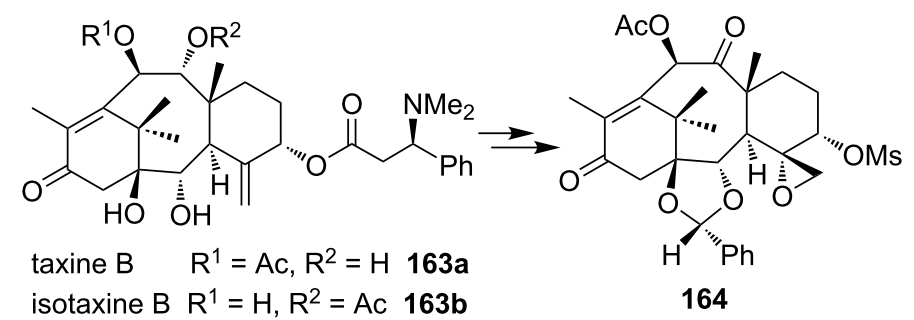
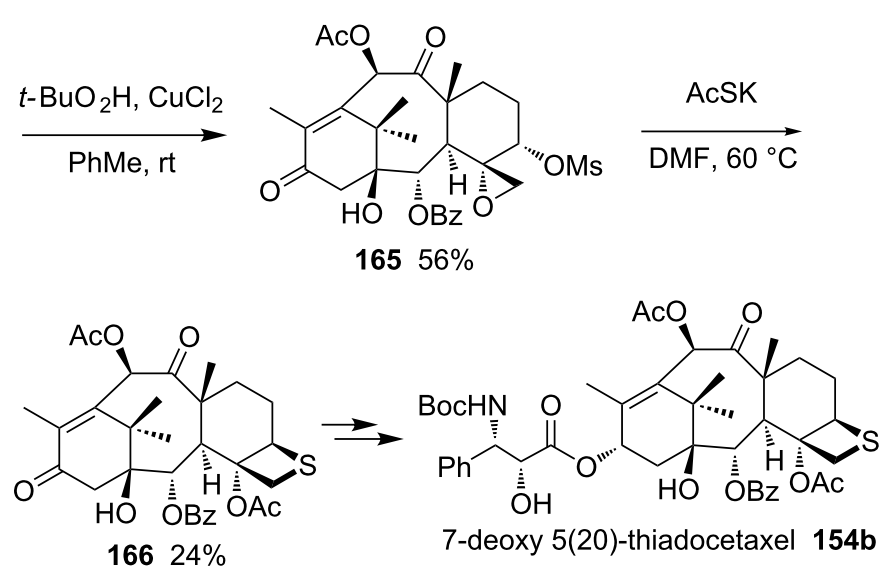

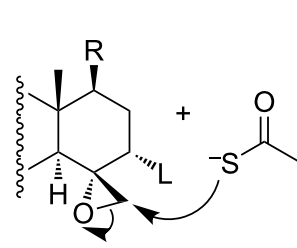

167

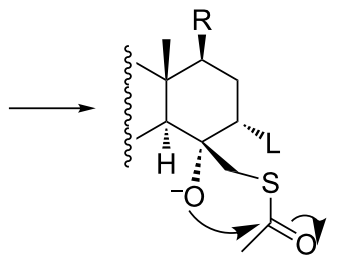

168

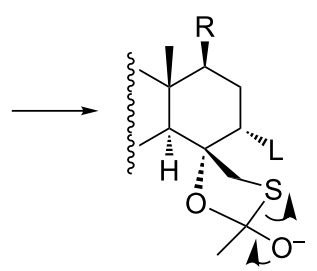

169

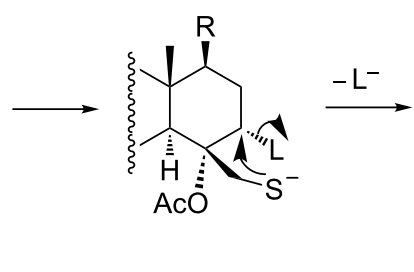

170

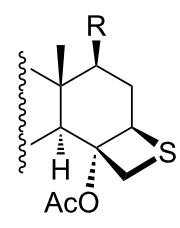

171

$\mathrm{R}=\mathrm{H}$ and $\mathrm{L}=\mathrm{OMs}$ or $\mathrm{R}=\mathrm{OTES}$ and $\mathrm{L}=\mathrm{Br}$ 


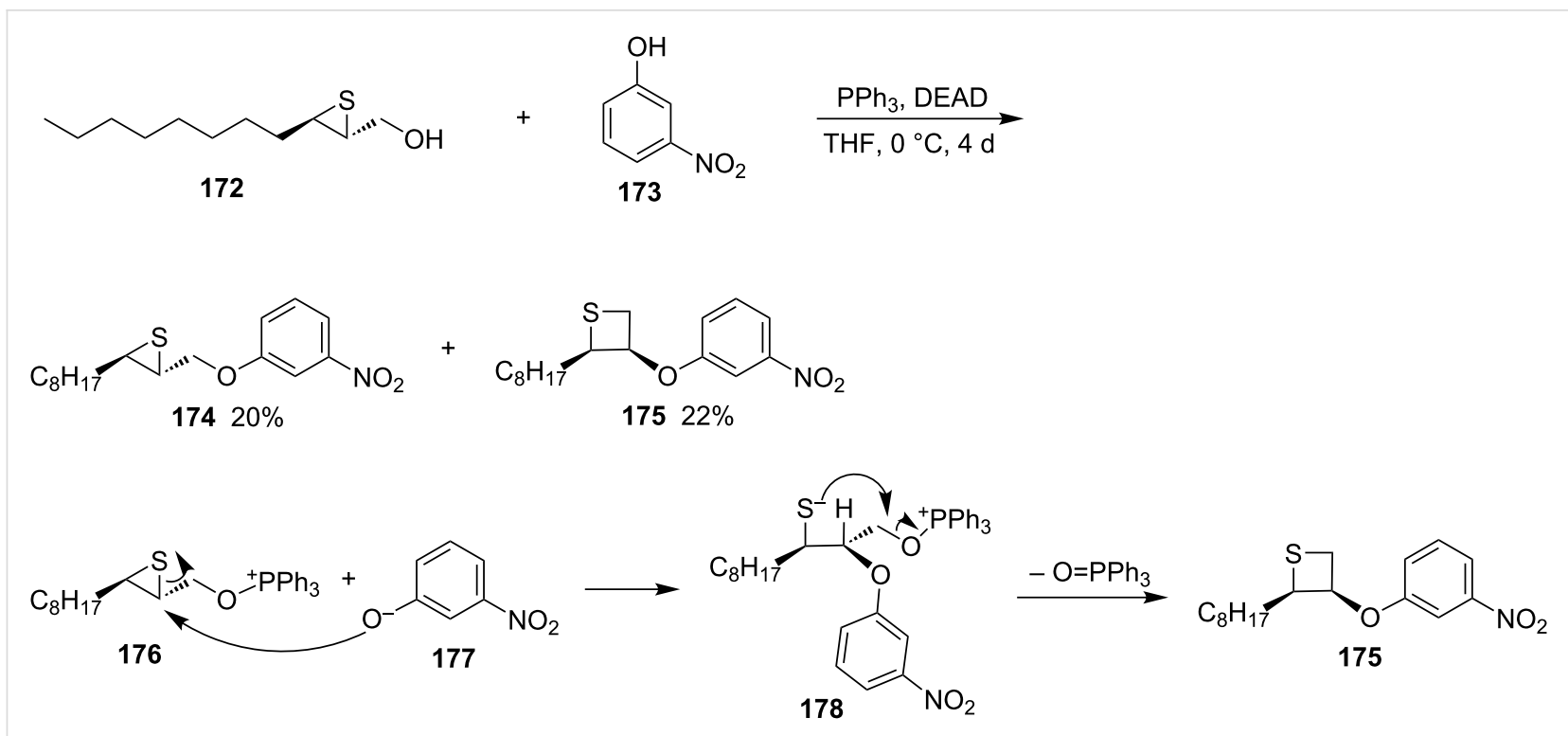

Scheme 36: Synthesis of cis-2,3-disubstituted thietane 175 from thiirane-2-methanol 172.

2.2.6 Synthesis via the nucleophilic ring-opening of threemembered heterocycles and subsequent displacement from aziridine-2-methyl tosylate: $(1 R, 2 S, 6 R)-6$-Methyl-7-tosyl-7azabicyclo[4.1.0]heptan-2-yl tosylate (179) is a derivative of aziridine-2-methyl tosylate. After the ring-opening with ammonium tetrathiomolybdate and subsequent intramolecular cyclization, the compound was converted into a bridged thietane 183 in $75 \%$ yield. The results indicated that, in the ring-opening step, tetrathiomolybdate nucleophilically attacked the more substituted aziridine carbon atom [62] (Scheme 37).

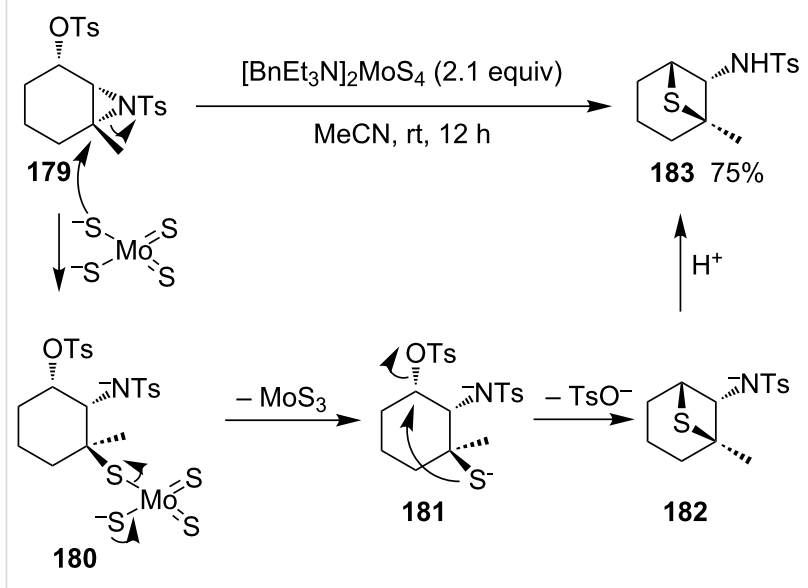

Scheme 37: Synthesis of a bridged thietane 183 from aziridine cyclohexyl tosylate 179 and ammonium tetrathiomolybdate.

The thioetherification cyclization of 1,3-dihaloalkanes, 3-haloalkyl sulfonates, or disulfonates of alkane-1,3-diols with sodium sulfide is a common method for the preparation of thietanes. However, this method is suitable for the preparation of 3-monosubstituted and 3,3-disubstituted thietanes but can hardly applied for the preparation of 2,2/2,4-disubstituted, 2,2,4-trisubstituted, and 2,2,4,4-tetrasubstituted thietanes due to steric hindrance in the substitution step. In these cases, the substitution reaction is accompanied by elimination reactions.

\section{Synthesis via cycloadditions}

Cycloadditions, especially the photochemical [2+2] cycloaddition (thia-Paternò-Büchi reaction) of thiones and thioamides with olefins [15-18], and formal cycloadditions are alternative routes for the construction of thietane derivatives, especially multisubstituted thietanes.

\subsection{Synthesis via photochemical [2 + 2] cycloaddi- tions}

3.1.1 Synthesis via intermolecular photochemical $[2+2]$ cycloadditions: In 1969, the first photo-assisted [2 + 2] cycloadditions of alkenes and thiocarbonyl compounds were applied for the synthesis of thietanes. Later, this transformation was considered as thia-Paternò-Büchi reaction. The reactions of thiobenzophenone (184a) with both, electron-rich olefins $\mathbf{1 8 5}$, 186a, and 187a under irradiation with UV light at $366 \mathrm{~nm}$, and electron-deficient olefins $\mathbf{1 8 7 b}, \mathbf{c}, \mathbf{1 8 8}$, and 189 under irradiation with either $366 \mathrm{~nm}$ or $589 \mathrm{~nm}$ UV light gave the desired thietanes 190-195 with retention of the olefin configuration in most cases. An exception was observed for the reaction of $\mathbf{1 8 4 a}$ with $(Z)$-prop-1-enylbenzene $[(Z)-\mathbf{1 8 5}]$, which generated a mixture of cis- and trans-thietanes, cis-190 and trans-190, both configuration retention and inversion products [63] 
<smiles>S=C(c1ccccc1)c1ccccc1</smiles>

184a<smiles>CC=Cc1ccccc1</smiles>

(E)-185

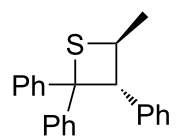

(士)-trans-190 $63 \%$<smiles>C/C=C\c1ccccc1</smiles>

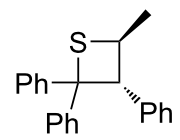

(士)-trans-190

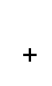

$63 \%$

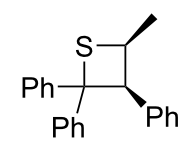

( \pm -cis-190<smiles></smiles><smiles>C=C(C)c1ccccc1</smiles><smiles>C1C[Tl]1</smiles><smiles>CC1(c2ccccc2)CSC1(c1ccccc1)c1ccccc1</smiles><smiles>CC(C)(C)C</smiles><smiles>[R]C=CC</smiles><smiles>c1ccccc1</smiles>
187

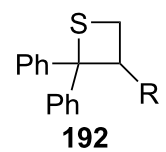

a: $\mathrm{R}=\mathrm{OAc}, 50 \%$

b: $\mathrm{R}=\mathrm{CO}_{2} \mathrm{Me}, 81 \%$

c: $\mathrm{R}=\mathrm{CN}, 93 \%$<smiles>S=C(c1ccccc1)c1ccccc1</smiles><smiles>Cl/C=C/Cl</smiles><smiles>[AlH2]</smiles>

(E)-188<smiles>ClC1SC(c2ccccc2)(c2ccccc2)C1Cl</smiles>

(士)-trans-193 $90 \%$<smiles>S=C(c1ccccc1)c1ccccc1</smiles><smiles>Cl/C=C\Cl</smiles><smiles>C1CC[Tl]CC1</smiles>

$184 a$

(Z)-188<smiles>S=C(c1ccccc1)c1ccccc1</smiles><smiles>C1CCCCC1</smiles><smiles>[R]C([R])=C[N]</smiles><smiles>C1CCCCC1</smiles>

$184 a$<smiles>ClC1SC(c2ccccc2)(c2ccccc2)C1Cl</smiles>

(士)-cis-193 $83 \%$

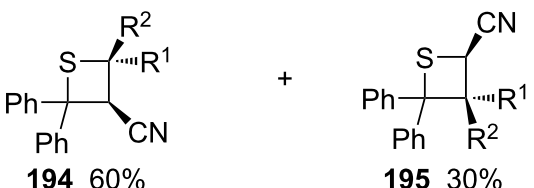

$R^{1}=M e, R^{2}=H ; R^{1}=H, R^{2}=M e$

Scheme 38: Synthesis of thietanes via the photochemical [2 +2] cycloaddition of thiobenzophenone 184a with various olefins.

(Scheme 38). However, some olefins, such as cyclohexene, oct1-ene, vinyl ether, vinyl sulfide, etc., produced 1,4-dithiane derivatives as products through the reaction of two molecules of thiobenzophenone (184a) and one molecule of the olefin under irradiation with $589 \mathrm{~nm}$ UV light [63].

In 1978, Gotthardt and Nieberl investigated the UV light-induced $[2+2]$ cycloaddition reaction of thiones with cyclic alkenes and realized the synthesis of spirothietane derivatives. Under $\mathrm{n} \rightarrow \pi^{*}$ excitation using Na light, xanthione (196) reacted with acenaphthylene (197), indene (198), or $N$-phenylmaleimide (199) with the formation of the corresponding spirothietane derivatives 200-202 in good yields. The analogous photoreactions of 2-thioparabanate (203) in the presence of indene (198), benzo[b]furan (204), or $N$-phenylmaleimide (199) gave spirothietanes 205-207 as well [64] (Scheme 39). 
<smiles>CN1C(=O)C(=O)N(C)C1=O</smiles>

Scheme 39: Synthesis of spirothietanes through the photo [2 + 2] cycloaddition of cyclic thiocarbonyls with olefins.
The irradiation of a $0.050 \mathrm{~mol} / \mathrm{L}$ solution of thioxanthenethione (208) in $\mathrm{CH}_{2} \mathrm{Cl}_{2}$ with butatrienes $\mathrm{Me}_{2} \mathrm{C}=\mathrm{C}=\mathrm{C}=\mathrm{CRR}^{1} 209$ through a $\mathrm{K}_{2} \mathrm{Cr}_{2} \mathrm{O}_{7}$ filter solution gave 70 to $>90 \%$ yields of the corresponding spirothietanes 210 [65] (Scheme 40).

The same research group also performed the reaction mechanistic studies. The reactivity of the substituted allenes towards triplet aromatic thiones was investigated. The product analysis revealed the formation of thietanes and occasionally of [4 +2] cycloadducts (thiopyrans) generally in high overall yields. Steady-state measurements showed that electron-donating substituents present in the allenes enhanced the overall reaction rate. There was little effect of the solvent polarity on the reaction rate. The formation of thietanes involved the excited triplet thiones and the $\pi$-bond of allenes [66].

In 1984, Bos and co-workers realized the photocycloaddition reaction of the first stable thiobenzaldehyde, 2,4,6-tri(tertbutyl)thiobenzaldehyde (211) with substituted allenes 212 . Irradiation of thiobenzaldehyde 211 with $\mathrm{RCR}^{1}=\mathrm{C}=\mathrm{CH}_{2}$ (212) gave diastereospecific [2+2] cycloadducts, thietanes 213 in $75-95 \%$ yields [67] (Scheme 41).

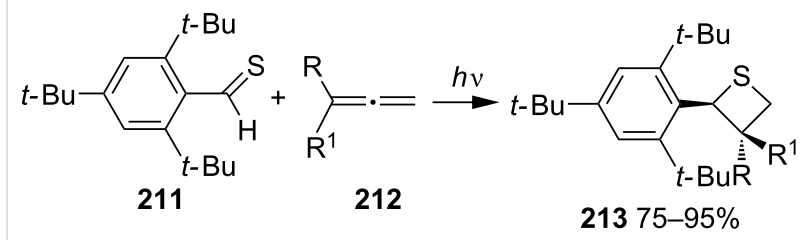

$\mathrm{R}=\mathrm{OMe}, \mathrm{OEt}, \mathrm{OCMe}_{3}, \mathrm{SMe}, \mathrm{SEt}, \mathrm{SCHMe}_{2}, \mathrm{Ph}$, $\mathrm{R}^{1}=\mathrm{H} ; \mathrm{R}=\mathrm{Ph}, \mathrm{R}^{1}=\mathrm{D}$

Scheme 41: Synthesis of thietanes 213 from 2,4,6-tri(tertbutyl)thiobenzaldehyde (211) with substituted allenes.

In 1984, Coyle and Rapley performed the photochemical cycloadditions of $N$-methylthiophthalimide (214) with 2,3dimethylbut-2-ene (215a) or with stilbene (186b) to give spirothietanes 216 and 217, respectively [68] (Scheme 42).<smiles>S=c1c2ccccc2sc2ccccc12</smiles>

$$
\begin{gathered}
\mathrm{Me}_{2} \mathrm{C}=\mathrm{C}=\mathrm{C}=\mathrm{CRR}^{1} \\
209
\end{gathered}
$$

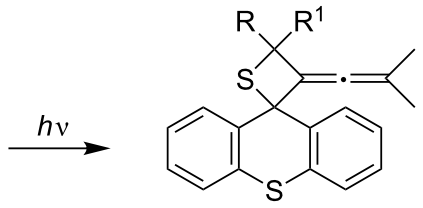

210 

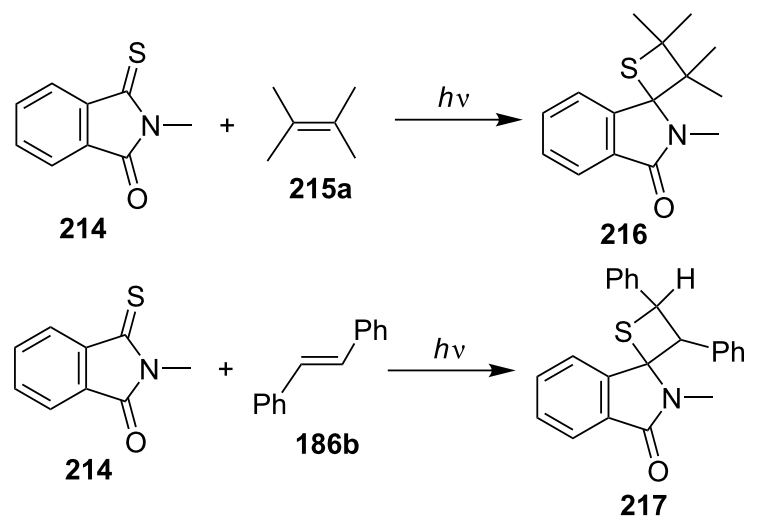

Scheme 42: Photochemical synthesis of spirothietanes 216 and 217 from $N$-methylthiophthalimide (214) with olefins.

In 1985, Jenner and Papadopoulos prepared fused thietane derivatives $\mathbf{2 2 0}$ by the photo [2+2] cycloaddition of quadricyclane 218 with thiocarbonyl derivatives 219 . With carbon disulfide, mono- and biscycloadducts $\mathbf{2 2 1}$ and $\mathbf{2 2 2}$ were formed depending on concentration, temperature, and pressure conditions [69] (Scheme 43).

In the same year, Kanaoka and co-workers reported the intermolecular photo [2+2] cycloadditions of $N$-methyldithiosuccinimides 223 and $N$-methyldithiophthalimide (225) with alkenes $\mathbf{2 1 5}$ and a conjugated diene 226, generating spirothietanes 224, 227-229, 231, 232, and 234. In some cases, the reverse $[2+2]$ cycloaddition occurred with the loss of a molecule of thioacetone [70] (Scheme 44).

The photoreaction of $\mathrm{N}$-methylthiosuccinimide (236) with 2,3dimethylbut-2-ene (215a) gave rise to a mixture of thietane and oxetane derivatives $\mathbf{2 3 8}$ and $\mathbf{2 3 9}$, with thietane $\mathbf{2 3 8}$ as the major component. However, the reaction of the aromatic counterpart, $N$-methylmonothiophthalimide (237a) with olefins 215a and 186b, produced exclusively thietane derivatives 240 and 241 [70] (Scheme 45).
The authors further investigated photoreactions of $N$-substituted monothiophthalimides 237 with styrene derivatives 186 and 242, affording the corresponding spirothietanes 243 and 244 [71] (Scheme 46).

They also documented the photocycloaddition of ring-substituted cyclic dithiosuccinimides $\mathbf{2 2 3}$ with 2,3-dimethyl-2-butene (215a), affording a series of spirothietanes 245 [72] (Scheme 47).

In 1986, Coyle and Rapley reported that the photochemical cycloaddition reactions of $N$-methylthiophthalimide (237a) and $\mathrm{N}$-methyldithiophthalimide (225) with alkenes worked as well [73].

In 1987, Ooms and Hartmann showed the photochemical $[2+2]$ cycloaddition of diaryl thione $\mathbf{1 8 4 b}$ with ketene acetals 247 [74] (Scheme 48).

In the same year, Nishio studied the photocycloadditions of nitrogen-containing cyclic thiones $\mathbf{2 4 9}$ and 250 with 2-methylacrylnitrile (251a) and methyl 2-methylacrylate (251b), respec-

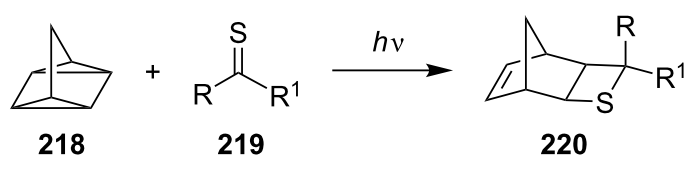

$\mathrm{R}=\mathrm{Cl}, \mathrm{CN} ; \mathrm{R}^{1}=\mathrm{Cl}, \mathrm{SMe}$

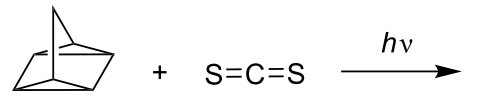

218

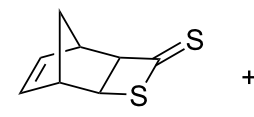

221

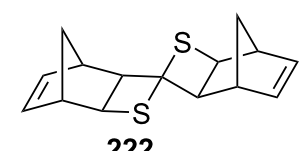

222

Scheme 43: Synthesis of fused thietanes from quadricyclane with thiocarbonyl derivatives 219. 


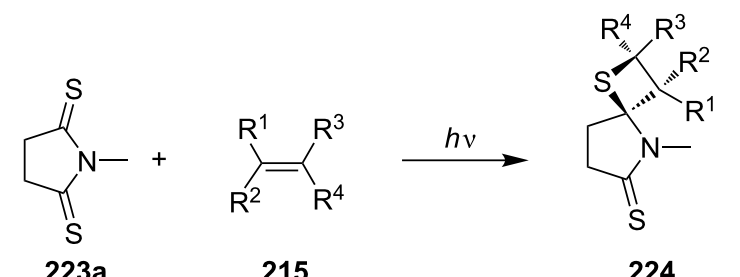

$223 a$

215<smiles>C[C@H]1C(=S)N(C)C(=S)C1(C)C</smiles>

223b<smiles>CN1C(=S)[C@H]2CCCC[C@H]2C1=S</smiles>

$223 c^{S}$<smiles>CN1C(=S)CCC1=S</smiles>

$223 a$<smiles>CN1C(=S)CCC1=S</smiles>

$223 a$<smiles>CN1C(=S)c2ccccc2C1=S</smiles>

225<smiles>CCC(C)=CC=C(C)C</smiles>

226
$215 a$<smiles>CC(C)=C(C)C</smiles>

$22832 \%$

$23175 \%$ olefin 215

reaction time (h)

a $\mathrm{R}^{1}=\mathrm{R}^{2}=\mathrm{R}^{3}=\mathrm{R}^{4}=\mathrm{Me} \quad 2.5$

b $R^{1}=R^{2}=R^{3}=M e, R^{4}=H \quad 2.5$

c $R^{1}=R^{2}=M e, R^{3}=R^{4}=H 1$

d $R^{1}=R^{3}=M e, R^{2}=R^{4}=H 1$

e $R^{1}=\mathrm{OEt}, \mathrm{R}^{2}=\mathrm{R}^{3}=\mathrm{R}^{4}=\mathrm{H} 2.5$

amixture of two stereoisomers
224 yield (\%)

83

$62^{a}$

58

$60^{a}$

$46^{a}$
224

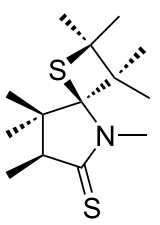

$22758 \%$<smiles>CN1C(=S)C2CCCCC2C12SC(C)(C)C2(C)C</smiles><smiles>CC(C)=CC1C(C)(C)SC12CC(=S)N2C</smiles>

229 trace

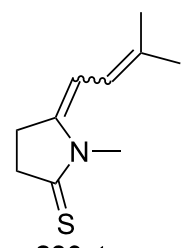

230 trace<smiles>CN1C(=S)CC[C@]12S[C@H]1CCCCC=C[C@@H]12</smiles><smiles>CN1C(=S)c2ccccc2C1=S</smiles>

225<smiles>CCCCCCC</smiles>

226<smiles>CC(C)=C1c2ccccc2C(=S)N1C</smiles>

$23310 \%$ 
<smiles>CC(C)=C(C)C[C@@H]1CCCCC1=S</smiles><smiles>CN1C(=O)CCC12SC(C)(C)C2(C)C</smiles>

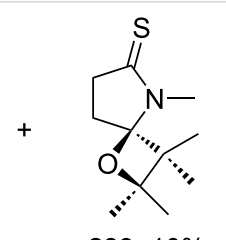<smiles>[Z16]C(C)=C(C)C</smiles>

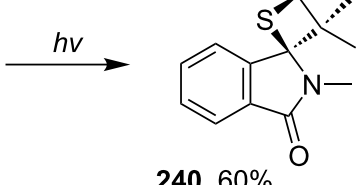

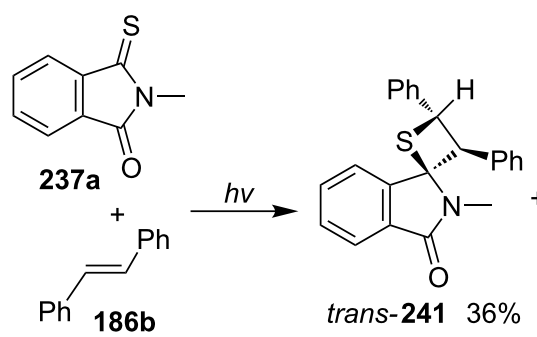<smiles></smiles>

Scheme 45: Synthesis of tricyclic thietanes via the photo [2+2] cycloaddition of $\mathrm{N}$-methylthiosuccinimide/thiophthalimide with olefins.<smiles>[R]N1C(=O)c2ccccc2C1=S</smiles>
237 $\mathrm{R}=\mathrm{Me}, \mathrm{CMe}_{3}, \mathrm{Ph}$<smiles>[R]N1C(=O)c2ccccc2C1=S</smiles>

237

$\mathrm{R}=\mathrm{Me}, \mathrm{CMe}_{3}, \mathrm{Ph}$<smiles>[R]/C=C(/[R1])Pc1ccccc1</smiles>

a: $R^{1}=M e, R^{2}=H$,

b: $R^{1}=H, R^{2}=P h$, c: $R^{1}=P h, R^{2}=H$,<smiles>[R]C(SC1(C([R])([R])C)C(=O)c2ccccc21)C1([R])CC(=O)N1</smiles>

243<smiles>[R]C1SC2(C(=O)N([R])C2c2ccccc2)c2ccccc21</smiles>

244
Scheme 46: Synthesis of tricyclic thietanes via the photo [2 + 2] cycloaddition of $\mathrm{N}$-alkylmonothiophthalimides with styrene derivatives.<smiles>[Z16]C(C)=C(C)C(C)=C(C)C</smiles>

$\mathrm{R}=\mathrm{Me}, \mathrm{Et}, \mathrm{R}^{1}=\mathrm{R}^{2}=\mathrm{H}$; 242

a: $\mathrm{R}^{1}=\mathrm{CN}$

b: $\mathrm{R}^{1}=\mathrm{CO}_{2} \mathrm{Me}$,

c: $R^{1}=A c$

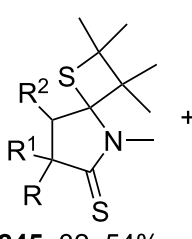

$24532-54 \%$

$\mathrm{R}=\mathrm{R}^{1}=\mathrm{Me}, \mathrm{R}, \mathrm{R}^{1}=\left(\mathrm{CH}_{2}\right)_{5}, \mathrm{R}^{2}=\mathrm{H}$;

$\mathrm{R}=\mathrm{H}, \mathrm{R}^{1}, \mathrm{R}^{2}=\left(\mathrm{CH}_{2}\right)_{2}$

Scheme 47: Synthesis of spirothietanes from dithiosuccinimides 223 with 2,3-dimethyl-2-butene (215a).

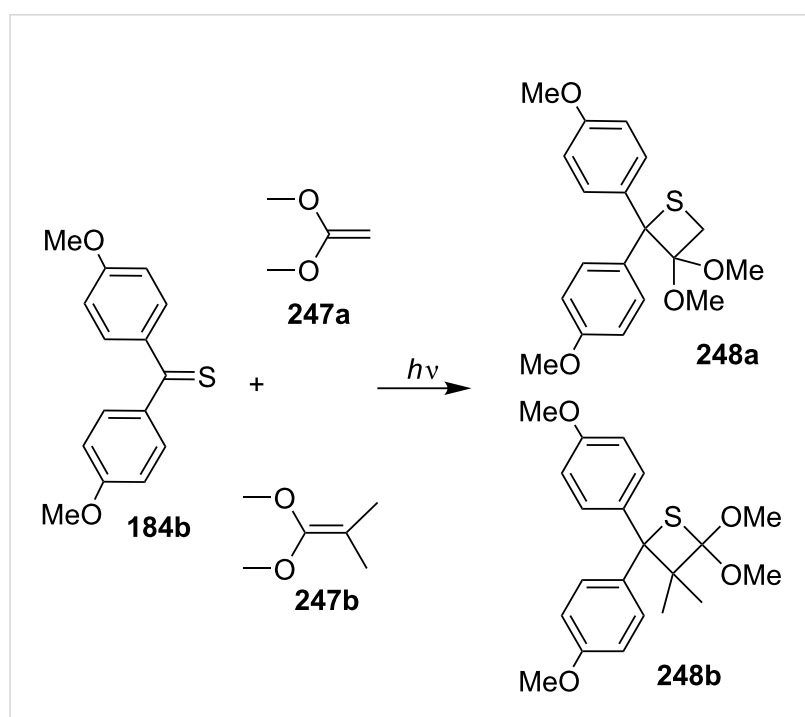

Scheme 48: Synthesis of thietanes $248 a, b$ from diaryl thione $184 b$ and ketene acetals $247 \mathbf{a}, \mathbf{b}$.

tively, affording the corresponding spirothietanes 253 regiospecifically in $67-99 \%$ yields for acridine-9-thione $249 \mathrm{~b}$ and its $\mathrm{N}$-methyl derivative 249a. However, for pyridine-4(1H)-thione (250), the generated thietane intermediates 254 underwent ring cleavage and aromatization to give substituted pyridines $\mathbf{2 5 5}$ [75] (Scheme 49).<smiles>Cn1c2ccccc2c(=S)c2ccccc21</smiles><smiles>C=C(C)C(C)(C)[13CH3]</smiles><smiles>CN1c2ccccc2C2(SCC2(C)C)c2ccccc21</smiles>

$25289 \%$

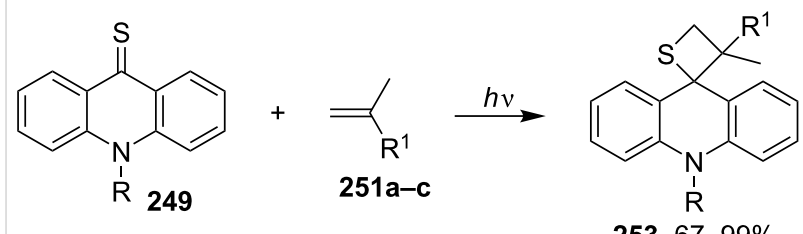

253 67-99\%

$\mathrm{R}=\mathrm{H}, \mathrm{R}^{1}=\mathrm{CN} ; \mathrm{R}=\mathrm{Me}, \mathrm{R}^{1}=\mathbf{a}: \mathrm{CN}, \mathbf{b}: \mathrm{CO}_{2} \mathrm{Me}, \mathbf{c}: \mathrm{Me}$<smiles>[R16]c1ccc(C([R])(C)CS)cc1</smiles>

$\mathrm{R}=\mathrm{CN}, 63 \% ; \mathrm{R}=\mathrm{CO}_{2} \mathrm{Me}, 67 \%$
Scheme 49: Photocycloadditions of acridine-9-thiones 249 and pyridine-4(1H)-thione (250) with 2-methylacrynitrile (251a) and methyl 2-methylacrylate (251b). 
In 1989, Kanaoka and co-workers further studied the photo $[2+2]$ cycloadditions of thiobarbiturates 256-258, whose skeletons consisted of a combination of a thioamide and an amide or a thioamide (two-imides system), and olefins. 2-Thiobarbiturate 256 generated both, the spirothietanes 259, 261, and 263 and the corresponding cycloreversion products 260, 262, and 264. When compound 256 was reacted with 2,3dimethylbut-2-ene (215a), the spirothietane $\mathbf{2 5 9}$ was formed in slight excess. However, the cycloreversion products $\mathbf{2 6 2}$ and $\mathbf{2 6 4}$ formed preferably, in the reaction of $\mathbf{2 5 6}$ with ethyl vinyl ether (215e) and propen-2-ylbenzene (186a). Notably, the photoreaction of 2,4-dithiobarbiturate 257 and 2,3-dimethylbut-2ene (215a) produced exclusively the 4-thietane derivative $\mathbf{2 6 5}$ in $91 \%$ yield. 2,4,6-Trithiobarbiturate $\mathbf{2 5 8}$ reacted with the same olefin to yield the corresponding 4-thietane derivative $\mathbf{2 6 6}$ accompanied with dithiouracil derivative $\mathbf{2 6 7}$ as byproduct [76] (Scheme 50).

Rao and Ramamurthy systematically investigated the intermolecular photocycloadditions of 1,1,3-trimethyl-2-thioxo-1,2dihydronaphthalene (268) with a series of electron-deficient olefins 187b,c, 189, 242a, and 269-272. The reactions afforded stereospecifically and regioselectively the 3 -functionalized spirothietanes $\mathbf{2 7 3}-\mathbf{2 8 5}$ as the major products. The stereospecific addition suggested either a concerted process or a pathway involving very short-lived diradicals as intermediates. To explain the regioselectivity, theoretical calculations were performed with thiochalcone and acrylonitrile as model substrates. For the frontier molecular orbital treatment, the largest coefficients in both HOMO and LUMO of thiochalcone existed on the sulfur atom, while the largest coefficients in both HOMO and LUMO of acrylonitrile were located at the $\beta$-carbon atom. These favored the overlapping between the sulfur atom and the $\beta$-carbon atom, deciding the regioselectivity $[76,77]$ (Scheme 51).

Interestingly, the photochemical behavior of thioenones was obviously different from that of enones. The latter underwent the $[2+2]$ annulation with olefins at their olefinic center to yield cyclobutane derivatives, and rarely undergo oxetane formation completely. The reaction parameters such as solvent affected the balance between the cyclobutane and oxetane formation. Whereas reactions of olefins with thioenones took place on the thiocarbonyl group to give stereospecific and regioselective thietane derivatives.

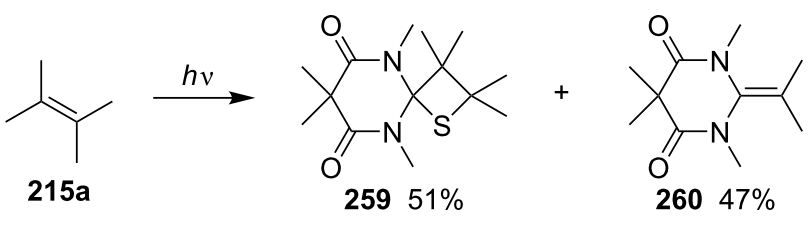

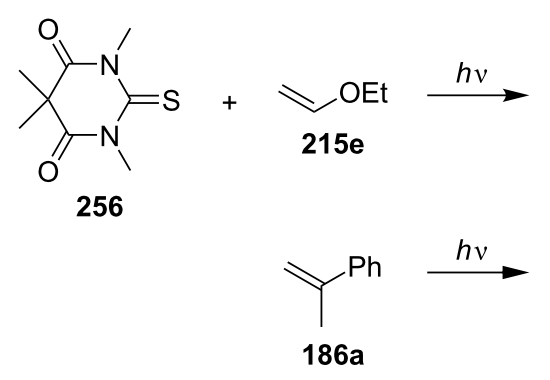<smiles>CCO/C=C1\N(C)C(=O)C(C)(C)C(=O)N1C(=O)OCC</smiles>

261 17\%

$26240 \%$

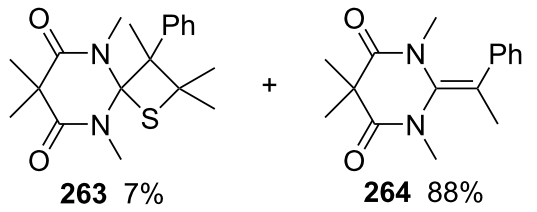<smiles>CN1C(=S)N(C)C(=S)C(C)(C)C1=S</smiles><smiles>[Z16]C(C)=C(C)C</smiles><smiles>CCCC</smiles><smiles>CN1C(=S)N(C)C2(SC1(C)C)N(C)C(=O)C(C)(C)C2(C)C</smiles><smiles>CN1C(=S)N(C)C(=S)C(C)(C)C1=S</smiles><smiles>CC(C)=C(C)[153I]</smiles>

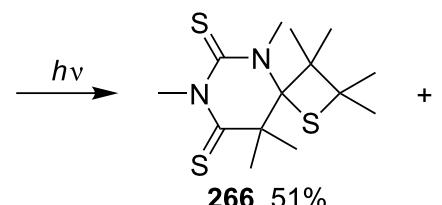<smiles></smiles>

Scheme 50: Synthesis of thietanes via the photo [2 + 2] cycloaddition of mono-, di-, and trithiobarbiturates $256-258$ with olefins. 


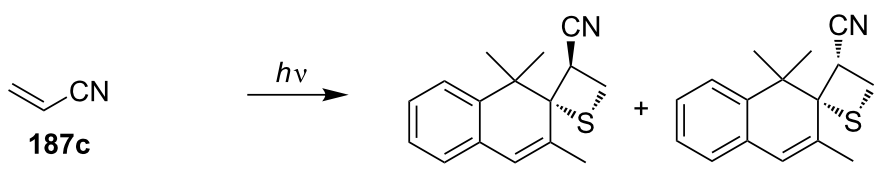

$( \pm)-273 \underbrace{1 \quad 8 \quad 8}_{70 \%}( \pm)-274$

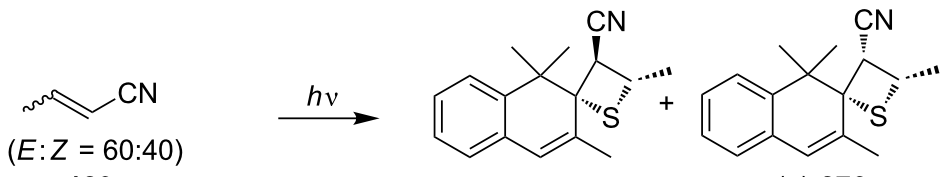
( \pm )-275
(士)-276

$42 \%$

$28 \%$

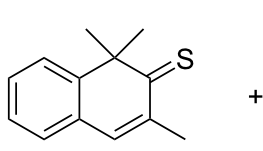

268<smiles>N#C/C=C\C#N</smiles><smiles>CC1=Cc2ccccc2C(C)(C)[C@@]12C[C@@H](C#N)[C@@H](C#N)S2</smiles>

$( \pm)-277$
$70 \%$

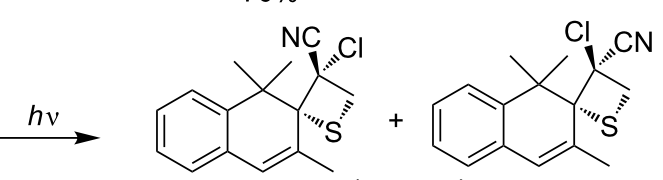

$$
\overbrace{\mathrm{Cl}}^{\mathrm{CN}}
$$

( \pm -278 $\underbrace{1 \quad: \quad 4}_{55 \%}$

$( \pm)-279$

$5 \%$

$$
\mathrm{Ph} \underset{242 a}{\curvearrowright} \mathrm{CN}
$$<smiles>CC1=Cc2ccccc2C(C)(C)C12S[C@H](C#N)[C@H]2Pc1ccccc1</smiles>

(士)-280

$40 \%$<smiles>CC1=Cc2ccccc2C(C)(C)[C@]12S[C@H](c1ccccc1)[C@H]2C#N</smiles>

$( \pm)-281$ $40 \%$<smiles>CCCCC(=O)OC(C)=CC(=O)OC</smiles>

$( \pm)-282$

$30 \%$<smiles>C=CC(C)=O</smiles>

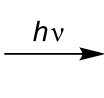

272
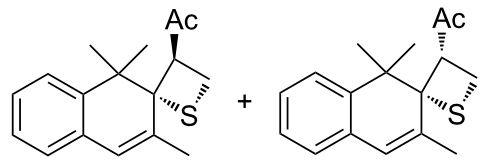

(士)-283

$30 \%$

$( \pm)-284$

$\gtrsim \mathrm{CO}_{2} \mathrm{Me}$

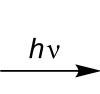

187b

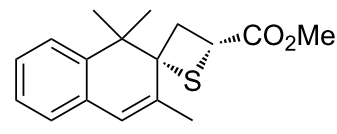

(士)-285

$10 \%$ 
The same group further studied the photo $[2+2]$ cycloadditions of thiocoumarin (286) and alkenes 187, 215a,f, and 271, producing the corresponding spirothietane derivatives 287-291 [78] (Scheme 52).

In 1988, Kanaoka et al. studied the photochemistry of semicyclic and acyclic thioimides 292-294 and 295 with 2,3dimethylbut-2-ene (215a) afforded the corresponding thietanes 296-299. However, the products were obtained together with pyrrolidinone, thiopyrrolidinone, or thiobenzamides as byproducts. The latter were generated in the competition between Paternò-Büchi-type and Norrish-type I reactions [79] (Scheme 53).

In the same year, Nishio and co-workers, investigated the photochemical $[2+2]$ cycloadditions of indoline-2-thiones with cyanoalkenes. Only 2 -alkylideneindolines were obtained via a ring cleavage of the thietanes, that had formed in the $[2+2]$ photocycloaddition of the thiocarbonyl moiety and the olefin. However, the reaction of 1,3,3-trimethylindoline-2-thione (300) and isobutene (215c) afforded the corresponding spiroindolinethietane derivative 301 [80] (Scheme 54).

They further investigated the photochemical $[2+2]$ cycloadditions of alkyl and aryl 2-thioxo-3H-benzoxazole-3-carboxylates 302 and alkenes 215a,b, 251a, and 227, affording the corresponding spirobenzoxazole-thietane derivatives 303 [81-84] (Scheme 55).

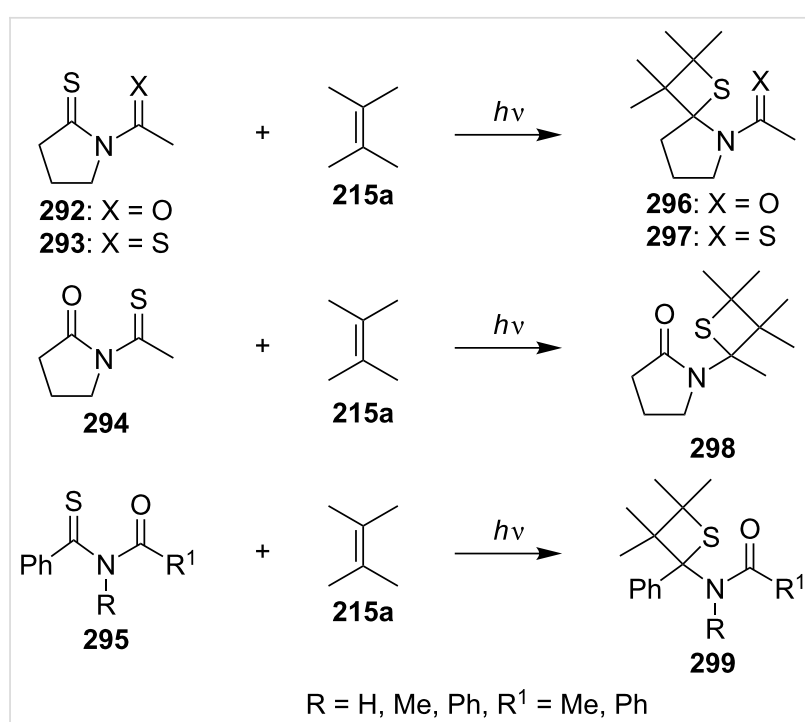

Scheme 53: Photochemical synthesis of thietanes 296-299 from semicyclic and acyclic thioimides 292-295 and 2,3-dimethylbut-2-ene (215a).

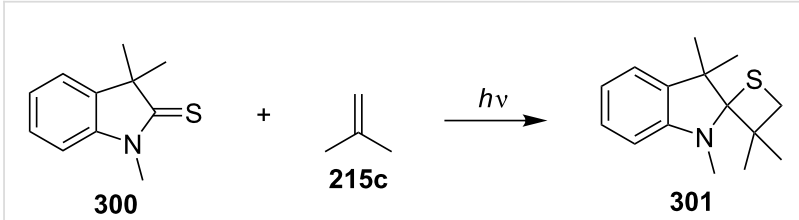

Scheme 54: Photochemical synthesis of spirothietane 301 from 1,3,3trimethylindoline-2-thione (300) and isobutene (215c).

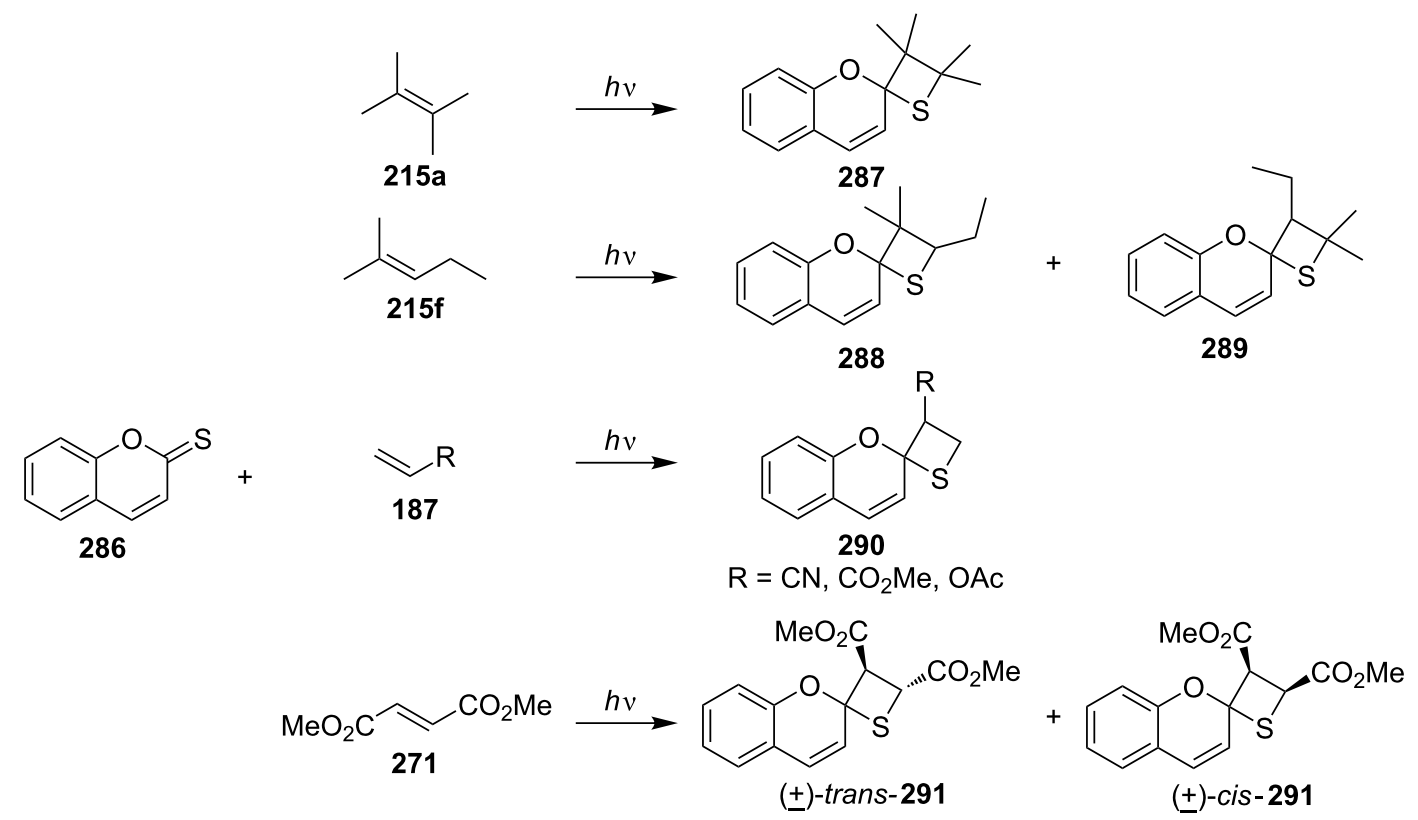

Scheme 52: Synthesis of spirothietanes via the photo [2+2] cycloaddition of thiocoumarin 286 with olefins. 


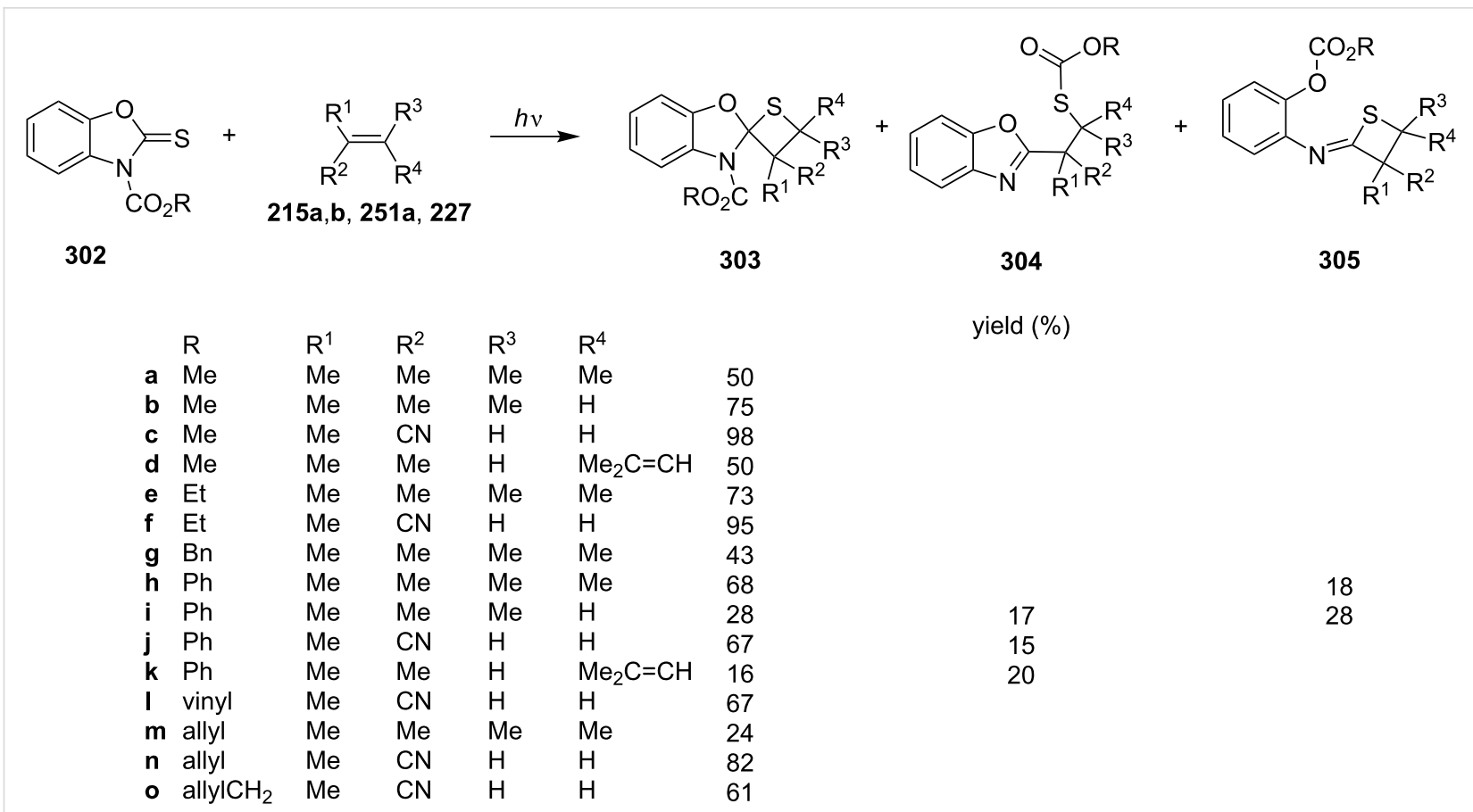

Scheme 55: Synthesis of spirobenzoxazolethietanes $\mathbf{3 0 3}$ via the photo [2 + 2] cycloaddition of alkyl and aryl 2-thioxo-3H-benzoxazole-3-carboxylates 302 and various alkenes.

Upon the irradiation of tetrahydrotrimethyldithioxo and [3-oxo1-thioxo or 1-oxo-3-thioxo]isoquinolines $\mathbf{3 0 6}$ and $\mathbf{3 0 7}$ with olefins $215 \mathbf{a}, \mathbf{b}$, and $186 \mathbf{c}$ or indene (198), the regioselective $[2+2]$ cycloaddition occurred to give oxo- or thiooxospiro[isoquinoline-1,2'(or 3,2')-thietane] derivatives 208-310. In some cases, the products were accompanied with the related alkylidenetetrahydrotrimethylthioxoisoquinolines as the byproducts [85] (Scheme 56).

Similar intramolecular photoreactions of $\mathrm{N}$-alkenylthiohomophthalimides were attempted as well, affording the tetracyclic thietane-fused isoquinoline derivatives regioselectively [86]

The reactions of isobenzofuran-1-thiones $\mathbf{3 1 1}$ and 2-benzothiophene-1-thiones 314 with 2,3-dimethylbut-2-ene (215a) gave the corresponding spirothietanes $\mathbf{3 1 2}$ and $\mathbf{3 1 5}$ under photo irradiation. The spirothietanes $\mathbf{3 1 2}$ derived from 3-unsubstituted or 3-monosubstituted 1,3-dihydroisobenzofuran-1-thiones $\mathbf{3 1 1}$ were less stable and underwent a thermal rearrangement to generate tricyclic isobenzofurans $\mathbf{3 1 3}$ through the ring-cleavage of the thietanes. It was assumed that the rearrangement was assisted through participation of the oxygen lone-pair electrons [17] (Scheme 57).

The silicon-containing phenyl triphenylsilyl thioketone (316) reacted with electron-poor olefins, such as acrylonitrile (187b), methyl acrylate $(\mathbf{1 8 7})$, and cis- and trans-1,2-dichloroethenes
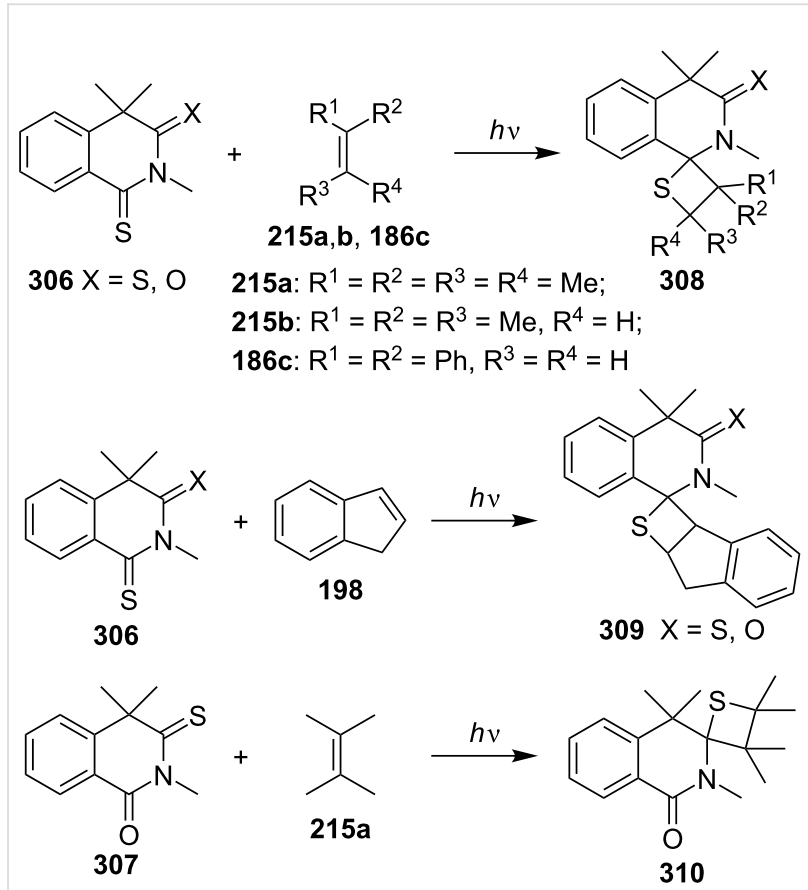

Scheme 56: Synthesis of spirothietanes from tetrahydrothioxoisoquinolines 306 and 307 with olefins.

188, under photochemical conditions, giving 2-silylthietanes 317 and 318 in a regio- and highly stereoselective manner. However, silyl thietanes without any regio- or stereocontrol 


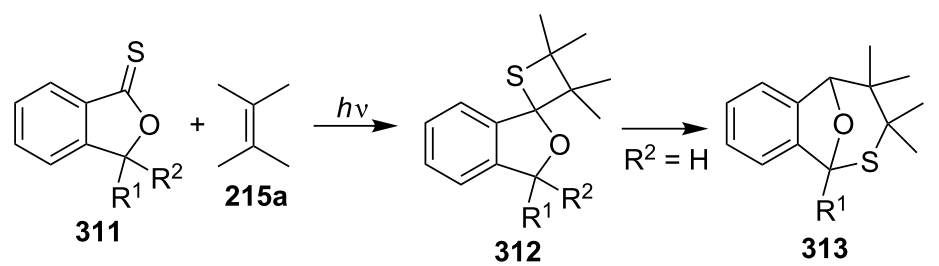

$\mathrm{R}^{1}=\mathrm{H}, \mathrm{Me}, \mathrm{Ph}, \mathrm{Bn}$, allyl; $\mathrm{R}^{2}=\mathrm{H}, \mathrm{Me}, \mathrm{Ph}$, allyl

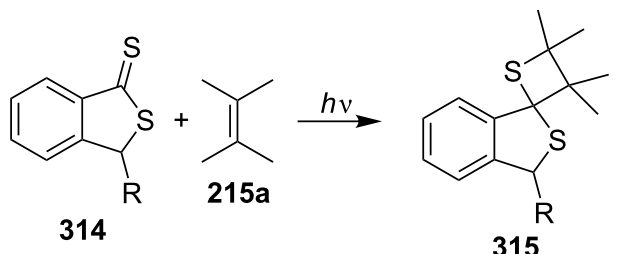

$\mathrm{R}=\mathrm{H}, \mathrm{Me}, \mathrm{Ph}$

Scheme 57: Synthesis of spirothietanes from 1,3-dihydroisobenzofuran-1-thiones 311 and benzothiophene-1-thiones 314 with 2,3-dimethylbut-2-ene (215a).

were obtained when $\mathbf{3 1 6}$ was reacted with electron-rich olefins, as for example, vinyl ethers [87] (Scheme 58).

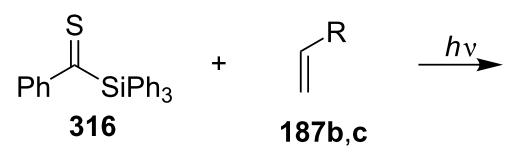

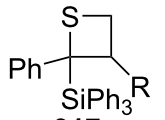

317 $\mathrm{R}=\mathrm{CN}, \mathrm{CO}_{2} \mathrm{Me}$<smiles>S=C([SnH2])[PbH2]</smiles><smiles>[R]/C([17NH2])=C\Cl</smiles><smiles>C[AsH2+]</smiles><smiles>[R]C1([R16])C(Cl)SC1([As])c1ccccc1</smiles>

$\mathrm{R}=\mathrm{H}, \mathrm{R}^{1}=\mathrm{Cl} ; \mathrm{R}=\mathrm{Cl}, \mathrm{R}^{1}=\mathrm{H}$
In 2003, Sakamoto and co-coworkers investigated the intermolecular diastereoselective photo [2+2] cycloaddition of axially chiral monothiosuccinimides 319 which could enantiomerize into both $(R)$ and $(S)$-isomers, and 1,1-diphenylethene (216c) under UV irradiation. As the products spirothietane-pyrrolidinones 320 were obtained in $65-89 \%$ yield. The diastereoselectivity was controlled by the steric effect of the ortho-substituents on the phenyl ring [88] (Scheme 59).

The intermolecular photochemical $[2+2]$ cycloaddition of tertbutyl 2-(5-methyl-2,4-dioxo-3,4-dihydropyrimidin-1(2H)yl)acetate (322) and thiobenzophenone (184a) was applied to prepare thietane $\mathbf{3 2 3}$ as a model compound for photolyses in a comparative flavin-induced cleavage study of oxetanes and thietanes [89] (Scheme 60).

2,5-Diphenylsilacyclopentadiene (324) underwent a photo-induced [2+2] cycloaddition with $\mathrm{CS}_{2}$ to afford two regioiso-

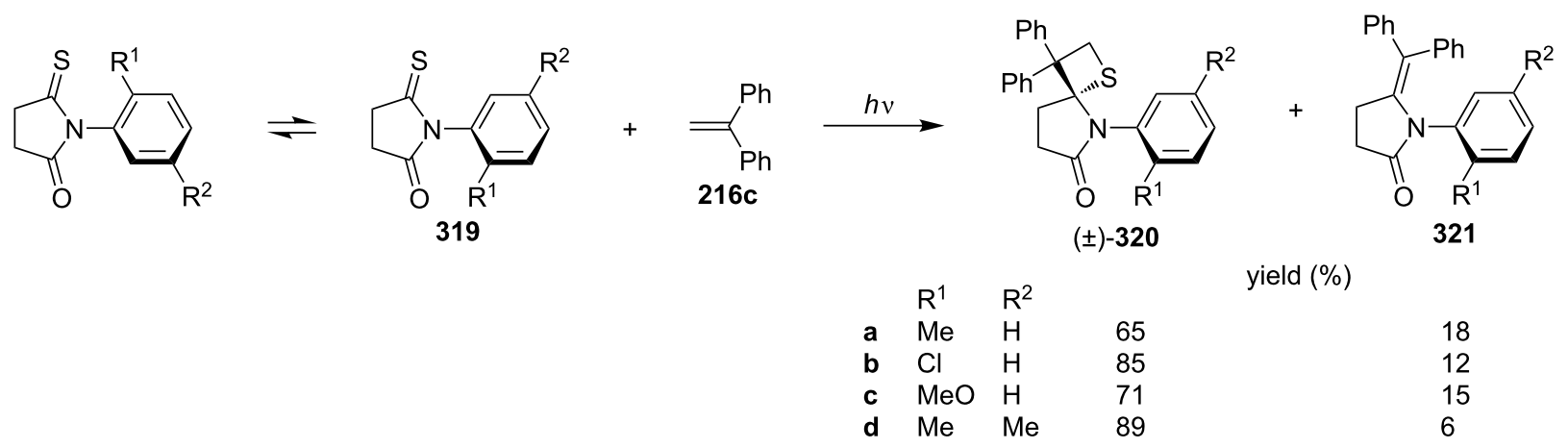


<smiles>Cc1cn(CC(=O)OC(C)(C)C)c(=O)[nH]c1=O</smiles>

Scheme 60: Synthesis of bicyclic thietane 323 via the photo [2 +2$]$ cycloaddition of 2,4-dioxo-3,4-dihydropyrimidine 322 and thiobenzophenone (184a).

meric fused thietane-2-thiones $\mathbf{3 2 5}$ and $\mathbf{3 2 6}$. The electron transfer from the singlet-excited state of silacyclopentadiene to $\mathrm{CS}_{2}$ was shown to play an important role in the cycloaddition [90] (Scheme 61).

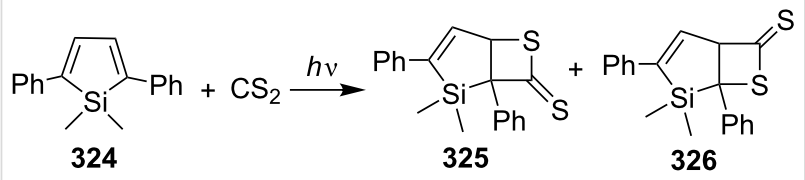

Scheme 61: Photo-induced synthesis of fused thietane-2-thiones 325 and $\mathbf{3 2 6}$ from silacyclopentadiene $\mathbf{3 2 4}$ and carbon disulfide.

3.1.2 Synthesis via intramolecular photochemical [2+2] cycloadditions: In 1985, Machida's group reported the intramolecular photo-assisted [2+2] cycloadditions of $\mathrm{N}$-allylthiosuccinimides 327 applying $1 \mathrm{~kW}$ high-pressure mercury lamp irradiation under a nitrogen atmosphere, giving the highly strained tricyclic thietanes 328 [91] (Scheme 62).<smiles>[R]C(=C)CN1C(=S)CCC1=[V]</smiles>

327

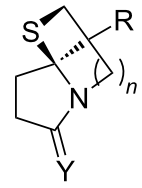

328

31

82

42

65
Scheme 62: Synthesis of highly strained tricyclic thietanes 328 via the intramolecular photo [2 + 2] cycloaddition of $N$-allyl/but-3-enylthiosuccinimides 327 .

One year later, the same group reported the intramolecular photo [2+2] cycloadditions of 2-allyl- $N$-methyldithiosuccinimide (329) with the same irradiation source at room tempera- ture for $1 \mathrm{~h}$, generating another highly strained tricyclic thietane 330. 2-((6,6-Dimethylbicyclo[3.1.1]hept-2-en-2-yl)methyl)- $N$ methyldithiosuccinimide (331) gave rise to the pentacyclic thietane derivative $\mathbf{3 3 2}$ under the same conditions [92] (Scheme 63).<smiles>C=CCC1CC(=S)NC1=S</smiles><smiles>C[C@H]1C[C@@H]1C</smiles>

329

330

$42 \%$ recovery $36 \%$ starting<smiles>CN1C(=S)CC(CC2CC3CCC2C3)C1=S</smiles>

331

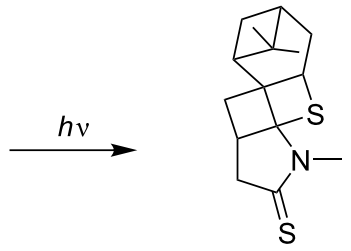

332
$45 \%$ recovery $45 \%$ starting

Scheme 63: Synthesis of tri- and pentacyclic thietanes $\mathbf{3 3 0}$ and $\mathbf{3 3 2}$ respectively, through the intramolecular photo [2+2] cycloaddition of allyldithiosuccinimides 329 and 331.

In 1987, Wipf and Heimgartner realized the photochemical intramolecular [2+2] cycloaddition of vinylthiazolethiones $\mathbf{3 3 3}$ to give tricyclic thietane derivatives 334 in $38-88 \%$ yields [93] (Scheme 64).

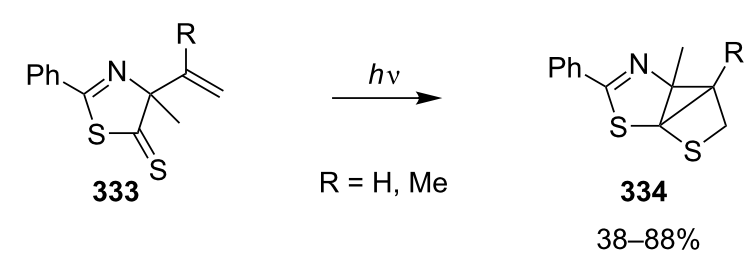

Scheme 64: Synthesis of tricyclic thietanes 334 via the intramolecular photo [2+2] cycloaddition of $N$-vinylthiazolethiones $\mathbf{3 3 3}$.

In 1992, Oda's group found that, under photo irradiation conditions $N$-but-3-enylthiophthalimides 335 underwent an intramolecular photo-assisted [2+2] cycloaddition first giving tricyclic thietanes 336, which further photochemically converted into pyridoisoindolones 337 [94] (Scheme 65).

To synthesize various pyrrolizidine alkaloids, Padwa's group used the intramolecular photocycloaddition of $\mathrm{N}$-but-3-enyl-5thiopyrrolidin-2-ones 338. The intramolecular photo $[2+2]$ cycloadditions first generated the tricyclic thietanes $\mathbf{3 3 9}$, which further underwent a ring-opening reaction to afford 


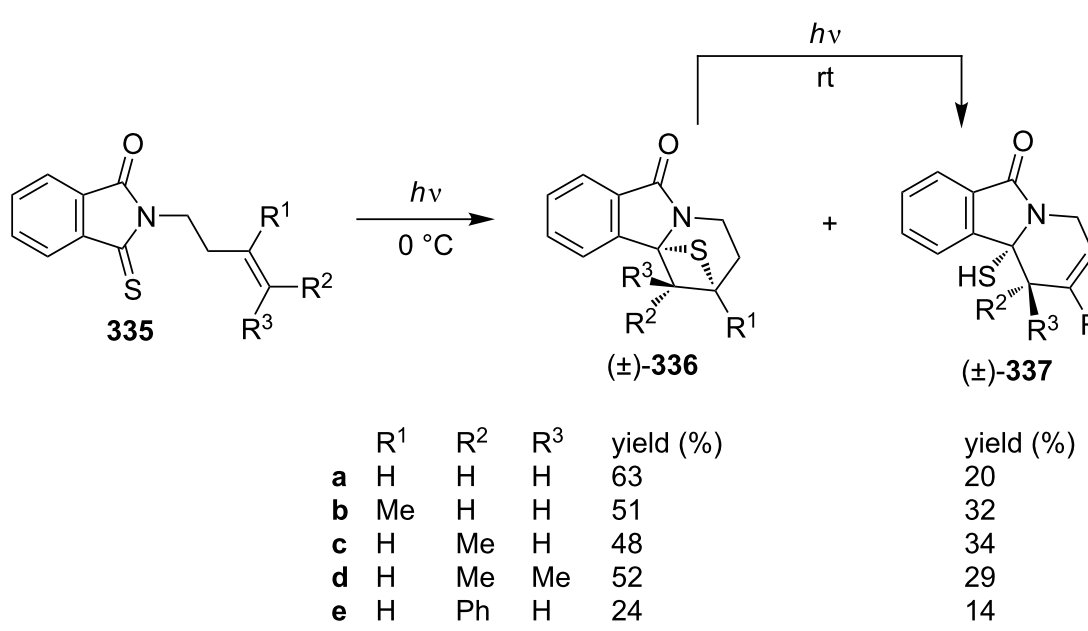

Scheme 65: Synthesis of tricyclic thietanes 336 via the intramolecular photo [2 + 2] cycloaddition of $N$-but-3-enylthiophthalimides 335 and photochemical conversion to pyridoisoindolones 337 .

pyrrolizinones 342. In case of $N$-but-3-enyl-5-thiopyrrolidin-2one $(338 \mathbf{a}, \mathrm{R}=\mathrm{H})$ the reaction afforded the product 7-mercaptomethyl-1,2,5,6-tetrahydropyrrolizin-3-one (340) directly in $68 \%$ yield under photo irradiation. However, $N$-(3-methylbut-3enyl)-5-thiopyrrolidin-2-one (338b, $\mathrm{R}=\mathrm{Me})$ initially generated a tricyclic fused thietane derivative $(\mathbf{3 3 9} \mathbf{b}, \mathrm{R}=\mathrm{Me})$, which gave rise to 2,5,6,7-tetrahydropyrrolizin-3-one $\mathbf{3 4 1}$ upon the treatment with dimethyl(methylthio)sulfonium tetrafluoroborate (DMTSF), or hexahydropyrrolizin-3-one $\mathbf{3 4 2}$ in the presence of Ra-Ni in ethanol [18,95] (Scheme 66).

$N$-1-(Cyclopent-1-enyl)ethyl-5-thiopyrrolidin-2-one (343) gave a tetracyclic thietane derivative $\mathbf{3 4 4}$, which further afforded a spirocyclopentane tetrahydropyrrolizin-3-one 346 under the similar treatments [95] (Scheme 67).
Similarly, linear and cyclic 3-but-3-enylpyrrolidine-2,5dithiones $\mathbf{3 4 7}$ gave tricyclic and tetracyclic fused thietane derivatives 348, 350, and 351 under photo irradiation [95] (Scheme 68).

Nishio and co-workers investigated the photochemical [2 +2] cycloaddition of vinyl 2-thioxo-3H-benzoxazole-3-carboxylate (353), affording the corresponding tetracyclic fused benzoxazolethietane derivative $\mathbf{3 5 4}$ in 20\% yield [83] (Scheme 69).

In 1991, Sakomto and co-workers started on the synthesis of highly rigid thietane-fused $\beta$-lactams. They prepared various derivatives 356 in high yields via the photochemical cycloaddition reactions of $N$ - $(\alpha, \beta$-disubstituted alkyl-2-enoyl)thiobenzamides 355. Some thioamides 355, (i.e., $\mathrm{R}=\mathrm{CHMe}_{2}$ ), formed

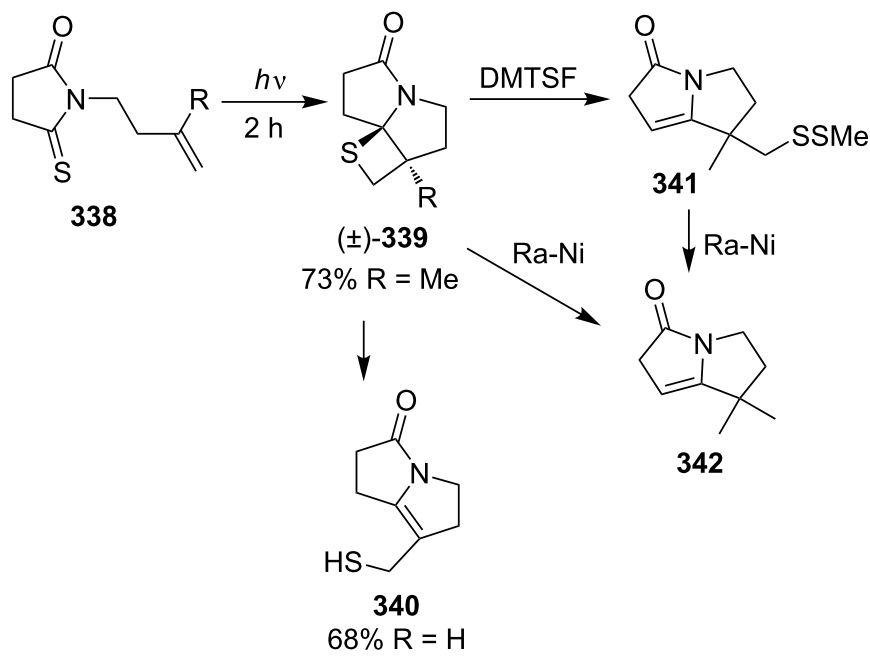

Scheme 66: Synthesis of tricyclic thietanes via the intramolecular photo [2+2] cycloaddition of $N$-but-3-enylthiosuccinimides 338 . 
<smiles>O=C1CCC(=S)N1CCC1=CCCC1</smiles>
343<smiles>O=C1CCC23SC4CCC[C@]42CCN13</smiles>

$( \pm)-344$ $68 \%$

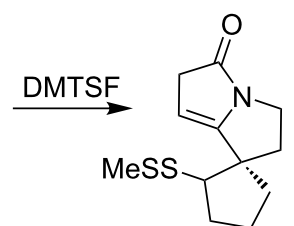

345

$\downarrow \mathrm{Ra}-\mathrm{Ni}$<smiles>O=C1CC=C2N1CCC21CCCC1</smiles>

346

Scheme 67: Synthesis of tetracyclic thietane $\mathbf{3 4 4}$ through the intramolecular photo [2 + 2] cycloaddition of $\mathrm{N}$-[2-(cyclopenten-1-yl)ethyl]thiosuccinimide 343
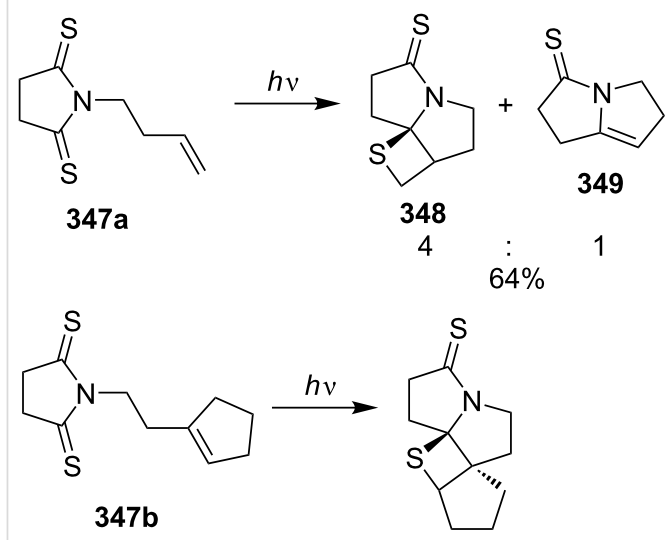

$( \pm)-350$

$48 \%$<smiles>S=C1CCC(=S)N1CCC1=CCCCC1</smiles>

$347 c$

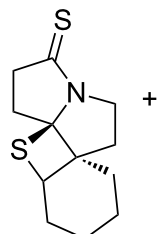

$( \pm)-351$

$28 \%$
Scheme 68: Synthesis of tri- and tetracyclic thietanes 348,350 , and 351 , through the intramolecular photo [2 +2] cycloaddition of $N$-but-3enyldithiosuccinimides $347 a-c$.

$\mathrm{R}^{2} \mathrm{CH}=\mathrm{CR}^{1} \mathrm{CONHCMe}{ }_{2} \mathrm{CSPh}$ via a $\beta-\mathrm{H}$ abstraction of the thiocarbonyl group. Substituents at the $\alpha$-position to the alk-2-enoyl moiety led to a preference for the $[2+2]$ cyclization over the $\beta-\mathrm{H}$ abstraction. The reaction was shown to proceed via an $n-\pi^{*}$ triplet-excited state [96] (Scheme 70).

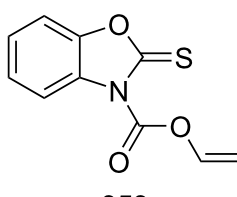<smiles>O=C1OC2CSC23Oc2ccccc2N13</smiles>

$35420 \%$

Scheme 69: Synthesis of tetracyclic fused thietane 354 via the photo [2 +2$]$ cycloaddition of vinyl 2-thioxo-3H-benzoxazole-3-carboxylate (353).<smiles>[R]C=C([R])C(=O)N([R])C(=S)c1ccccc1</smiles>

$\mathrm{R}=\mathrm{Me}, \mathrm{Et}, \mathrm{CHMe}_{2}, \mathrm{Bn}, \mathrm{Ph}$;

$\mathrm{R}^{1}=\mathrm{H}, \mathrm{Me} ; \mathrm{R}^{2}=\mathrm{H}, \mathrm{Me}, \mathrm{Ph} ; \mathrm{R}^{1}, \mathrm{R}^{2}=\left(\mathrm{CH}_{2}\right)_{3},\left(\mathrm{CH}_{2}\right)_{4}$

Scheme 70: Synthesis of highly rigid thietane-fused $\beta$-lactams via the intramolecular photo [2+2] cycloaddition of monothioimides 355 .

In 1993, the same group first attempted to prepare a chiral thietane-fused $\beta$-lactam 356a from an achiral monothioimide 355a using a chiral crystal environment through a topochemically controlled intramolecular photochemical [2+2] cycloaddition. The reaction afforded the product in $70 \%$ yield with $40 \%$ ee at $-45{ }^{\circ} \mathrm{C}$ and in $75 \%$ yield with $10 \%$ ee at $0{ }^{\circ} \mathrm{C}$, respectively [97] (Scheme 71).

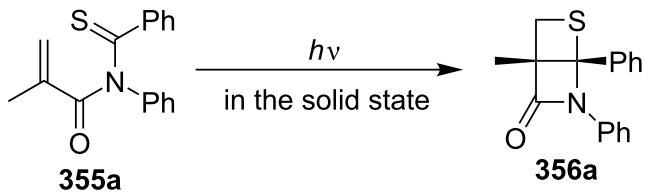

Scheme 71: Asymmetric synthesis of a highly rigid thietane-fused $\beta$-lactam 356a via the intramolecular photo [2 +2$]$ cycloaddition of monothioimide $355 a$

One year later, they studied the diastereoselective synthesis of highly rigid thietane-fused $\beta$-lactams 358-361 from a chiral monothioimide 357. The photochemical [2+2] cycloaddition reaction was performed both in benzene solution and in the solid state, affording $78 \%$ yield with a ratio of syn/trans $8.7: 1$ and $61 \%$ de for $s y n$-isomers at $15{ }^{\circ} \mathrm{C}$ in crystals, while no diastereoselectivity could be observed in benzene solution [16] (Scheme 72).

In 2001, they performed the absolute asymmetric synthesis of highly rigid thietane-fused $\beta$-lactams $\mathbf{3 5 6}$ from achiral monothioimides 355 using a chiral crystal environment through a 


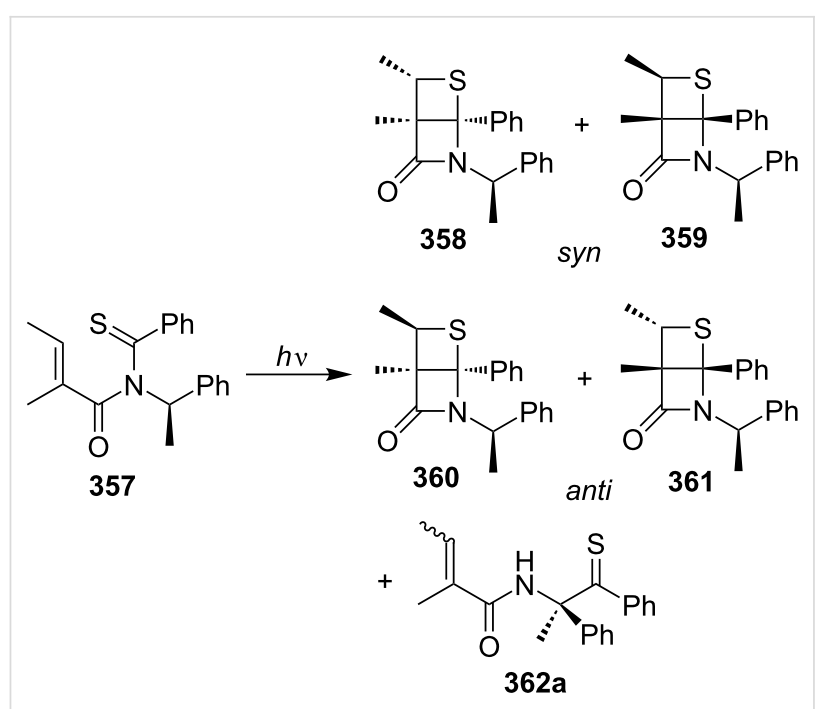

Scheme 72: Diastereoselective synthesis of the thietane-fused $\beta$-lactams via the intramolecular photo $[2+2]$ cycloaddition of the chiral monothioimide 357.

topochemically controlled intramolecular photochemical [2+2] cycloaddition in a benzene solution. Only the 2-methylacrylamide derivative 355a afforded the desired product 356a in $70 \%$ yield with $40 \%$ ee at $-45{ }^{\circ} \mathrm{C}$ and $75 \%$ yield with $10 \%$ ee at $0{ }^{\circ} \mathrm{C}$, respectively, in the solid state [98] (Scheme 73).

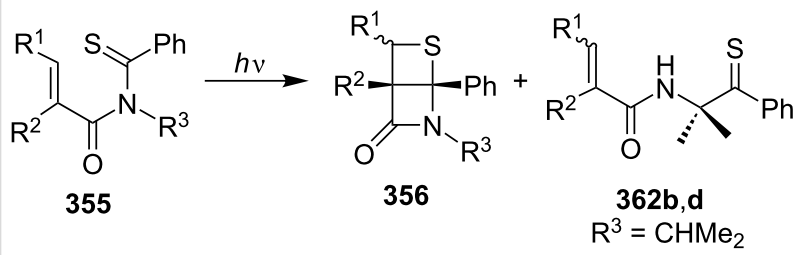

$$
\begin{aligned}
& \begin{array}{llllll} 
& & & & \text { yield (\%) } & \text { yield (\%) } \\
& \mathrm{R}^{1} & \mathrm{R}^{2} & \mathrm{R}^{3} & \text { in solid } & \text { in benzene } \\
\text { a } & \mathrm{H} & \mathrm{Me} & \mathrm{Ph} & 75 & 77 \\
\text { b } & \mathrm{H} & \mathrm{Me} & \mathrm{iPr} & 93 & 73 \\
\text { c } & \mathrm{Me} & \mathrm{Me} & \mathrm{Ph} & 92 & 80 \\
\text { d } & \mathrm{Me} & \mathrm{Me} & \mathrm{iPr} & 95 & 80
\end{array}
\end{aligned}
$$

Scheme 73: Asymmetric synthesis of thietane-fused $\beta$-lactams 356 via the intramolecular photo [2 + 2] cycloaddition of monothioimides 355 .

Compared with cyclic thioetherification reactions, the photochemical cycloadditions of thiocarbonyl compounds and olefins are highly suitable for the preparation of multiple substituted thietanes, including fused and spirothietanes.

3.2 Synthesis via the formal thermal [2+2] cycloadditions involving hexafluorothioacetone

The formal thermal [2+2] cycloadditions have also been applied in the synthesis of bis(trifluoromethyl)thietanes from 2,2,4,4-tetrakis(trifluoromethyl)-1,3-dithietane-generated bis(trifluoromethyl)thioacetone with various olefins in nucleophilic solvents DMF or DMSO. Previously, the reaction of 2,2,4,4-tetrakis(trifluoromethyl)-1,3-dithietane (363) and quadricyclane (218) was carried out in diglyme in the presence of $\mathrm{CsF}$ as catalyst, affording the thietane $\mathbf{3 6 4}$ in $74 \%$ yield. However, a $60 \%$ yield of the thietane $\mathbf{3 6 4}$ was obtained without the catalyst and solvent. The reaction of sulfur, KF, perfluorobut-2-ene (365) and quadricyclane $(\mathbf{2 1 8})$ in DMF at $130{ }^{\circ} \mathrm{C}$ generated 4-trifluoromethyl-4-pentafluoroethyl-3thiatricyclo[4.2.1.0 2,5$]$ non-7-ene $(\mathbf{3 6 6})$ in $11 \%$ yield with a trans:cis ratio of 55:45 [99] (Scheme 74).

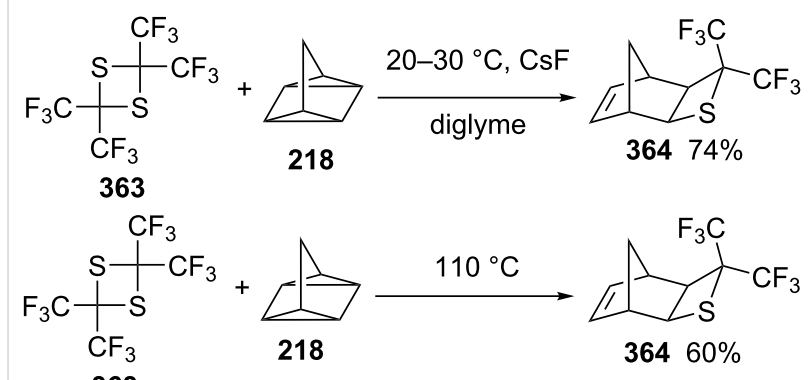

363

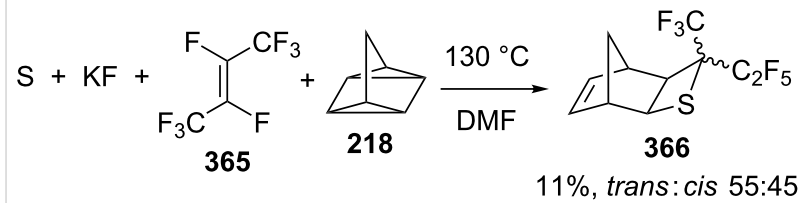

Scheme 74: Synthesis of the bridged bis(trifluoromethyl)thietane from 2,2,4,4-tetrakis(trifluoromethyl)-1,3-dithietane (363)and quadricyclane (218).

The reaction of 2,2,4,4-tetrafluoro-1,3-dithietane (367) and quadricyclane (218) generated the difluoro-bridged thietane 368 in $13 \%$ yield and two other byproducts $\mathbf{3 6 9}$ and $\mathbf{3 7 0}$ [99] (Scheme 75).

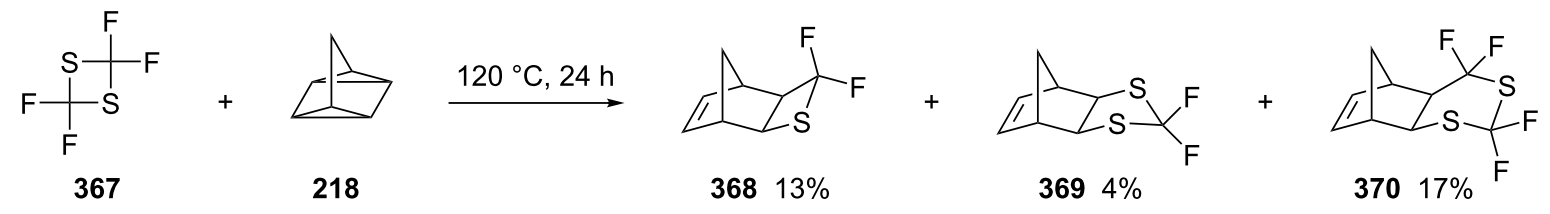

Scheme 75: Synthesis of the bridged-difluorothietane 368 from 2,2,4,4-tetrafluoro-1,3-dithietane (367) and quadricyclane (218). 
The reaction of 2,2,4,4-tetrakis(trifluoromethyl)-1,3-dithietane (363) with electron-rich olefins 371 and 372a gave the corresponding thietanes $\mathbf{3 7 4}$ and $\mathbf{3 7 5 a}$. On the other hand, reacting 2,2,4,4-tetrakis(trifluoromethyl)-1,3-dithietane (363) with 2,3dihydrofuran (373) gave the corresponding fused thietane 6,6bis(trifluoromethyl)-2-oxa-7-thiabicyclo[3.2.0]heptane (376) [19] (Scheme 76).<smiles>[R9]C1CC(C(F)(F)F)(C(F)(F)F)S1</smiles>
$363 \mathrm{R}=\mathrm{Et}, \mathrm{Pr}, \mathrm{iPr}, \mathrm{Bu}, t-\mathrm{Bu}, \mathrm{cHex}, \mathrm{CH}_{2} \mathrm{CH}_{2} \mathrm{Cl}$<smiles>FC(F)(F)C1([Se])SC(C(F)(F)F)(C(F)(F)F)S1</smiles><smiles>FC(F)(F)C1(C(F)(F)F)SC(C(F)(F)F)(C(F)(F)F)S1</smiles>

Scheme 76: Synthesis of bis(trifluoromethyl)thietanes from 2,2,4,4tetrakis(trifluoromethyl)-1,3-dithietane (363) and electron-rich olefins.

The reaction of 2,2,4,4-tetrafluoro-1,3-dithietane (363) with 1,1-dimethylthioethene (377) generated 2,2-dimethylthio-4,4di(trifluoromethyl)thietane $\mathbf{( 3 7 8 )}$ in $80 \%$ yield [100] (Scheme 77).

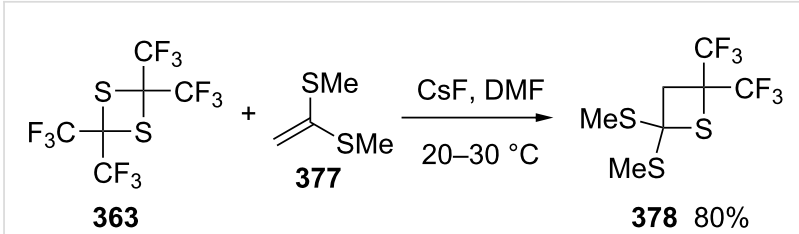

Scheme 77: Synthesis of 2,2-dimethylthio-4,4di(trifluoromethyl)thietane (378) from 2,2,4,4-tetrakis(trifluoromethyl)1,3-dithietane (363) and 1,1-dimethylthioethene (377).

A recent mechanistic investigation revealed that the CsF catalyst was not required. The solvent, such as DMSO (379), nucleophilically attacked the 1,3-dithietane $\mathbf{3 6 3}$, resulting in ring opening and further formation of bis(trifluoromethyl)thioacetone (381). The latter reacted with olefins 371 to afford thietanes 374. The reaction of 2,2,4,4-tetrakis(trifluoromethyl)1,3-dithietane (363) with alkyl vinyl ethers 371 or phenyl vinyl sulfide (372b) in DMSO at $70{ }^{\circ} \mathrm{C}$ afforded the corresponding 2,2-bis(trifluoromethyl)-3-alkoxy/phenylthiothietanes $\mathbf{3 7 4}$ and $\mathbf{3 7 5 b}$, respectively, with 1,3-dithiolanes $\mathbf{3 8 2}$ as byproducts [101] (Scheme 78).

The reactions of 2,2,4,4-tetrakis(trifluoromethyl)-1,3-dithietane (363) and styrenes 383 produced the [2+2] adducts 4-aryl-2,2bis(trifluoromethyl)thietanes $\mathbf{3 8 4}$ and Diels-Alder adducts $\mathbf{3 8 5}$, which further reacted with another molecule of bis(trifluoromethyl)thioketone (381) to yield the double Diels-Alder adducts $\mathbf{3 8 5}$ and thiochromane derivatives 386, respectively, through another Diels-Alder reaction and an ene reaction [101] (Scheme 79).<smiles>C[SH](C)OCCCCCC(C(F)(F)F)(C(F)(F)F)C(SC(C)(C)C)(C(F)(F)F)C(F)(F)F</smiles><smiles>FC(F)(F)C1(C(F)(F)F)SC(C(F)(F)F)(C(F)(F)F)S1</smiles>

363<smiles>FC(F)(F)C1(C(F)(F)F)SC(C(F)(F)F)(C(F)(F)F)S1</smiles>

363

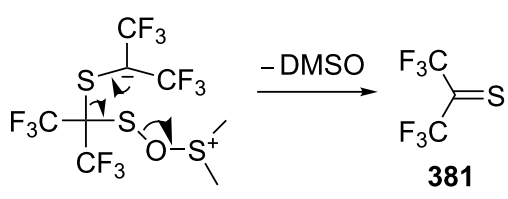

380

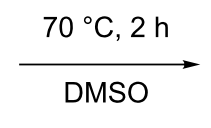<smiles>[R]OC1CC(C(F)(F)F)(C(F)(F)F)S1</smiles><smiles>[R]OC1CSC(C(F)(F)F)(C(F)(F)F)S1</smiles>

$$
382
$$$$
\mathrm{R}=\operatorname{Pr}, 5 \%
$$

$\mathrm{R}=\mathrm{Pr}, 95 \%$
$\mathrm{R}=\mathrm{Bu}, 95 \%$ $\mathrm{R}=\mathrm{Bu}, 5 \%$<smiles>FC(F)(F)C1(C(F)(F)F)CC(S)S1</smiles>

375b $85 \%$

Scheme 78: Formation of bis(trifluoromethyl)thioacetone (381) through nucleophilic attack of dithietane $\mathbf{3 6 3}$ by DMSO (379) and synthesis of 2,2bis(trifluoromethyl)thietanes $\mathbf{3 7 5}$ and $\mathbf{3 7 6}$ b from 2,2,4,4-tetrakis(trifluoromethyl)-1,3-dithietane (363) and olefins in DMSO. 
<smiles>FC(F)(F)C1(C(F)(F)F)SC1(C(F)(F)F)C(F)(F)F</smiles>

363<smiles>C=Cc1ccc(PC)cc1</smiles>
383 $70^{\circ} \mathrm{C}, 20-48 \mathrm{~h}$

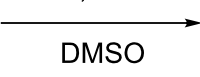

$\mathrm{F}_{3} \mathrm{C}$<smiles>[R19]c1ccc(CCC(F)(F)F)cc1</smiles><smiles>[R]c1ccc(C2CC(C(F)(F)F)(C(F)(F)F)S2)cc1</smiles><smiles>[3H]C1=CC2SC(C(F)(F)F)(C(F)(F)F)CC=C2C=C1</smiles><smiles>CC[AsH2]C(C)CC</smiles>

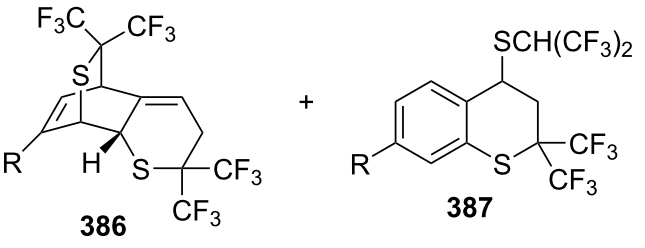

$\begin{array}{lllrlr}\mathrm{R}=\mathrm{H} & 29 & : & 46 & : & 25 \\ \mathrm{R}=\mathrm{Me} & 72 & : & 26 & : & 2 \\ \mathrm{R}=\mathrm{MeO} & 98 & : & 2 & : & 0\end{array}$

Scheme 79: Synthesis of 2,2-bis(trifluoromethyl)thietanes from 2,2,4,4-tetrakis(trifluoromethyl)-1,3-dithietane (363) and styrenes $\mathbf{3 8 3}$ in DMSO

The reaction of 2,2,4,4-tetrakis(trifluoromethyl)-1,3-dithietane (363) and quadricyclane (218) gave the bridged-thietane derivative 364 quantitatively in DMSO at $50{ }^{\circ} \mathrm{C}$ within 30 min [101] (Scheme 80).<smiles>FC(F)(F)C1(C(F)(F)F)SC(C(F)(F)F)(C(F)(F)F)S1</smiles>

363
218

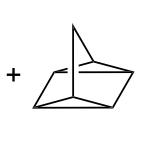

$50^{\circ} \mathrm{C}, 30 \mathrm{~min}$ DMSO<smiles>FC(F)(F)C1C2CCC(C2)SC1C(F)(F)C(F)(F)F</smiles>

364
Scheme 80: Synthesis of the bridged bis(trifluoromethyl)thietane 364 from of 2,2,4,4-tetrakis(trifluoromethyl)-1,3-dithietane (363) and quadricyclane (218) in DMSO.

\subsection{Synthesis via formal [2 +2$]$ cycloadditions}

The $[2+2]$ cycloaddition of alkenimines $\left(\mathrm{R}_{2} \mathrm{C}=\mathrm{C}=\mathrm{NAr}, \mathbf{3 8 8}\right)$ and $4-$ methylbenzenesulfonyl isothiocyanate (4- $\mathrm{MeC}_{6} \mathrm{H}_{4} \mathrm{SO}_{2} \mathrm{NCS}, 389$ ) gave 2,4-diiminothietanes 390 in $48-54 \%$ yields. This is a general method to prepare 2,4diiminothietane derivatives [102] (Scheme 81).

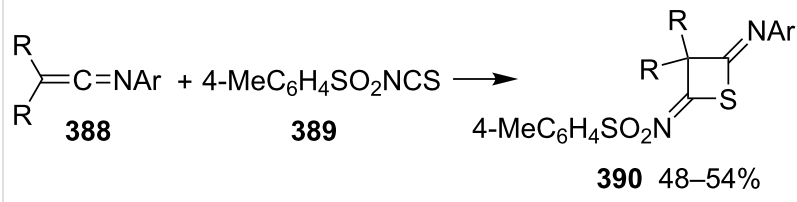

$\mathrm{R}=\mathrm{Ph}, \mathrm{Ar}=4-\mathrm{MeOC}_{6} \mathrm{H}_{4} ; \mathrm{R}=\mathrm{Me}, \mathrm{Ar}=\mathrm{Ph}, 4-\mathrm{MeC}_{6} \mathrm{H}_{4}$

Scheme 81: Synthesis of 2,4-diiminothietanes $\mathbf{3 9 0}$ from alkenimines and 4-methylbenzenesulfonyl isothiocyanate (389).

Phosphonium ylides, $\mathrm{Ph}_{3} \mathrm{P}^{+}-\mathrm{C}^{-}=\mathrm{C}=\mathrm{NR}$ (391) reacted with isothiocyanate in a $[2+2]$ cycloaddition to form the four-membered ring phosphonium ylides $\mathbf{3 9 2}$, which further reacted with aromatic aldehydes to afford the corresponding arylidene-2,4diiminothietanes 393 [103] (Scheme 82).

Thietan-2-ylideneacetates 397 were synthesized through aminecatalyzed formal $[2+2]$ cycloadditions. The DABCO-catalyzed tunable formal [4+2] and [2+2] cycloadditions of benzyl allenoate (395) and methyl 2-oxoalkanedithioates 394 generated the 5-(methylthio)-2-phenylethylidene-2,3-dihydro-

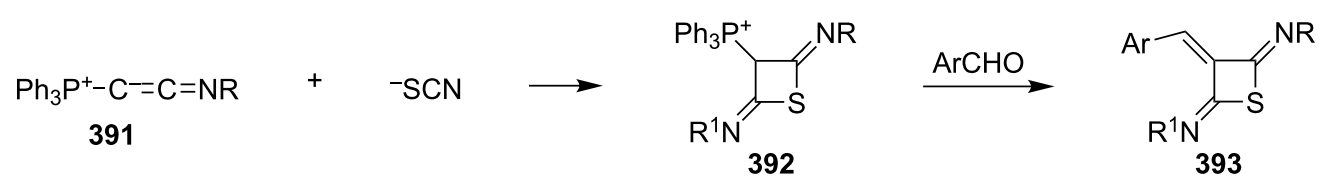

$\mathrm{R}=\mathrm{Me}, \mathrm{Ph} ; \mathrm{R}^{1}=\mathrm{Me}, \mathrm{Ph}, \mathrm{c}-\mathrm{Hex}, \mathrm{Bn}, 4-\mathrm{MeC}_{6} \mathrm{H}_{4}, 4-\mathrm{Me}_{2} \mathrm{NC}_{6} \mathrm{H}_{4}$;

$\mathrm{Ar}=\mathrm{Ph}, 4-\mathrm{MeOC}_{6} \mathrm{H}_{4}, 4-\mathrm{NO}_{2} \mathrm{C}_{6} \mathrm{H}_{4}, 2-\mathrm{Py}$ 


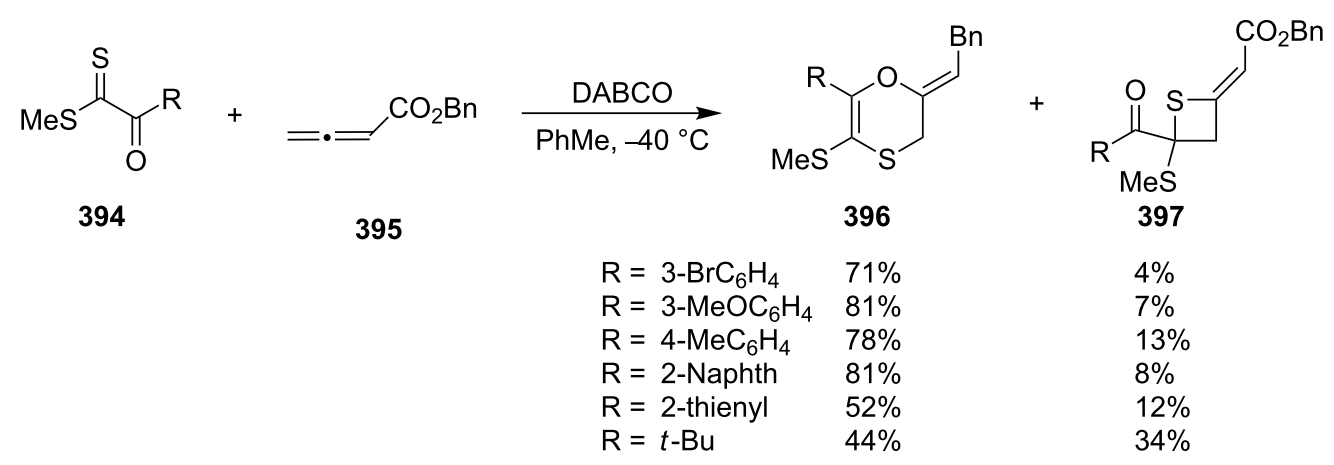

Scheme 83: Synthesis of thietane-2-ylideneacetates 397 through a DABCO-catalyzed formal [2 + 2] cycloaddition of benzyl allenoate (395) and dithioesters 394 .

1,4-oxathiines 396 with benzyl thietane-2-ylideneacetates 397 as byproducts [104] (Scheme 83).

\section{Synthesis via the ring expansions and contractions}

\subsection{Synthesis via ring expansion}

The ring expansions of thiiranes are alternative ways to prepare thietane derivatives. The transformations included the nucleophilic ring expansion of (1-haloalkyl)thiiranes with various nucleophiles, nucleophilic ring expansion of thiiranes with sulfur ylides, and the electrophilic ring expansion of thiiranes with carbenes generated from sulfur ylides under the catalysis of transition-metal catalysts.

4.1.1 Synthesis via nucleophilic ring expansion of 2-(1haloalkyl)thiiranes: A thiirane-thietane rearrangement took place upon the interaction of (1-haloaklyl)thiiranes 398 with hard and weak nucleophiles $\left(: \mathrm{Nu}^{-}\right)$in the presence of a base. It was an efficient method for the preparation of 3-substituted thietanes $\mathbf{4 0 0}$ from (1-haloalkyl)thiiranes $\mathbf{3 9 8}$ through an intramolecular nucleophilic substitution followed by an intermolecu- lar nucleophilic displacement with the in-situ generated 1-thiabicyclo[1.1.0]butan-1-iums 399 as key intermediates. Following this route, 3 -substituted thietanes $\mathbf{4 0 0}$ were prepared from reactions of 2-(1-chloroalkyl)thiiranes 398, especially chloromethylthiirane (epithiochlorohydrin, 398a), with hard and weak nucleophiles [105-109], including phenoxides [105], carboxylates and dicarboxylates [106,107], potassium cyanide, sodium azide, hydroxylamine, trifluoromethanesulfonamide, and pyridine [108]. However, the method could only applied to the synthesis of 3-substituted thietanes $\mathbf{4 0 0}$ from (1-chloroalkyl)thiiranes 398 (Scheme 84).

Nitrogen-containing aromatic heterocycles, such as 2-chloro5(6)-nitrobenzimidazole (401) and 3,5-dibromo-1,2,4-triazole (402), were used as nucleophiles in the reaction with chloromethylthiirane (398a) giving rise to 3-heteroarylthietanes $\mathbf{4 0 3}$ and 404, respectively [109,110] (Scheme 85).

The treatment of various $\mathrm{N}$-substituted sulfonamides $\mathbf{4 0 5}$ with chloromethylthiirane (398a) in the presence of $\mathrm{KOH}$ in water

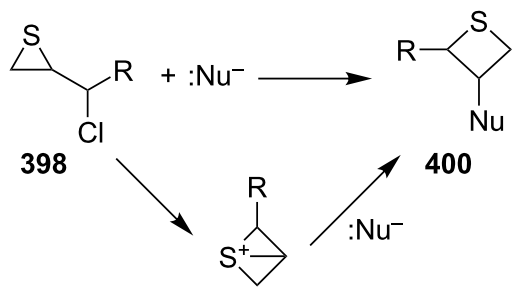

399

$: \mathrm{Nu}^{-}=\mathrm{ArO}^{-}, \mathrm{RCO}_{2}{ }^{-}, \mathrm{CN}^{-}, \mathrm{N}_{3}^{-}, \mathrm{HONH}_{2}, \mathrm{CF}_{3} \mathrm{SO}_{2} \mathrm{NH}_{2}, \mathrm{Py}$, etc. 
<smiles>O=[N+]([O-])c1ccc2[nH]c(Cl)nc2c1</smiles>

401<smiles>ClCC1CS1</smiles>

$398 a$<smiles>Brc1nnc(Br)[nH]1</smiles>

402

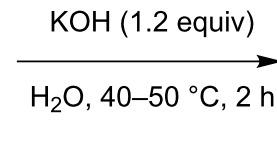

$\underset{\mathrm{H}_{2} \mathrm{O}, 40-50^{\circ} \mathrm{C}, 2 \mathrm{~h}}{\stackrel{\mathrm{KOH}(1.2 \text { equiv) }}{\longrightarrow}}$<smiles>O=[N+]([O-])c1ccc2c(c1)nc(Cl)n2C1CSC1</smiles><smiles>CC(C)(C)OC1CSC1n1c(Br)nnc1Br</smiles>

Scheme 85: Synthesis of $N$-(thietane-3-yl)azaheterocycles 403 and 404 through reaction of chloromethylthiirane (398a) with benzimidazole 401 and 1,2,4-triazole 402.

gave rise to the corresponding 3-sulfonamidothietanes 406 in low to moderate yields [111] (Scheme 86).

Also isatins 407 reacted with chloromethylthiirane (398a) to afford $N$-(thietane-3-yl)isatin derivatives $\mathbf{4 0 8}$ in moderate yields [112] (Scheme 87).

When weakly nucleophilic nitrophenols 409 were used as nucleophiles, the ring-expansion reaction of chloromethylthiirane (398a) yielded the corresponding 3-(nitrophenyloxy)thietanes 410 in only low to moderate yields under basic conditions [113] (Scheme 88).

Similarly, various $N$-arylcyanamides 411 reacted with chloromethylthiirane (398a) under basic conditions to give the

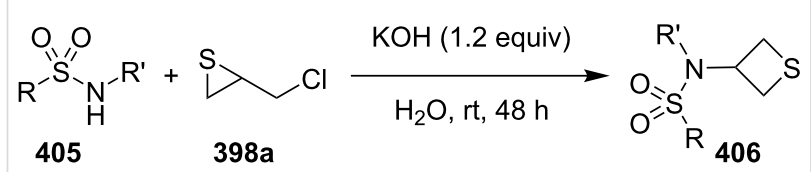

$\mathrm{R}=\mathrm{Ph}, \mathrm{R}^{\prime}=4-\mathrm{MeOC}_{6} \mathrm{H}_{4}, 62 \% ; \mathrm{R}^{\prime}=\mathrm{Bn}, 5 \% ; \mathrm{R}^{\prime}=\mathrm{H}, 25 \%$;

$\mathrm{R}^{\prime}=4-\mathrm{O}_{2} \mathrm{NC}_{6} \mathrm{H}_{4}, 30 \% ; \mathrm{R}=\mathrm{Me}, \mathrm{R}^{\prime}=4-\mathrm{MeOC}_{6} \mathrm{H}_{4}, 56 \%$;

$\mathrm{R}^{\prime}=$ naphth-1-yl, $25 \%$

Scheme 86: Synthesis of 3-sulfonamidothietanes $\mathbf{4 0 6}$ from sulfonamides and chloromethylthiirane (398a).

$$
\mathrm{ArOH}+\underset{398 \mathrm{a}}{\mathrm{S}} \mathrm{Cl} \underset{\mathrm{H}_{2} \mathrm{O}, \mathrm{rt}, 48 \mathrm{~h}}{\stackrel{\mathrm{KOH}(1.2 \text { equiv) }}{\longrightarrow}} \mathrm{ArO} \longrightarrow
$$

$\mathrm{Ar}=2-\mathrm{O}_{2} \mathrm{NC}_{6} \mathrm{H}_{4}, 35 \% ; \mathrm{Ar}=3-\mathrm{O}_{2} \mathrm{NC}_{6} \mathrm{H}_{4}, 33 \%$;

$\mathrm{Ar}=4-\mathrm{O}_{2} \mathrm{NC}_{6} \mathrm{H}_{4}, 39 \% ; \mathrm{Ar}=5-\mathrm{Me}-2-\mathrm{O}_{2} \mathrm{NC}_{6} \mathrm{H}_{3}, 45 \%$;

$\mathrm{Ar}=3-\mathrm{Me}-4-\mathrm{O}_{2} \mathrm{NC}_{6} \mathrm{H}_{3}, 19 \%$

Scheme 88: Synthesis of 3-(nitrophenyloxy)thietanes $\mathbf{4 1 0}$ from nitrophenols 409 and chloromethylthiirane (398a).

corresponding $N$-aryl- $N$-(thietane-3-yl)cyanamides 412 in moderate to good yields [113] (Scheme 89).

Pyrimidine-2,4(1H,3H)-diones 413 were derivatized with chloromethylthiirane (398a), giving rise to 1-(thietane-3-

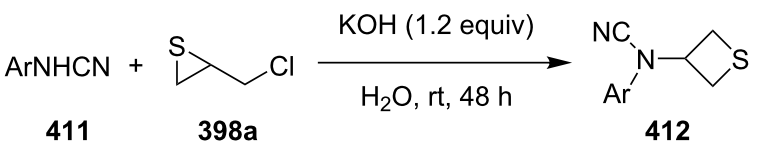

$\mathrm{Ar}=\mathrm{Ph}, 72 \% ; \mathrm{Ar}=2,6-\mathrm{Me}_{2} \mathrm{C}_{6} \mathrm{H}_{3}, 34 \% ; \mathrm{Ar}=4-\mathrm{MeC}_{6} \mathrm{H}_{4}, 59 \%$; $\mathrm{Ar}=$ naphth-1-yl, $38 \% ; \mathrm{Ar}=2-\mathrm{ClC}_{6} \mathrm{H}_{4}, 63 \% ; \mathrm{Ar}=4-\mathrm{ClC}_{6} \mathrm{H}_{4}, 76 \%$; $\mathrm{Ar}=4-\mathrm{BrC}_{6} \mathrm{H}_{4}, 69 \% ; \mathrm{Ar}=3-\mathrm{FC}_{6} \mathrm{H}_{4}, 74 \% ; \mathrm{Ar}=2-\mathrm{O}_{2} \mathrm{NC}_{6} \mathrm{H}_{4}, 44 \%$; $\mathrm{Ar}=3-\mathrm{O}_{2} \mathrm{NC}_{6} \mathrm{H}_{4}, 59 \% ; \mathrm{Ar}=4-\mathrm{O}_{2} \mathrm{NC}_{6} \mathrm{H}_{4}, 38 \%$

Scheme 89: Synthesis of $N$-aryl- $N$-(thietane-3-yl)cyanamides 412 from $\mathrm{N}$-arylcyanamides 411 and chloromethylthiirane (398a).<smiles>O=C1Nc2cc[R1]cc2C1=O</smiles>

$\mathrm{R}=\mathrm{H}, 24 \% ; \mathrm{R}=5-\mathrm{Br}, 22 \% ; \mathrm{R}=5-\mathrm{MeO}, 34 \% ; \mathrm{R}=5,6-\left(\mathrm{OCH}_{2} \mathrm{O}\right), 24 \%$

$\mathrm{KOH}(1.1$ equiv)
$\mathrm{H}_{2} \mathrm{O}, 25^{\circ} \mathrm{C}, 20 \mathrm{~h}$<smiles>O=C1C(=O)N(C2CSC2)c2cc[R17]cc21</smiles> 
<smiles>[R]c1c(C)n(C2CS([Z15])([Z16])C2)c(=O)[nH]c1=O</smiles>

Scheme 90: Synthesis of 1-(thietane-3-yl)pyrimidin-2,4(1H,3H)-diones 414 from chloromethylthiirane (398a) and pyrimidine-2,4(1H,3H)diones.

yl)pyrimidin-2,4(1H,3H)-dione derivatives $\mathbf{4 1 4}$ in low yields [114] (Scheme 90).

4.1.2 Synthesis via nucleophilic ring expansion of thiiranes: The nucleophilic ring expansion of thiiranes was used for the synthesis of thietanes. Isocyanoalkanes $\mathbf{4 1 5}$ can be considered as nucleophiles. However, after the nucleophilic addition, they could become electrophiles. Thus, they can be applied in the nucleophilic ring expansion of thiiranes 416, in which the generated thiolates $\mathbf{4 1 7}$ as nucleophiles undergo a further intramolecular addition to form iminothietanes 418. 2-Iminothiiranes 416 underwent a nucleophilic ring expansion with isocyanoalkanes $\mathbf{4 1 5}$ as nucleophiles to give rise to 2,4diiminothietanes 418 in 33 to 52\% yields [101] (Scheme 91).

3-Chloroallyl lithium (420) was also applied as a nucleophile to synthesize 2-vinylthietanes $\mathbf{4 2 1}$ in the electrophilic ring expansion of thiiranes $\mathbf{4 1 9}$. The corresponding thiiranes 419 reacted with 3-chloroallyl lithium (420), yielding vinylthietanes 421 in $10-73 \%$ yields. This was a general route towards the synthesis of 2-vinylthietanes $\mathbf{4 2 2}$. From a mechanistic point of view, 3-chloroallyl lithium (420) first coordinated with the thiiranes
419 followed by a nucleophilic ring opening and intramolecular substitution [115] (Scheme 92).

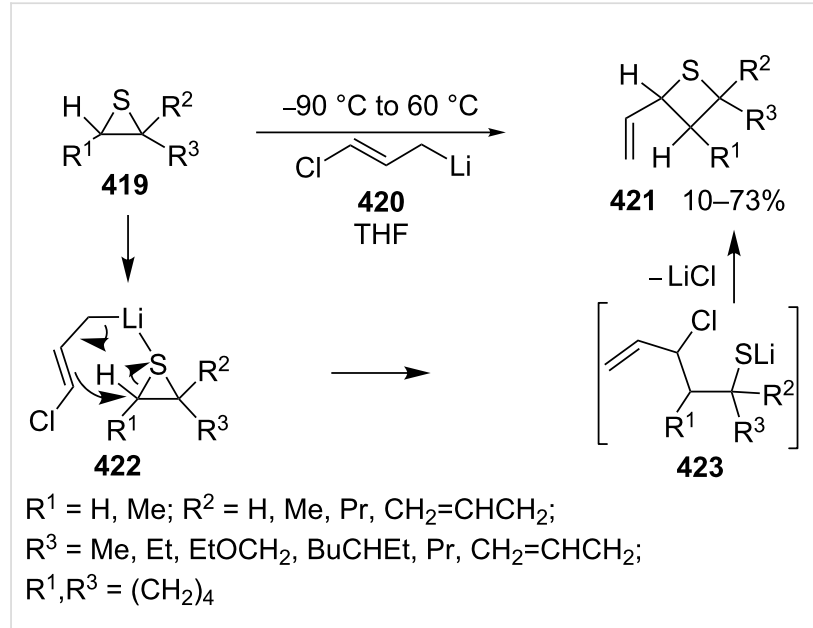

Scheme 92: Synthesis of 2-vinylthietanes 421 from thiiranes 419 and 3-chloroallyl lithium (420).

One carbon-containing nucleophiles with a good leaving group should be another reagent for the nucleophilic ring expansion of thiiranes. In the ring expansion, the nucleophiles first nucleophilically open the thiiranes and the generated thiolates then serve as nucleophiles to undergo a further intramolecular displacement to give the thietanes. Dimethyloxosulfonium methylide was demonstrated to be a suitable reagent for the nucleophilic ring expansion of three-membered heterocycles. It was successfully applied in the preparation of oxetanes and azetidines via the ring expansions of oxiranes [116-118] and aziridines $[119,120]$. However, both thiiranes and thietanes were less stable than the corresponding oxa and aza-analogs.

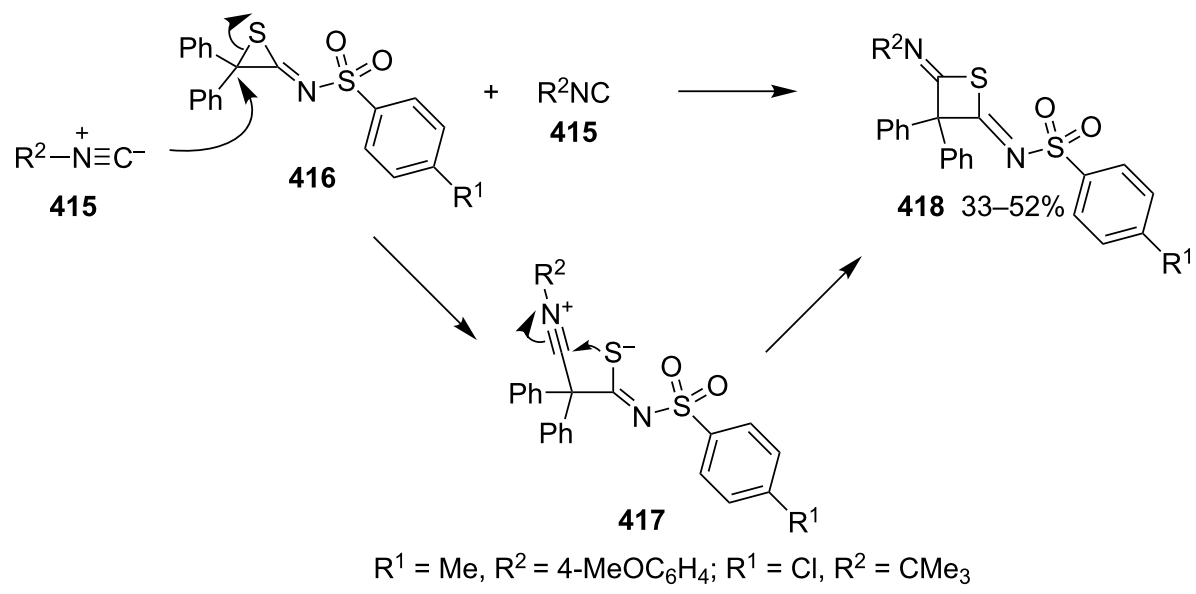

Scheme 91: Synthesis of 2,4-diiminothietanes $\mathbf{4 1 8}$ from 2-iminothiiranes 416 and isocyanoalkanes 415. 


\begin{tabular}{|c|c|c|c|c|c|c|c|}
\hline & $\begin{array}{r}\mathrm{R}^{1} f_{\mathrm{T}}^{\mathrm{S}} \\
\mathrm{R}^{2} \\
41\end{array}$ & $\begin{array}{c}+\mathrm{Me}_{3} \mathrm{~S}^{+}=\mathrm{Ol}^{-} \\
424\end{array}$ & $\begin{array}{c}\mathrm{NaH} \\
\text { THF, DMSO } \\
40^{\circ} \mathrm{C}, 3.5-7.5 \mathrm{~h}\end{array}$ & & 4 & & \\
\hline $\begin{array}{l}a \\
c \\
e \\
g \\
i \\
k \\
m\end{array}$ & $\begin{array}{l}\mathrm{R}^{1} \\
\mathrm{H} \\
\mathrm{H} \\
\mathrm{H} \\
\mathrm{H} \\
\mathrm{H} \\
\mathrm{Me} \\
\mathrm{Me}\end{array}$ & $\begin{array}{l}\mathrm{R}^{2} \\
\mathrm{PhOCH}_{2} \\
3-\mathrm{MeC}_{6} \mathrm{H}_{4} \mathrm{OCH}_{2} \\
4-\mathrm{ClC}_{6} \mathrm{H}_{4} \mathrm{OCH}_{2} \\
\mathrm{PhCH}_{2} \mathrm{OCH}_{2} \\
\mathrm{PhCH}_{2} \\
4-\mathrm{MeC}_{6} \mathrm{H}_{4} \mathrm{OCH}_{2} \\
4-\mathrm{O}_{2} \mathrm{NC}_{6} \mathrm{H}_{4} \mathrm{OCH}_{2}\end{array}$ & $\begin{array}{l}\text { yield }(\%) \\
62 \\
63 \\
38 \\
75 \\
63 \\
91 \\
17\end{array}$ & $\begin{array}{l}b \\
d \\
f \\
h \\
j \\
\text { l } \\
\text { n }\end{array}$ & $\begin{array}{l}\mathrm{R}^{1} \\
\mathrm{H} \\
\mathrm{H} \\
\mathrm{H} \\
\mathrm{H} \\
\mathrm{H} \\
\mathrm{Me} \\
\mathrm{Me}\end{array}$ & $\begin{array}{l}\mathrm{R}^{2} \\
\text { 4- } \mathrm{MeC}_{6} \mathrm{H}_{4} \mathrm{OCH}_{2} \\
\text { 4- } \mathrm{MeOC}_{6} \mathrm{H}_{4} \mathrm{OCH}_{2} \\
\mathrm{PhCH}_{2} \mathrm{CH}_{2} \mathrm{OCH}_{2} \\
\text { 4- } \mathrm{ClC}_{6} \mathrm{H}_{4} \mathrm{SCH}_{2} \\
\text { n- } \mathrm{Hex} \\
3-\mathrm{MeC}_{6} \mathrm{H}_{4} \mathrm{OCH}_{2} \\
\mathrm{PhCH}_{2} \mathrm{CH}_{2}\end{array}$ & $\begin{array}{l}\text { yield }(\%) \\
75 \\
59 \\
74 \\
18 \\
72 \\
92 \\
52\end{array}$ \\
\hline
\end{tabular}

Scheme 93: Synthesis of thietanes from thiiranes $\mathbf{4 1 9}$ and trimethyloxosulfonium iodide $\mathbf{4 2 4}$.

Thiiranes $\mathbf{4 1 9}$ were readily prepared from the corresponding oxiranes [121-123]. The ring expansion reactions of trimethyloxosulfonium iodide (424) and various thiiranes $\mathbf{4 1 9}$ delivered the corresponding thietanes $\mathbf{4 2 5}$ in the presence of $\mathrm{NaH}$ in a mixture of THF and DMSO at $40{ }^{\circ} \mathrm{C}$ [22] (Scheme 93).

The reaction mechanism was proposed as following. The treatment of trimethyloxosulfonium iodide (424) with sodium hydride generated dimethyloxosulfonium methylide (426) as the one carbon-containing nucleophile with DMSO (379) as a good leaving group. The nucleophilic attack of $\mathbf{4 2 6}$ on thiiranes 419 from the least substituted ring carbon atom generated the zwitterionic intermediates $\mathbf{4 2 7}$, with a good regioselectivity following the general regioselectivity rule in nucleophilic ring opening reactions of aliphatic three-membered heterocycles [124-132]. The generated thiolate in the zwitterionic intermediates $\mathbf{4 2 7}$ then further underwent an intramolecular nucleophilic substitution to yield the desired thietanes $\mathbf{4 2 5}$ by loss of a molecule of DMSO [22] (Scheme 94).

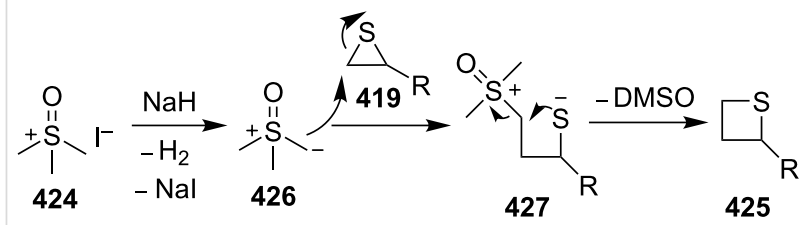

Scheme 94: Mechanism for synthesis of thietanes 425 from thiiranes 419 and trimethyloxosulfonium iodide 424

4.1.3 Synthesis via electrophilic ring expansion of thiiranes: To realize the synthesis of functionalized thietanes, electrondeficient sulfur ylides were investigated in the ring expansion of thiiranes. However, the reactions failed due to the poor nucleophilicity of the electron-deficient sulfur ylides. However, in the presence of rhodium catalysts, the electron-deficient sulfur ylides were converted into electrophilic metallocarbenes, which favorably reacted with the electron-rich sulfur atom in the thiiranes and further underwent an electrophilic ring expansion to afford thietanes.

Dimethylsulfonium acylmethylides $\mathbf{4 2 8}$ reacted with 2-alkylthiiranes 419 to produce 2-acyl-4-alkylthietanes 429 and 430 in moderate to good yields. However, they gave rise to mixtures of 2-acyl-4-arylthietanes 432 and 2-acyl-3-arylthietanes 433 in ratios between 1:4 to $1: 10$ in the reactions with 2-arylthiiranes 431 [23] (Scheme 95).

The reaction mechanism was proposed as following. The nucleophilic acyl sulfur ylides $\mathbf{4 2 8}$ first reacted with the rhodium catalyst to generate the electrophilic metallocarbenes $\mathbf{4 3 4}$ by loss of dimethyl sulfide, realizing an umplung. Thiiranes 419 then reacted nucleophilically with the electrophilic metallocarbenes 434 to yield thiiranium intermediates 435 , which were nucleophilically attacked by the released dimethyl sulfide, producing the ring-opened zwitterionic intermediates 436. The intermediates $\mathbf{4 3 6}$ further underwent an intramolecular substitution, affording the desired thietanes $\mathbf{4 2 9}$ by loss of dimethyl sulfide and the rhodium catalyst. In this transformation dimethyl sulfide worked as a transient nucleophile and leaving group in the reaction system [23] (Scheme 96).

4.1.4 Synthesis via thermal expansion reaction of spirooxazoline-thiiranes: Acyl isothiocyanates (RCONCS, 437) reacted with two equivalents of diphenyldiazomethane (438) at room temperature to give 4,5-dihydro-1,3-oxazole-4-spiro-2'-thiiranes 439, which isomerized thermally to 3-iminothietanes 440 [133135] (Scheme 97).

\subsection{Synthesis via ring contraction reactions}

4.2.1 Synthesis through the ring contraction of thiolanes: Compared to the ring expansion reactions of thiiranes to thietanes, the ring contraction of thiolanes to thietanes was applied in only limited cases. As an example, 3-chloro-2- 


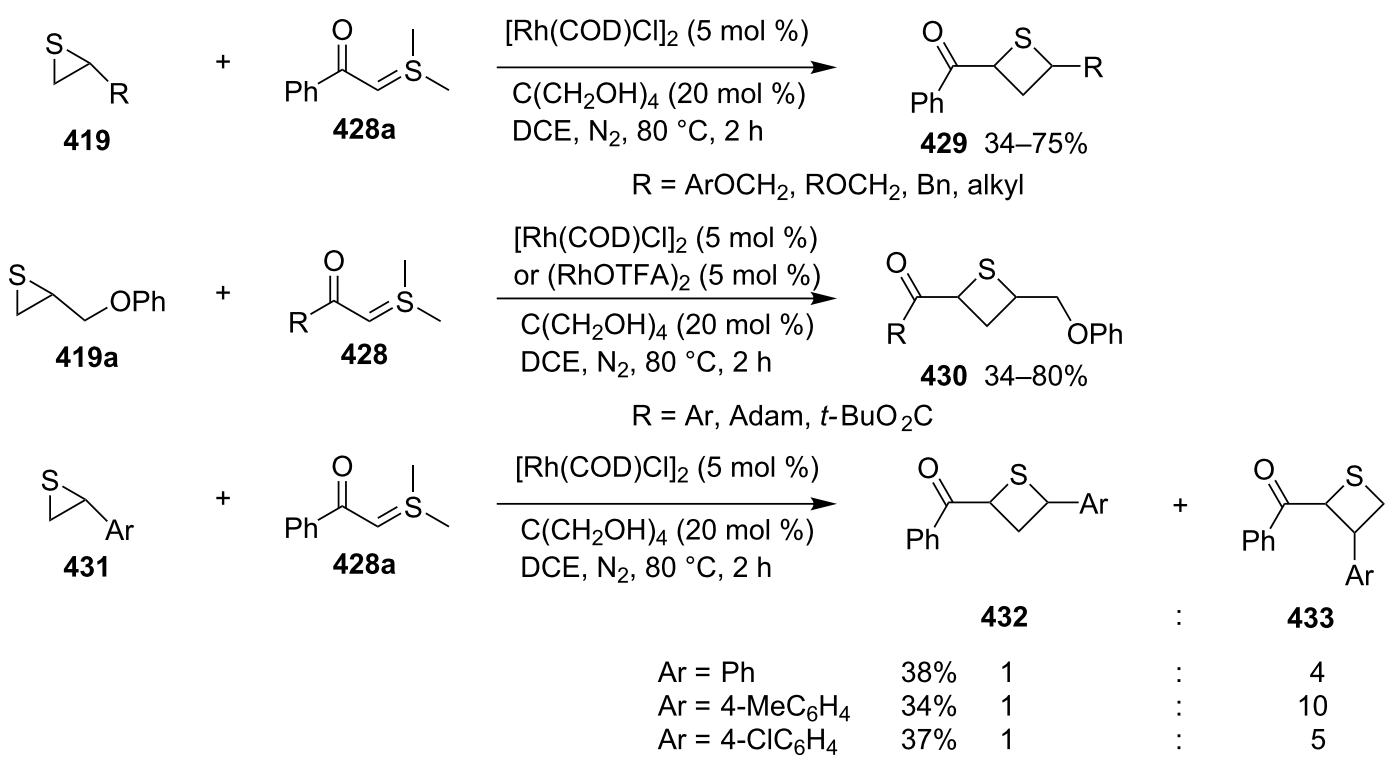

Scheme 95: Synthesis of functionalized thietanes from thiiranes and dimethylsulfonium acylmethylides.

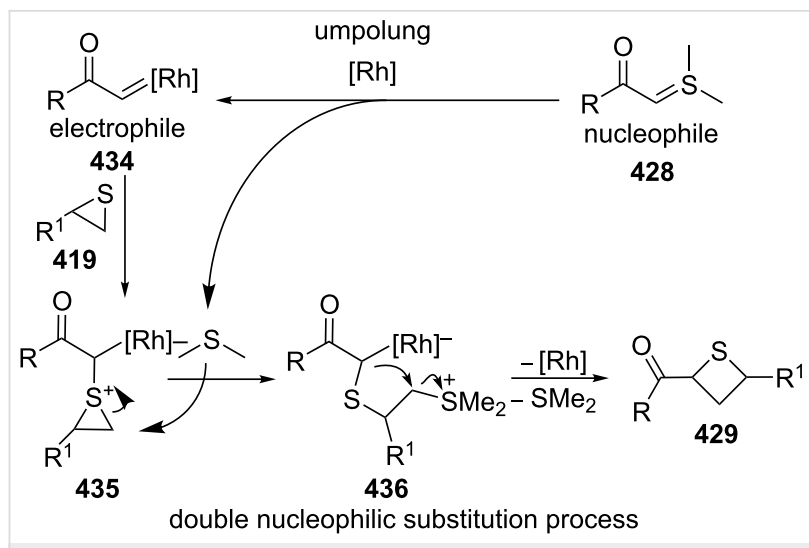

Scheme 96: Mechanism for the rhodium-catalyzed synthesis of functionalized thietanes $\mathbf{4 2 9}$ from thiiranes $\mathbf{4 1 9}$ and dimethylsulfonium acylmethylides.

methylthiolane (441) underwent a ring contraction to give 2-(1hydroxyethyl)thietane (442) and 2-(1-acetoxyethyl)thietane (443), respectively, when it was treated with water in ethanol or sodium acetate in acetic acid. The ring contraction proceeded through a thiiranium intermediate $\mathbf{4 4 4}$, which was isolated as chloride salt from the reaction system, indicating that an intramolecular nucleophilic substitution occurred, followed by the nucleophilic ring opening of the thiiranium ring [32] (Scheme 98).

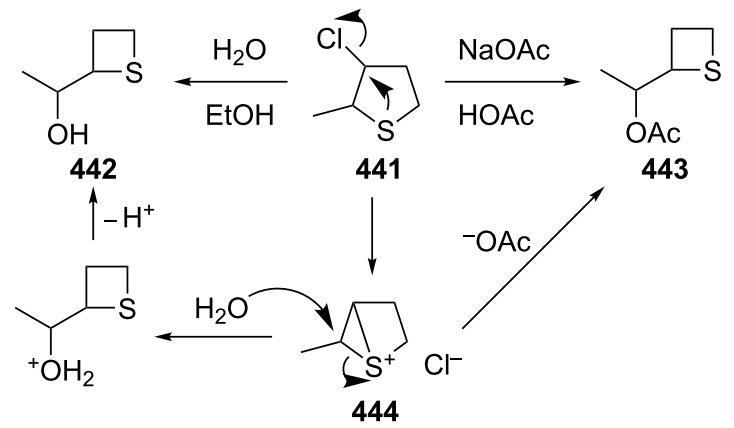

Scheme 98: Synthesis of thietanes 443 from 3-chloro-2-methylthiolane (441) through ring contraction.

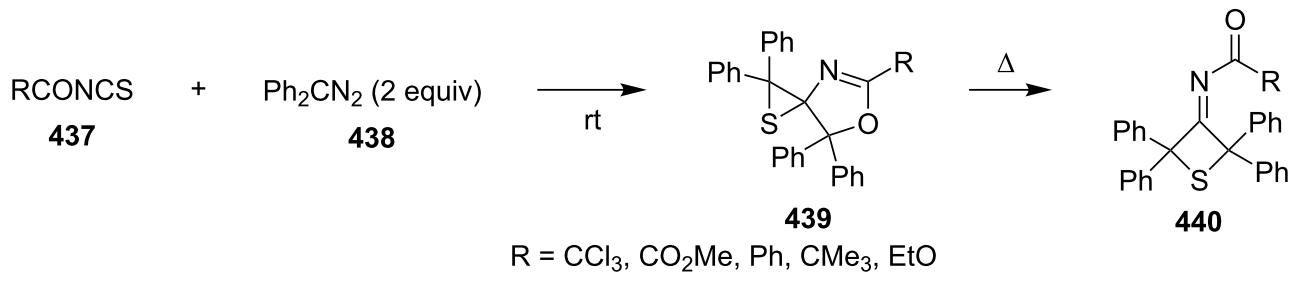

Scheme 97: Synthesis of 3-iminothietanes $\mathbf{4 4 0}$ through thermal isomerization from 4,5-dihydro-1,3-oxazole-4-spiro-2'-thiiranes $\mathbf{4 3 9}$. 
The ring contraction of thiolanes to thietanes was also utilized in the synthesis of thietanoses. The ring contraction was realized by the DAST-mediated conversion of thiofuranose $\mathbf{4 4 5}$ derived from D-xylose into the protected fluorinated thietanose 447 through a thiiranium intermediate $446[135,136]$ (Scheme 99).

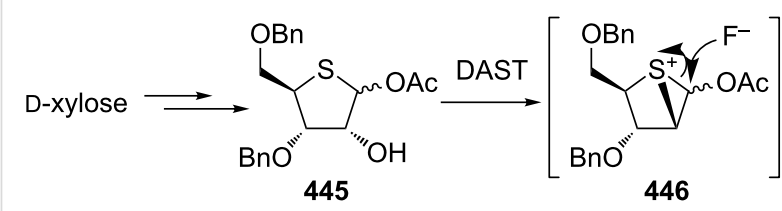<smiles>[B]OC[C@@H]1S[C@H]([C@@H](F)OC(C)=O)[C@@H]1OBr</smiles>

Scheme 99: Synthesis of an optically active thietanose 447 from D-xylose involving a ring contraction.

The similar DAST-mediated ring contraction of thiopentose $\mathbf{4 4 8}$ to thiotetraose 447 was also reported [20] (Scheme 100).

The DAST-mediated ring contraction of a thiopentose to a thiotetraose was realized in the direct conversion of the thiopentose in thionucleoside $\mathbf{4 5 0}$ to its thiotetraose analogue 451 [20] (Scheme 101).

The reaction of 3,3,5,5-tetramethylthiolane-2,4-dithione (452) with benzyne (453) gave a spirothietane-benzodithiole 456 in a good yield. In the transformation, the thiocarbonyl group of the dithioester in thiolane-2,4-dithione $\mathbf{4 5 2}$ initially attacked benzyne (453) to afford a betaine $\mathbf{4 5 4}$, which finally rearranged to give the spirothietane-benzodithiole 456 [137] (Scheme 102).

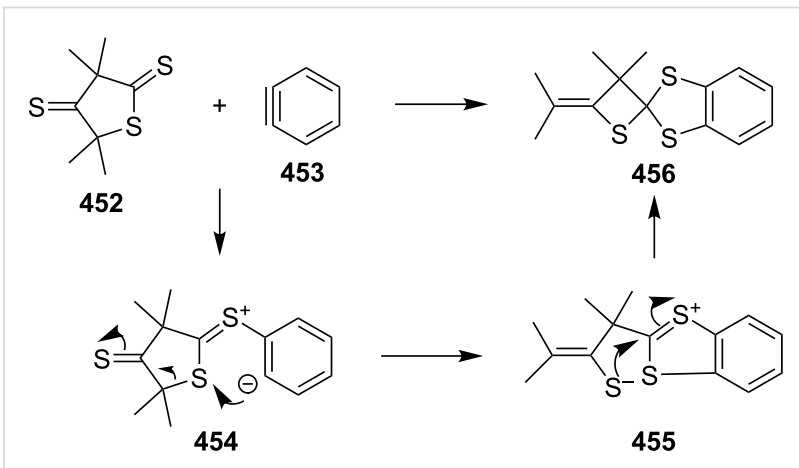

Scheme 102: Synthesis of spirothietane 456 from 3,3,5,5-tetramethylthiolane-2,4-dithione (452) and benzyne (453).

4.2.2 Synthesis via the ring contraction of $2 \mathrm{H}, 6 \mathrm{H}$-thiin-3ones: $2 H, 6 H$-Thiin-3-ones 459 were first generated from 3-bromo-3-methylbutan-2-one (457) and mercapto esters $\left(\mathrm{R}_{2} \mathrm{C}(\mathrm{SH}) \mathrm{CO}_{2} \mathrm{Et}, \mathbf{4 5 8}\right)$ in four steps. Upon UV irradiation $\left(350 \mathrm{~nm}\right.$ ) in either $\mathrm{MeCN}$, benzene or $\mathrm{Me}_{2} \mathrm{CHOH}$ solution, these newly synthesized heterocycles $\mathbf{4 5 9}$ isomerized efficiently to 2-(1-alkenyl)thietan-3-ones $\mathbf{4 6 1}$. The rearrangement was assumed to proceed via an excited-singlet state and sulfuranyl-alkyl biradicals 460 formed by bonding of $\mathrm{C}(\alpha)$ of the enone $\mathrm{C}=\mathrm{C}$ bond on sulfur as possible intermediates [21] (Scheme 103).

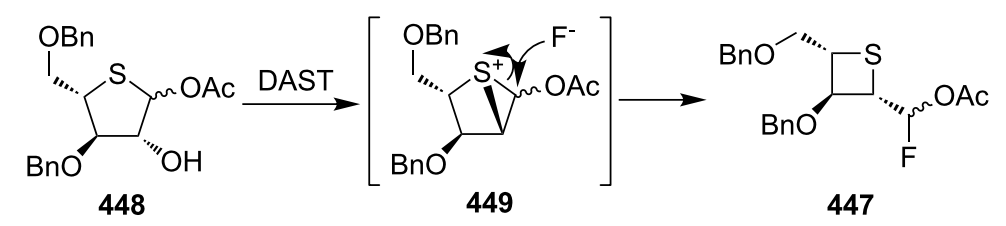

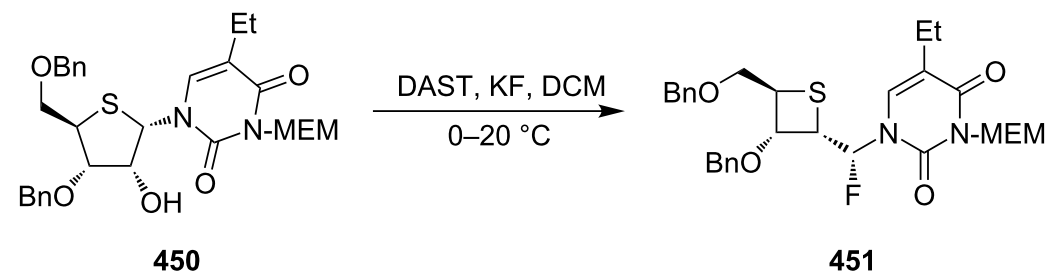


<smiles>CC(=O)C(C)(C)Br</smiles>

457<smiles>[R]C([R])(S)C(=O)OCC</smiles>

458<smiles>C=C1C(C)[C@H]1C</smiles><smiles>[R]C1([R])SC(C)(C)C=CC1=O</smiles><smiles>C1=CCCC1</smiles>

459<smiles>[R]C([R])(S)C(=O)C(=CC(C)C)CC(C)C</smiles>

$460 a$<smiles>[R]C1([R])SC(C=C(C)C)C1=O</smiles>

461

$\mathrm{R}=\mathrm{H}, \mathrm{Me}$<smiles>[R]C1([R])SCC(=C(C)C)C1=O</smiles>

$460 b$

Scheme 103: Synthesis of thietanes 461 via photoisomerization of $2 H, 6 H$-thiin-3-ones 459.

\section{Phosphorothioate-mediated synthesis}

\subsection{Synthesis from enones}

In 1981, Ueno and co-workers were the first who utilized $O, O$ diethyl hydrogen phosphorodithioate (462) as a nucleophile in the Michael addition of chalcones $\mathbf{4 6 2}$, affording $O, O$-diethyl $S$-(1,3-diaryl-3-oxopropyl)phosphorodithioates $\mathbf{4 6 4}$, which were further reduced with sodium borohydride and treated with sodium hydride to give rise to 2,4-diarylthietanes 465 [138] (Scheme 104).

In this reaction, the $O, O$-diethyl $S$-(1,3-diaryl-3oxopropyl)phosphorodithioates 464 were converted to the corresponding alkoxides 467 after the reduction with sodium boro- hydride and the treatment with sodium hydride. The alkoxides 467 underwent an intramolecular nucleophilic addition to the phosphorus atom followed by an elimination and an intramolecular substitution to give rise to 2,4-diarylthietanes 465 . In this strategy, $O, O$-diethyl hydrogen phosphorodithioate $\mathbf{( 4 6 3 )}$ first worked as a nucleophile to introduce a sulfur atom in the substrates followed by its conversion to $O, O, O$-trialkylphosphorothioate $\mathbf{4 6 9}$ as a leaving group in the final nucleophilic substitution [138] (Scheme 105).

In 2002, when Yadav worked independently, he further developed Ueno's synthetic strategy. He and his co-worker treated $O, O$-diethyl $S$-(1,3-diaryl-3-oxopropyl)phosphorodithioates 464

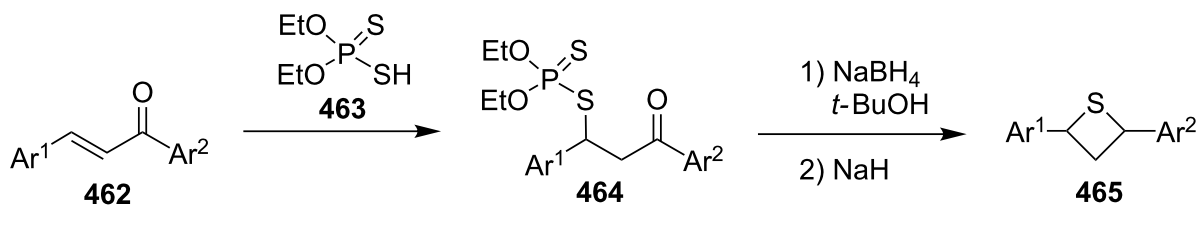

$78-98 \%$

$78-94 \%$

$\mathrm{Ar}^{1}, \mathrm{Ar}^{2}=\mathrm{Ph}, 4-\mathrm{ClC}_{6} \mathrm{H}_{4}, 4-\mathrm{MeOC}_{6} \mathrm{H}_{4}$

Scheme 104: Phosphorodithioate-mediated synthesis of 1,4-diarylthietanes 465.<smiles>CCOP(=S)(S)OP(=S)(OCC)SC(C)CC(=O)CC([Al])SP(=S)(OCC)OCC</smiles>

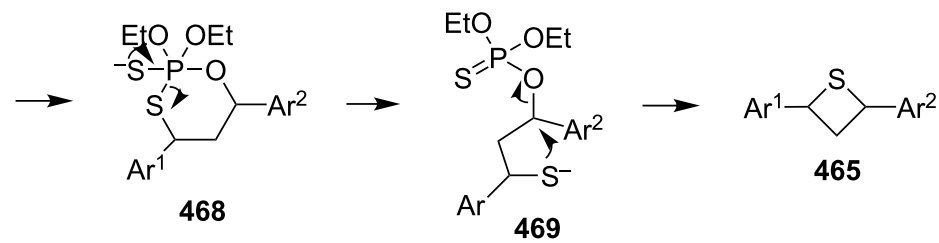

Scheme 105: Mechanism of the phosphorodithioate-mediated synthesis of 1,4-diarylthietanes 465. 


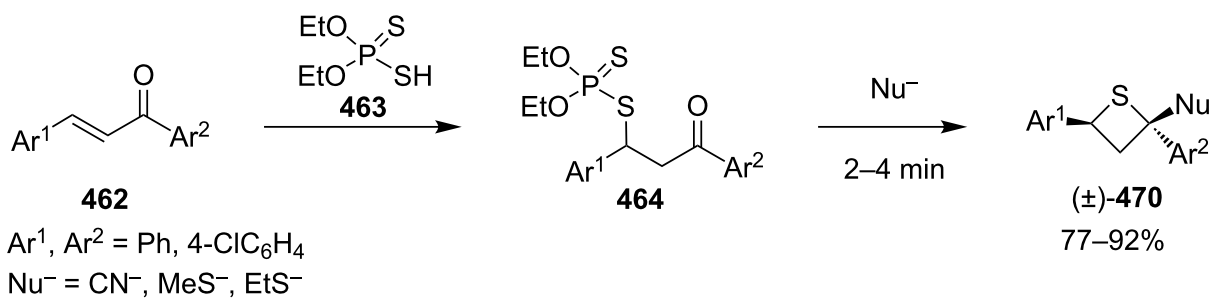

Scheme 106: Phosphorodithioate-mediated synthesis of trisubstituted thietanes $( \pm)-\mathbf{4 7 0}$.

with nucleophiles, such as cyanide, methanethiolate, and ethanethiolate, in the solid state under microwave irradiation affording the 2-functionalized 2,4-diarylthietanes 470 [139] (Scheme 106).

In this reaction, the nucleophiles attacked the carbonyl group of $O, O$-diethyl $S$-(1,3-diaryl-3-oxopropyl)phosphorodithioates 464 to generate the corresponding alkoxides $\mathbf{4 7 1}$. Compounds $\mathbf{4 7 1}$ then underwent an intramolecular nucleophilic addition to phosphorus followed by an elimination and an intramolecular substitution to give rise to 2-functionalized 2,4-diarylthietanes $\mathbf{4 7 0}$ [139] (Scheme 107).
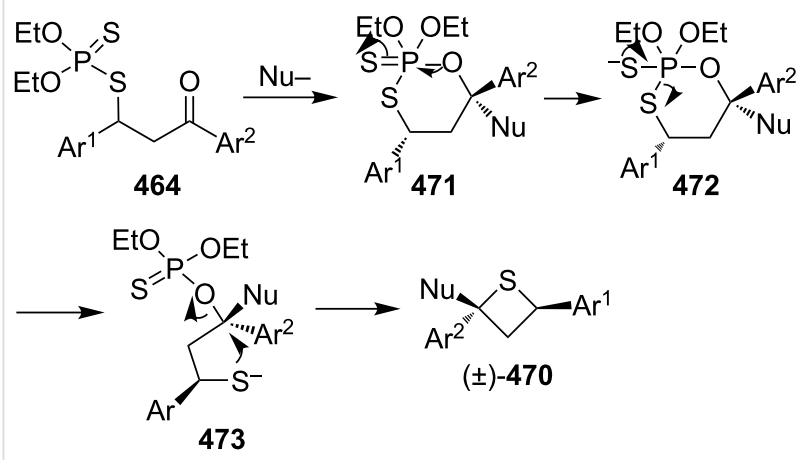

Scheme 107: Mechanism on the phosphorodithioate-mediated synthesis of trisubstituted thietanes.
In 2011, Myrboth and co-workers mentioned a similar transformation. The reaction of $O, O$-diethyl hydrogen phosphorodithioate (463) and $\alpha, \beta$-alkenones 474 was applied for the synthesis of 2,4-disubstituted thietanes $\mathbf{4 7 5}$ under microwave conditions. In this reaction, the nucleophile-induced cyclization of the Michael adducts in the presence of $O, O$-diethyl hydrogen phosphorodithioate (463) was realized in an alumina bath [140] (Scheme 108).

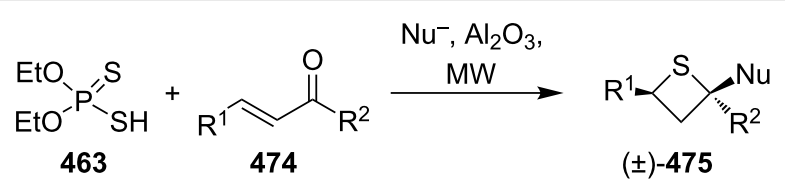

Scheme 108: Phosphorodithioate-mediated synthesis of thietanes ( \pm )475 .

\subsection{Synthesis from electron-deficient olefins}

Yadav and co-worker first realized the synthesis of functionalized thietanes 478 from $O, O$-diethyl hydrogen phosphorodithioate (463), aromatic aldehydes $\mathbf{4 7 6}$, and electron-deficient olefins (acrylonitrile (187b) and methyl acrylate (187c)). They first conducted a Baylis-Hillman reaction to prepare the Baylis-Hillman adducts 477 of aromatic aldehydes 476 with acrylonitrile (187b) and methyl acrylate $(\mathbf{1 8 7 c})$, and then cyclized the adducts 477 with $O, O$-diethyl hydrogen phosphorodithioate (463) in the presence of two equivalents of sodium hydride to afford the functionalized thietanes 478 [141] (Scheme 109).

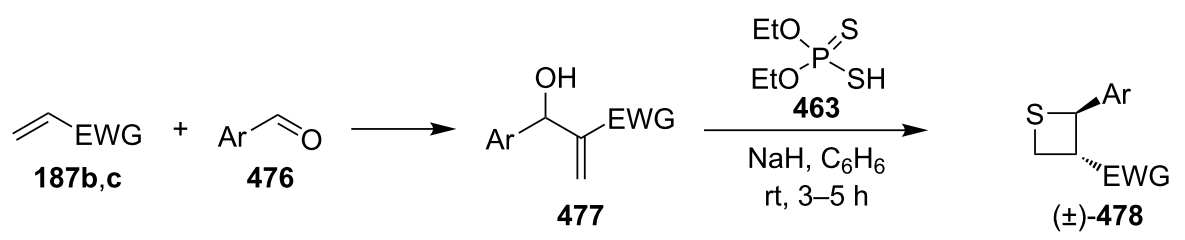

overall yield: $51-57 \%$ 
To make the strategy more efficient, the same group developed a one-pot protocol. The one-pot three-component coupling reaction of $O, O$-diethyl hydrogen phosphorodithioate $(\mathbf{4 6 3})$, aromatic aldehydes 476, and electron-deficient olefins $187 \mathrm{~b}, \mathbf{c}$ proofed as efficient method for the highly diastereoselective synthesis of functionalized thietanes $\mathbf{4 7 8}$ in high yields [141] (Scheme 110).

Mechanistically, the reaction started with the Michael addition of phosphorodithioate (479) and acrylonitrile/acrylate $(\mathbf{1 8 7 b} /$ $\mathbf{1 8 7 c )}$ to generate the resonance-stabilized carbanions 480 . The latter attacked aldehydes 476 to give the alkoxide anions 481 that underwent an intramolecular addition and elimination to generate thiolates $\mathbf{4 8 3}$. The thiolates then afforded the desired thietane products $\mathbf{4 7 8}$ after intramolecular substitution [141] (Scheme 111).

In 2012, Yadav and co-worker reported the synthesis of 3-nitrothietanes 486 from the Baylis-Hillman adducts 485 of nitroolefins and $O, O$-diethyl hydrogen phosphorodithioate (463). The reaction of $O, O$-diethyl hydrogen phosphorodithioate (463) and 3-aryl-2-nitropropenols $\mathbf{4 8 5}$ gave rise to trans-2-aryl-3-nitrothietanes $\mathbf{4 8 6}$ in the presence of sodium hydride [142] (Scheme 112).

The Baylis-Hillman alcohols $\mathbf{4 8 5}$ could also be oxidized to 3-aryl-2-nitropropenals $\mathbf{4 8 7}$ with IBX as an oxidant. They were then converted to 2,3,4-trisubstituted thietanes $\mathbf{4 8 8}$ after the

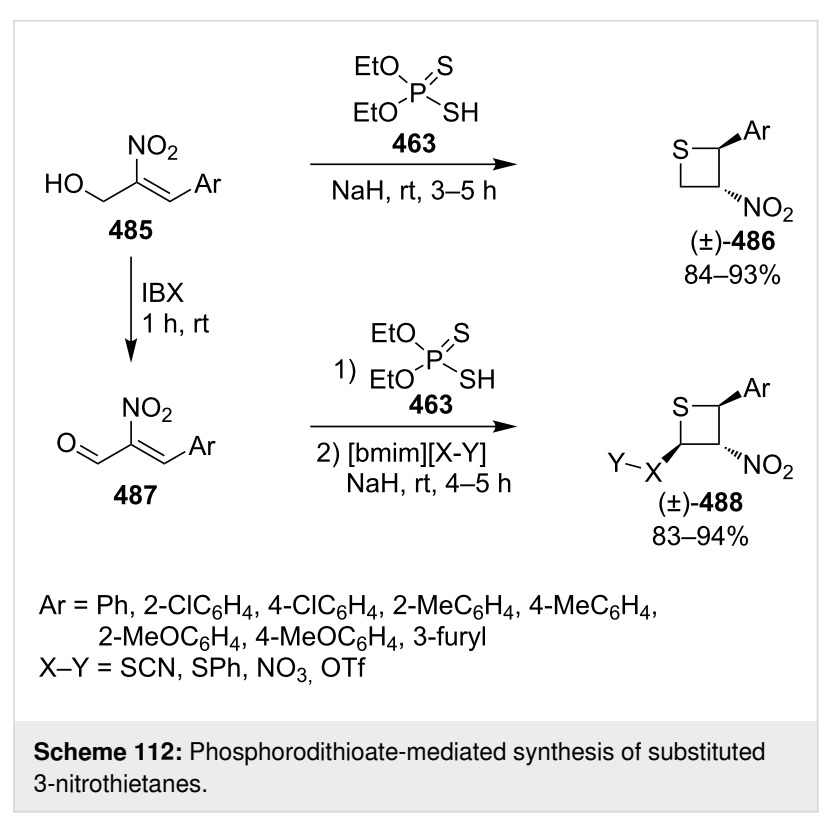

treatment with $O, O$-diethyl hydrogen phosphorodithioate $\mathbf{( 4 6 3 )}$ followed by [bmim][X-Y] in the presence of sodium hydride [142] (Scheme 112).

For the formation mechanism, $O, O$-diethyl phosphorodithioate (479) nucleophilically attacked the 3-aryl-2-nitropropenals 485 to generate alkoxides $\mathbf{4 8 9}$, which underwent an intramolecular addition and elimination followed by an intramolecular substi-

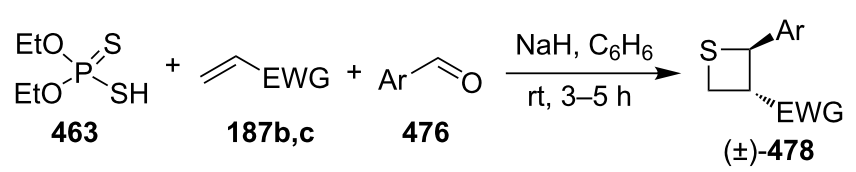

$\mathrm{EWG}=\mathrm{CN}, \mathrm{CO}_{2} \mathrm{Me}$

yield: $85-95 \%$

$\mathrm{Ar}=\mathrm{Ph}, 2-\mathrm{ClC}_{6} \mathrm{H}_{4}, 4-\mathrm{ClC}_{6} \mathrm{H}_{4}, 3-\mathrm{O}_{2} \mathrm{NC}_{6} \mathrm{H}_{4}$, trans: cis $93: 7$ to $96: 4$ $4-\mathrm{O}_{2} \mathrm{NC}_{6} \mathrm{H}_{4}, 4-\mathrm{MeOC}_{6} \mathrm{H}_{4}$

Scheme 110: Phosphorodithioate-mediated synthesis of 1,2-disubstituted thietanes via a one-pot three-component coupling reaction.

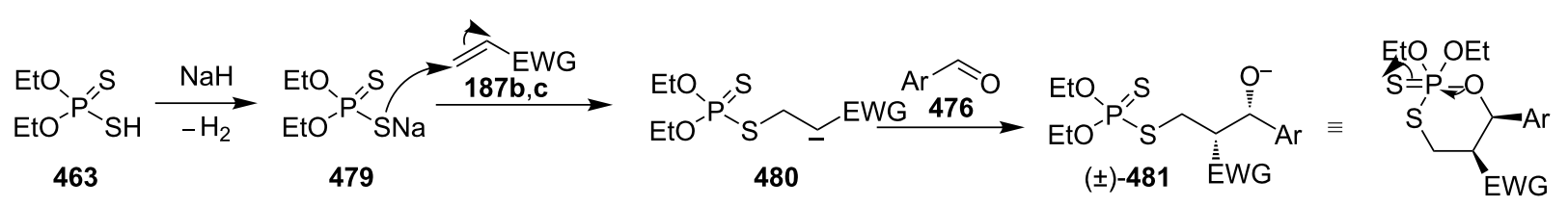

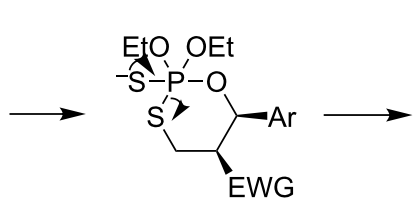

$( \pm)-482$

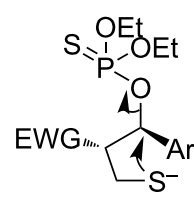

$( \pm)-483$ 


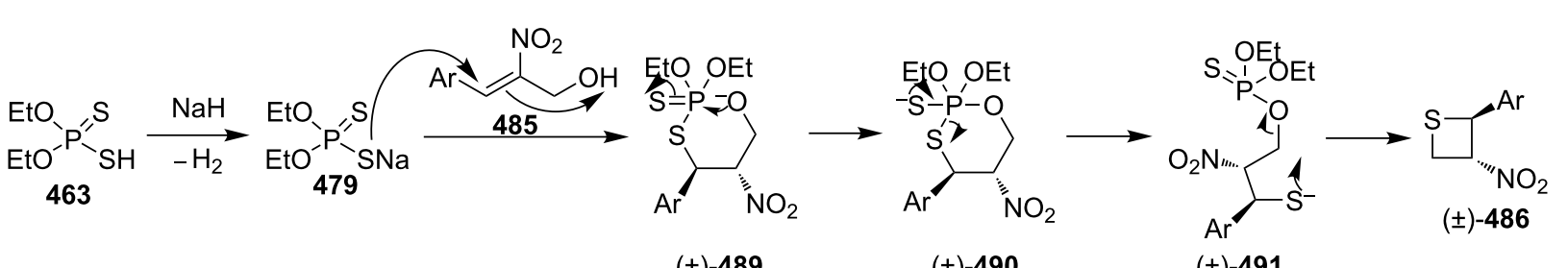

$( \pm)-489$

$( \pm)-490$

$( \pm)-491$

Scheme 113: Mechanism on the phosphorodithioate-mediated synthesis of 1,2-disubstituted thietanes $( \pm)$-486.

tution to afford trans-2-aryl-3-nitrothietanes $\mathbf{4 8 6}$ as the product [142] (Scheme 113).

$\mathrm{Wu}$ and Robertson realized the first asymmetric synthesis of (S)-2-phenylthietane (497) through a similar phosphorothioatemediated strategy. They first prepared $O, O$-diethyl $S$-(3-oxo-3phenylpropyl) phosphorothioate (494) from 3-iodo-1-phenylpropan-1-one (492) and sodium $O, O$-diethyl phosphorothioate (493). After an asymmetric borane reduction and the treatment with sodium hydride, $(S)$-2-phenylthietane (497) was obtained in $74 \%$ yield with $87 \%$ ee via the similar cyclization step [143] (Scheme 114).

In 2016, Soós and co-workers developed a bifunctional thiourea-catalyzed stereoablative retro-sulfa-Michael reaction of $S$-(1,3-diaryl-3-oxopropyl) $O, O$-diethyl phosphorothioates $\mathbf{4 9 8}$ under biphasic conditions, that afforded enantiomerically enriched $S$-(1,3-diaryl-3-oxopropyl) $O, O$-diethyl phosphorothioates 499. Both enantiomeric products $(R)$ - and $(S)-499$ were obtained in up to $40 \%$ yield with up to $90 \%$ ee in the presence of different enantiomeric catalysts, cat $\mathbf{1}$ and cat $\mathbf{2}$. After the asymmetric borane reduction under the catalysis of one of a pair of enantiomeric catalysts (cat $\mathbf{3}$ and cat ent-3) and the treatment with sodium hydride, all of four enantiomerically enriched 2,4diarylthietanes $\mathbf{5 0 1}$ were obtained with up to $99 \%$ ee [144] (Scheme 115).

\section{Synthesis via cyclizations}

\subsection{Synthesis via intramolecular thioesterification}

2-Amino-3-mercapto-3-methylbutanoic acid (502), penicillamine, was converted into the corresponding thietan-2-one de- rivative $\mathbf{5 0 3}$ with acetic anhydride as a coupling reagent in pyridine accompanied by $N$-acetylation [145] (Scheme 116).

Similarly, Pattenden and Shuker cyclized 3-mercapto-3methylbutanoic acid into 4,4-dimethylthietan-2-one for the synthesis of antitumor antibiotic Leinamycin [146,147]. Leinamycin (LNM) is a new antitumor antibiotic produced by Streptomyces atroolivaceus S-140. For its preparation, its important fragment was first synthesized from butane-1,4-diol (504) as starting material. 3-Mercapto carboxylic acid $\mathbf{5 0 5}$ as a key intermediate was cyclized with isobutyl chloroformate as a coupling reagent, affording the thietan-2-one derivative $\mathbf{5 0 6}$ [147,148] (Scheme 117).

In 2013, Gates's group prepared a small analogue of the anticancer natural product leinamycin. They first synthesized 3-mercapto carboxylic acid $\mathbf{5 1 0}$ as a key intermediate and then cyclized it with DCC and DMAP as coupling reagents, affording the thietan-2-one derivative $\mathbf{5 1 1}$ which was further converted into a small analogue $\mathbf{5 1 2}$ of leinamycin [149] (Scheme 118).

To investigate the structure-activity relationship of leinamycin (LNM), 8,4'-didehydroxy-leinamycin (515) was synthesized. During the synthesis, a spirothietan-2-one intermediate $\mathbf{5 1 4}$ was prepared through an intramolecular thioesterification of 3-mercaptoalkanoic acid $\mathbf{5 1 3}$ and further transformed into the target product 515 [150] (Scheme 119).

Tetrahydrolipstatin (orlistat) is currently marketed as xenical for the treatment of obesity [151]. Crich and co-workers synthe-

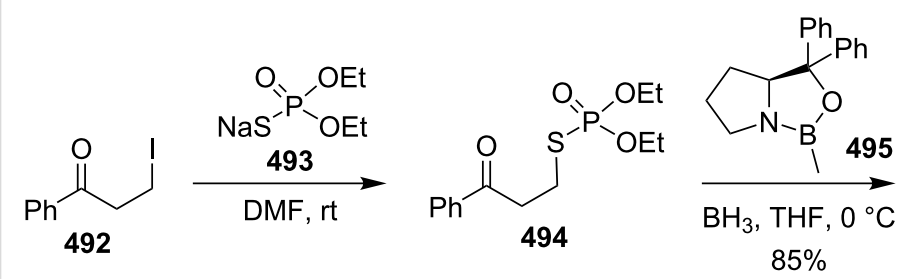<smiles>CCOP(=O)(OCC)SCC[C@H](O)c1ccccc1</smiles> 


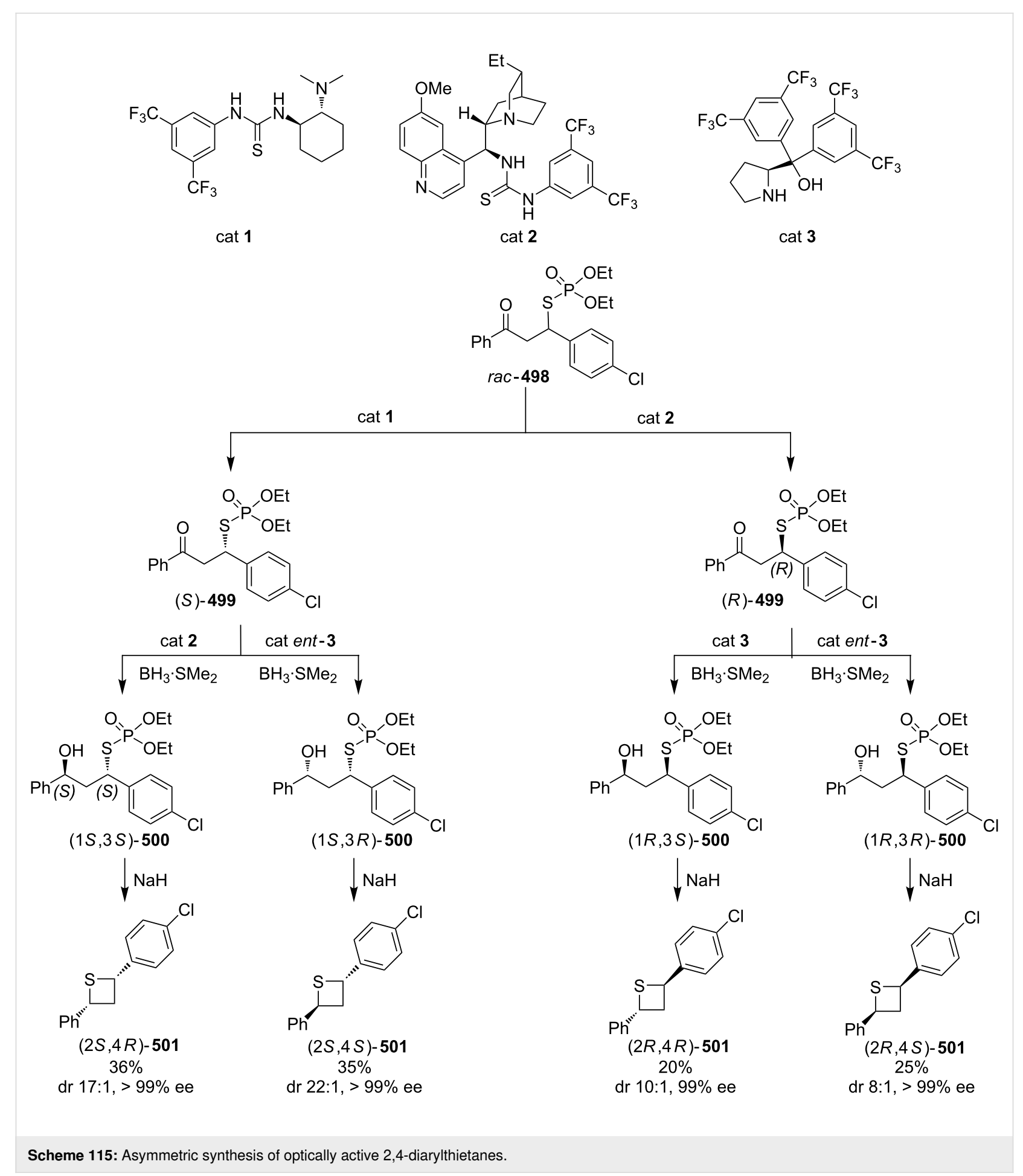

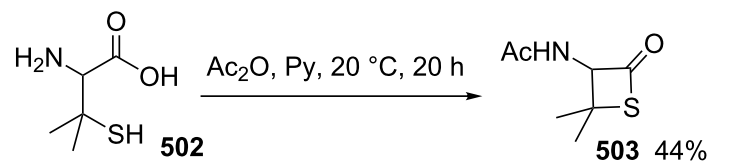

Scheme 116: Synthesis of 3-acetamidothietan-2-one 503 via the intramolecular thioesterification of 3-mercaptoalkanoic acid $\mathbf{5 0 2}$. sized its sulfur analogue $\mathbf{5 1 8}$ from $(S)$-(-)-epichlorohydrin $((S)$ 142a). After 12 steps, 3-mercapto carboxylic acid 516 was obtained and further cyclized into a thia- $\beta$-lactone $\mathbf{5 1 7}$ in more than $65 \%$ yield with EDCI as a coupling reagent and pentafluorophenyl ester as an active ester intermediate. After 3 steps, the thia- $\beta$-lactone $\mathbf{5 1 7}$ was transformed into thiatetrahydrolipstatin 518 [152] (Scheme 120). 


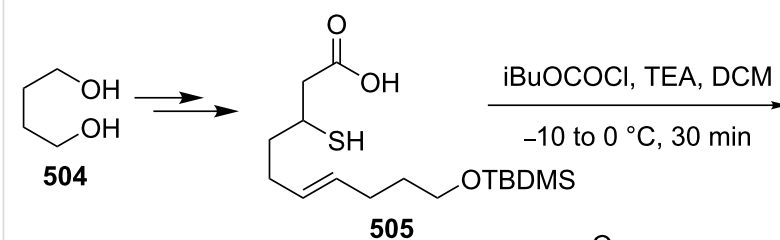

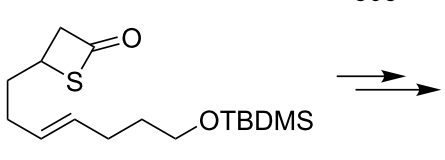

$50656 \%$

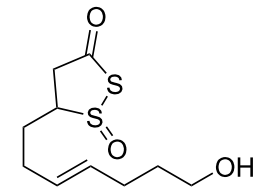

507

Scheme 117: Synthesis of 4-substituted thietan-2-one via the intramolecular thioesterification of 3-mercaptoalkanoic acid.

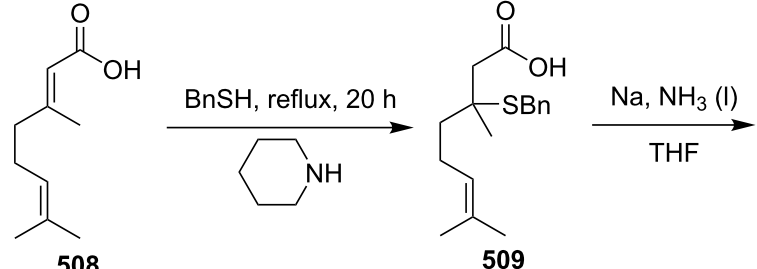

508

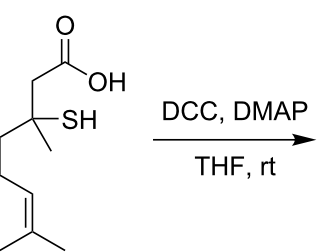

$51075 \%$<smiles>CC(C)=CCCC1(C)CC(=O)S1</smiles>

511

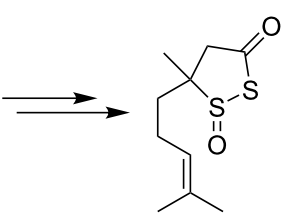

512
Scheme 118: Synthesis of 4,4-disubstituted thietan-2-one 511 via the intramolecular thioesterification of the 3-mercaptoalkanoic acid $\mathbf{5 1 0}$

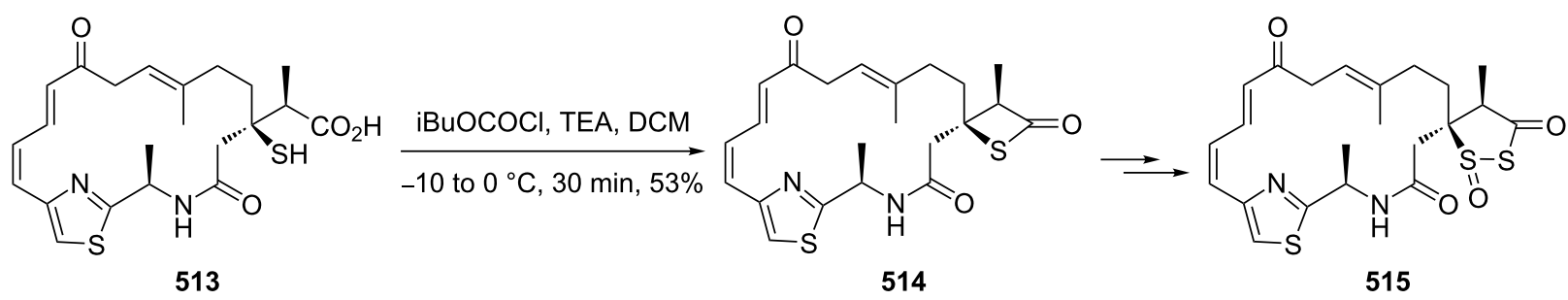<smiles>CC(=O)CC[C@@]1(CC(=O)N[C@@H](C)c2nc(/C=C\C=C/C(=O)[C@H](O)/C=C(\C)C(=O)O)cs2)SSC(=O)[C@H]1O</smiles>

8,4'-didehydroxy LNM

Scheme 119: Synthesis of a spirothietan-2-one $\mathbf{5 1 4}$ via the intramolecular thioesterification of 3-mercaptoalkanoic acid
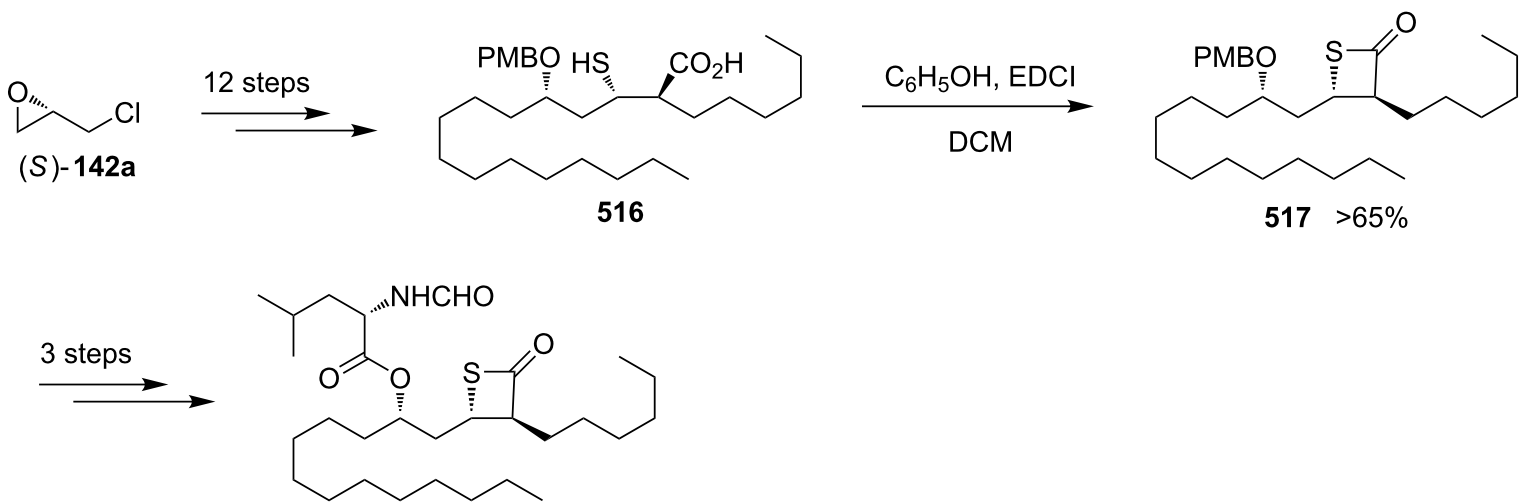

518

Scheme 120: Synthesis of thiatetrahydrolipstatin starting from (S)-(-)-epichlorohydrin ((S)-142a). 


\subsection{Synthesis via the intramolecular nucleophilic} substitution of 2-bromoalk-1-ene-4-thiols

When Narasaka and co-workers investigated the formal intramolecular nucleophilic substitution at $\mathrm{sp}^{2}$ carbon centers for the preparation of oxygen, nitrogen, and sulfur-containing unsaturated five-membered heterocycles, they found that the method could be applied for the synthesis of 2-alkylidenethietanes. They obtained 2-phenethyl-4-(propan-2-ylidene)thietane (520) from 5-bromo-6-methyl-1-phenylhept-5-ene-3-thiol (519) as a substrate in 1,3-dimethyl-2-imidazolidinone (DMI) as solvent [25] (Scheme 121).<smiles>CC(C)=C(Br)CC(S)CCc1ccccc1</smiles>
519

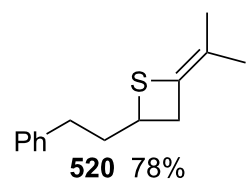

$52078 \%$
Scheme 121: Synthesis of 2-phenethyl-4-(propan-2-ylidene)thietane (520) from 5-bromo-6-methyl-1-phenylhept-5-ene-3-thiol (519).

They further applied the method to synthesize 2-phenethyl-4(propan-2-ylidene)thietane (520) from $S$-(5-bromo-6-methyl-1phenylhept-5-en-3-yl)thioacetate (521) directly because $\mathrm{K}_{2} \mathrm{CO}_{3}$ led to deacetylation of the acetyl group from the thioacetate 521, which was prepared from the corresponding alcohol and thiolacetic acid with the Mitsunobu reagent [153] (Scheme 122).

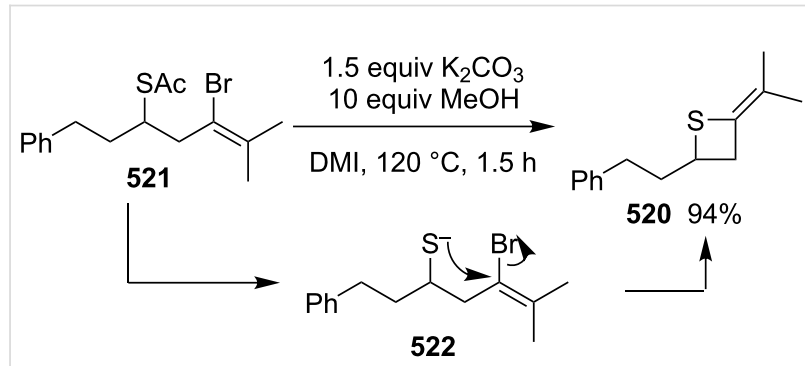

Scheme 122: Synthesis of 2-phenethyl-4-(propan-2-ylidene)thietane (520) directly from S-(5-bromo-6-methyl-1-phenylhept-5-en-3-yl)thioacetate (521).

The method was applied using various substrates to synthesize a series of 2-alkylidenethietanes 528-532. The $S$-(2,7-dibromoocta-1,7-dien-4-yl)thioacetate (527) generated the 2-methylidenethietane derivative $\mathbf{5 3 2}$ exclusively under the reaction conditions, revealing that the reaction preferred the 4-exo ring closure [153,154] (Scheme 123).<smiles>[R]C(Br)CC(=C)[Ge]</smiles>
523

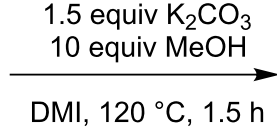

DMI, $120^{\circ} \mathrm{C}, 1.5 \mathrm{~h}$

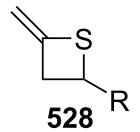

$\mathrm{R}=\mathrm{Bn}, 92 \% ; \mathrm{R}=\left(\mathrm{CH}_{2}\right)_{4} \mathrm{CO}_{2} \mathrm{Et}, 67 \% ; \mathrm{R}=c \mathrm{Hex}, 65 \%$;

$\mathrm{R}=4-\mathrm{MeOC}_{6} \mathrm{H}_{4}, 30 \%, \mathrm{R}=\mathrm{Ph}\left(\mathrm{CH}_{2}\right)_{2}, 93 \%$<smiles>C=C(Br)C(CCc1ccccc1)C(CCc1ccccc1)C(C)(C)C</smiles>

524<smiles>CCCCCCCCCCCCC(=O)OCc1ccccc1</smiles>

525<smiles>BrC1=COCCCCCC(CCc2ccccc2)C1</smiles>

526<smiles>C=C(Br)CCC([Ge])CC(=C)Br</smiles>

527

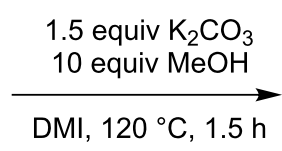

equiv $\mathrm{K}_{2} \mathrm{CO}_{3}$ 10 equiv $\mathrm{MeOH}$

DMI, $120^{\circ} \mathrm{C}, 1.5 \mathrm{~h}$

1.5 equiv $\mathrm{K}_{2} \mathrm{CO}_{3}$ $\underset{\mathrm{DMl}, 120^{\circ} \mathrm{C}, 1.5 \mathrm{~h}}{\stackrel{10}{\longrightarrow}}$

1.5 equiv $\mathrm{K}_{2} \mathrm{CO}_{3}$ 10 equiv $\mathrm{MeOH}$

DMI, $120^{\circ} \mathrm{C}, 1.5 \mathrm{~h}$<smiles>C=C1SC(CCc2ccccc2)C1CCc1ccccc1</smiles>

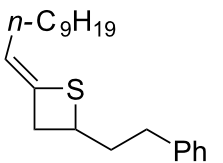

$53070 \%$

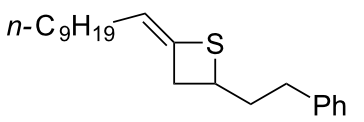

$53162 \%$

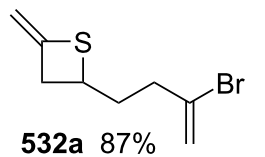


In 2009, Li and his co-workers developed a ligand-free CuI-catalyzed intramolecular $S$-vinylation of 2-bromo/chloroalk-1-ene4-thiols 533-539 for the preparation of 2-alkylidenethietanes 528, 532, and 540-544. They designed some substrates 537-539 possessing double bromovinyl moieties with different chain lengths and performed the reaction. The results indicated that the reaction preferred the 4-exo ring closure over other modes, such as 5-exo, 6-exo, and 6-endo cyclizations [155] (Scheme 124).

\subsection{Synthesis via nucleophilic addition}

The reaction of bulky $\alpha, \beta$-unsaturated trifluoromethyl ketone, adamantylmethylene trifluoromethyl ketone (545), and ammonium hydrosulfide generated a spiroadamantine-thietan-3-ol 548 in $86 \%$ yield. The reaction involved a thia-Michael addition, proton transfer, and nucleophilic addition [156] (Scheme 125).

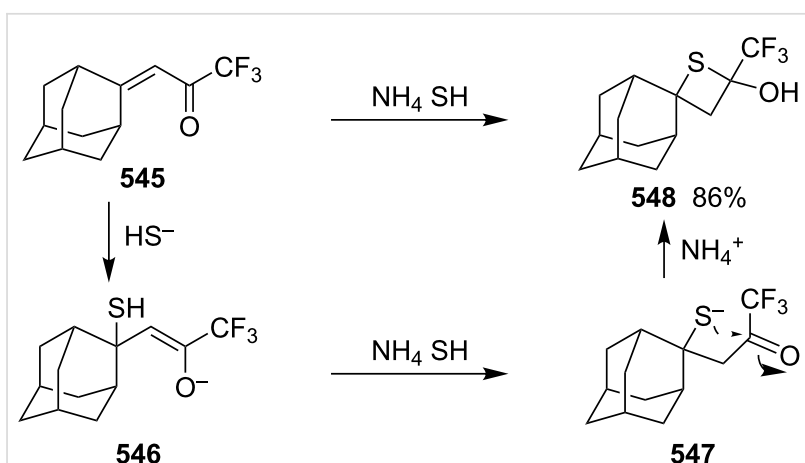

Scheme 125: Synthesis of spirothietan-3-ol 548 from enone 545 and ammonium hydrosulfide.

The de novo synthesis of the enantiopure thietane derivative $\mathbf{5 5 3}$, a four-membered ring thiosugar, was conducted from cisbut-2-ene-1,4-diol (47). The two asymmetric centers were<smiles>[X]C(=C)CC([R])S</smiles>

533

\section{$\underset{\mathrm{MeCN}, \text { reflux, } 0.5-2.5 \mathrm{~h}}{\stackrel{\mathrm{Cul}, \mathrm{K}_{3} \mathrm{PO}_{4} \cdot 3 \mathrm{H}_{2} \mathrm{O}}{\longrightarrow}}$}

$\mathrm{R}=n-\mathrm{C}_{7} \mathrm{H}_{15}, \mathrm{X}=\mathrm{Cl}, 95 \%, \mathrm{X}=\mathrm{Br}, 88 \% ; \mathrm{R}=\mathrm{CH}_{2} \mathrm{Bn}, \mathrm{X}=\mathrm{Cl}, 85 \%, \mathrm{X}=\mathrm{Br}, 80 \%$;

$\mathrm{R}=\mathrm{Ph}, \mathrm{X}=\mathrm{Cl}, 93 \%, \mathrm{X}=\mathrm{Br}, 90 \%$; dioxane was used for $\mathrm{X}=\mathrm{Cl}$<smiles>[X]C(=C)C([R])(Br)CS</smiles>

$\underset{\mathrm{MeCN}, \text { reflux, } 0.5-2 \mathrm{~h}}{\stackrel{\mathrm{Cul}, \mathrm{K}_{3} \mathrm{PO}_{4} \cdot 3 \mathrm{H}_{2} \mathrm{O}}{\longrightarrow}}$

534

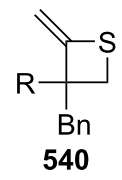

$\mathrm{R}=\mathrm{H}, \mathrm{X}=\mathrm{Cl}, 92 \%, \mathrm{X}=\mathrm{Br}, 90 \% ; \mathrm{R}=\mathrm{Me}, \mathrm{X}=\mathrm{Br}, 92 \%$<smiles>CCC/C=C(/Br)C(C)CS</smiles>

535

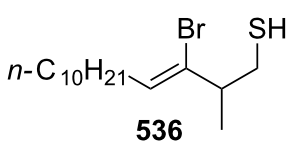<smiles>[R]C([R])=C(Br)CCC(S)CC(=C)Br</smiles><smiles>C=C(Br)CC(S)CC/C=C\Br</smiles>

538<smiles>C=C(Br)CCCC(S)CC(=C)Br</smiles>

539

$$
\underset{\text { MeCN, reflux, } 0.5 \mathrm{~h}}{\stackrel{\text { Cul, } \mathrm{K}_{3} \mathrm{PO}_{4} \cdot 3 \mathrm{H}_{2} \mathrm{O}}{\longrightarrow}}
$$<smiles>C[N+](C)=O</smiles>

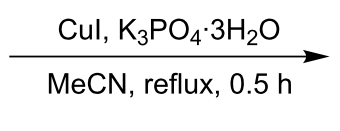

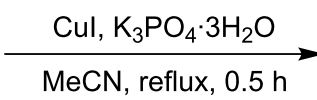

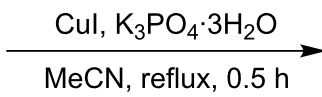

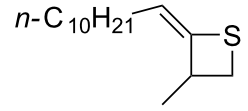

$54199 \%$<smiles>[14CH3]</smiles><smiles>CC=C1SCC1C</smiles>

542 99\%<smiles>[R]C([R])=C(Br)CCC1CC(=C)S1</smiles>

$\mathrm{R}=\mathrm{H}, 68 \% ; \mathrm{R}=\mathrm{Me}, 85 \%$<smiles>C=C1CC(CC/C=C\Br)S1</smiles>

$54383 \%$<smiles>C=C(Br)CCCC1CC(=C)S1</smiles> 
generated first via the Sharpless asymmetric epoxidation. The epoxide 549 was then converted into the corresponding thiirane 550 through a cyclic xanthate intermediate generated by the treatment with $\mathrm{CS}_{2}$ and $\mathrm{KH}$. After the protection of the secondary hydroxy group, methanolysis of the xanthate afforded the desired thiirane $\mathbf{5 5 0}$ in $63 \%$ overall yield. The AgOAc-mediated regioselective ring opening of the thiirane $\mathbf{5 5 0}$ provided a thiol 551, which was converted to 1-O-ethyl-thietanoside 553 through the acid-catalyzed elimination of EtOH followed by the thiol nucleophilic addition induced by the treatment with CSA in refluxing benzene. The highly stereoselective conversion proceeded via an oxocarbenium intermediate 552, leading to the thermodynamically favored trans,trans-substituted thietane derivative 553 [157] (Scheme 126).

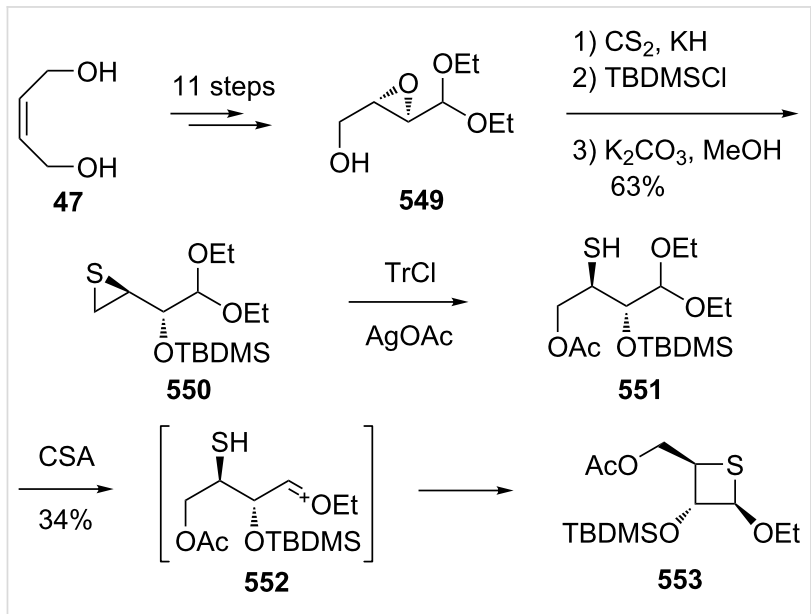

Scheme 126: Asymmetric synthesis of the optically active thietanoside from cis-but-2-ene-1,4-diol (47).

(Z)- $\alpha$-Silyl vinyl sulfides $\mathbf{5 5 4}$ were prepared from $(Z)$ - $\alpha$-silyl enethiols and chloromethyl ketones and further converted into 2-alkylidenethietan-3-ols $\mathbf{5 5 7}$ by the treatment with fluoride. The conversion included the desilylation, intramolecular nucleophilic addition, and protonation [158] (Scheme 127).

The treatment of propargylbenzene (558) with butyllithium generated 1,3-dilithiopropargylbenzene (559), which underwent a nucleophilic addition to isothiocyanates $\mathbf{5 6 0}$ followed by protonation, isomerization, intramolecular nucleophilic addition, and methylation, affording 2-iminothietane derivatives 564 $[159,160]$ (Scheme 128).

One example of a 2-benzylidenethietane $\mathbf{5 6 7}$ was prepared in $82 \%$ yield from 1-phenylhex-1-en-4-ylthioacetate (565) via a nickel complex-catalyzed electroreduction [161] (Scheme 129). However, the electrochemical synthetic method was widely applied for the synthesis of thiacyclopetanes and thiacyclohexanes [161].

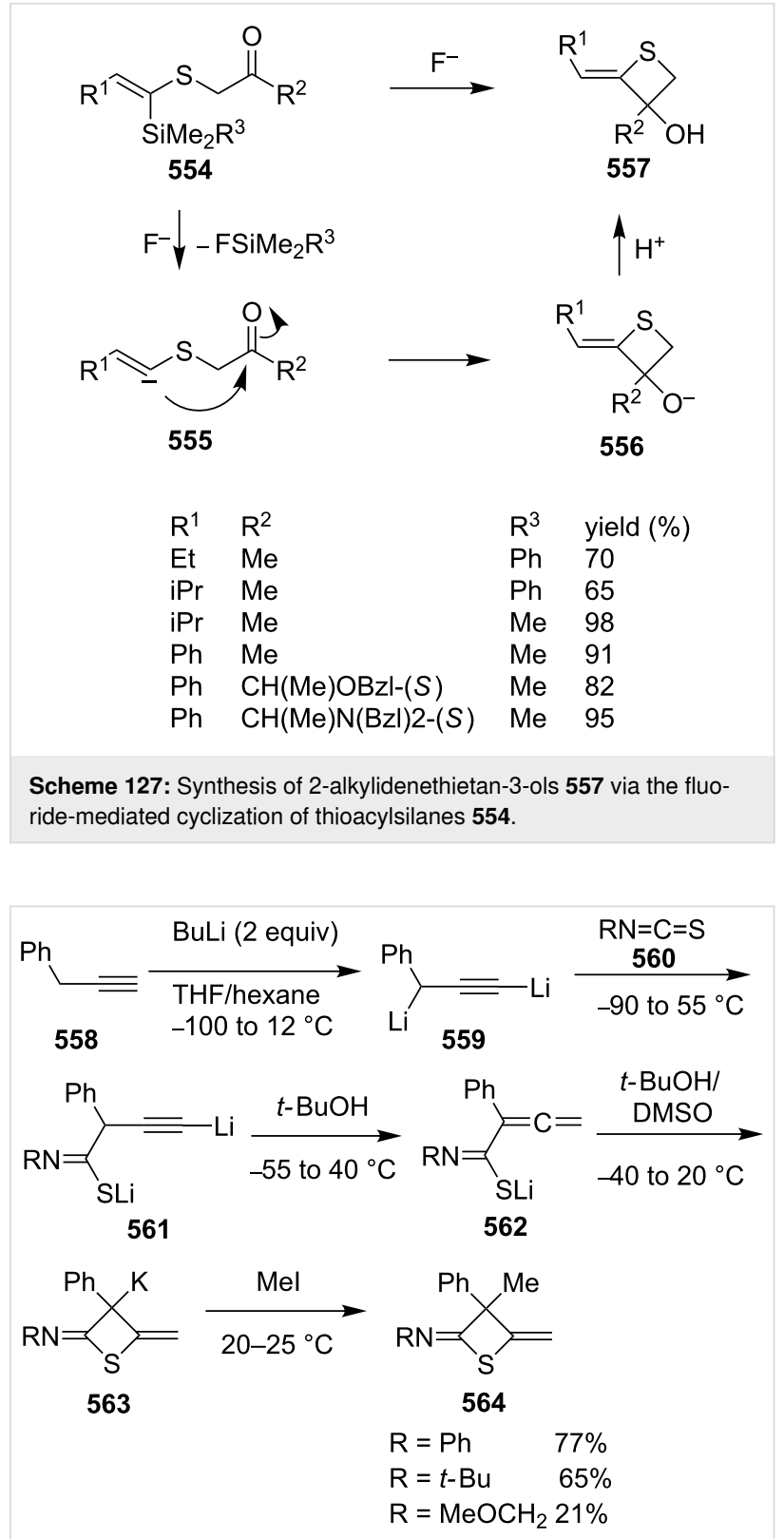

Scheme 128: Synthesis of 2-iminothietanes via the reaction of propargylbenzene (558) and isothiocyanates 560 in the presence of butyllithium as strong base.

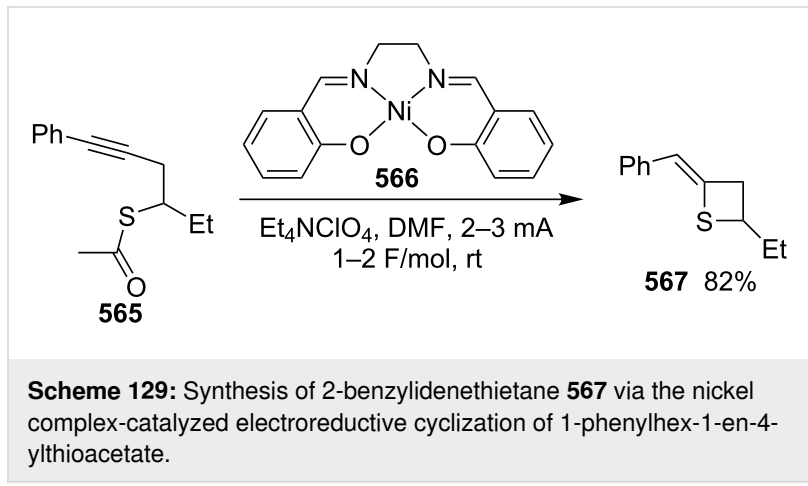




\subsection{Synthesis via electrocyclic reaction}

Besides the cyclization through the inter- and intramolecular nucleophilic substitutions, the photo-assisted electrocyclic reaction of $N$-monosubstituted $\alpha, \beta$-unsaturated thioamides $\mathbf{5 6 8}$ was also applied for the synthesis of 2-iminothietane derivatives $\mathbf{5 6 9}$ [162] (Scheme 130)<smiles>[R]C=C([R])C(=S)N[R15]</smiles><smiles>C1C2CC1C2</smiles>

568

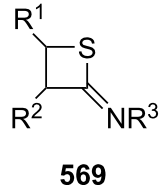

569

$\begin{array}{lllll}\mathrm{R}^{1} & \mathrm{R}^{2} & \mathrm{R}^{3} & \text { yield (\%) } & \text { trans: cis } \\ \mathrm{H} & \mathrm{Me} & \mathrm{CHMe}_{2} & 55 & \\ \mathrm{H} & \mathrm{Me} & \mathrm{Bn} & 85 & \\ \mathrm{H} & \mathrm{Me} & \mathrm{CH}(\mathrm{Me}) \mathrm{Ph} & 50 & \\ \mathrm{Me} & \mathrm{Me} & \mathrm{CHMe} & \\ \mathrm{Me} & \mathrm{Me} & \mathrm{Bn} & 82 & 4.1: 1.0 \\ \mathrm{Me} & \mathrm{Me} & \mathrm{CH}(\mathrm{Me}) \mathrm{Ph} & 73 & 3.2: 1.0 \\ \mathrm{Me} & \mathrm{Me} & \mathrm{Ph} & 76 & 1.3: 1.0 \\ \mathrm{Me} & \mathrm{H} & \mathrm{CH}(\mathrm{Me}) \mathrm{Ph} & 70 & \end{array}$

Scheme 130: Synthesis of 2-iminothietanes 569 via the photo-assisted electrocyclic reaction of $N$-monosubstituted $\alpha, \beta$-unsaturated thioamides.

\subsection{Synthesis via nucleophilic addition-elimination} Iminothietanes [162-169], diiminothietanes [101,170], and triiminothietanes [171] are less reported four-membered thiaheterocycles. Langer and Doring prepared ethyl 3,4-diiminothietane-2-carboxylates $\mathbf{5 7 3}$ through the cyclization of the vicinal dianion 571 generated from ethyl thioglycolate (570) and LDA in TMEDA with 1,2-dielectrophiles, bis(imidoyl chloride)s 572. However, only one target diiminothietane 572a was obtained in $40 \%$ yield $\left(\mathrm{R}=4-\mathrm{MeC}_{6} \mathrm{H}_{4}\right)$. The other two reacted directly with another molecule of the dianion $\mathbf{5 7 1}$ to generate 4-amino-5imino-1,2-dithiole-3-carboxylates 574 [172] (Scheme 131).

\section{Miscellaneous syntheses}

Press and co-workers developed a rearrangement method to derivatize aromatic azaheterocyclethiones, including 1,9dihydro-6H-purine-6-thiones 575, 1,5-dihydro-4Hpyrazolo[3,4- $d]$ pyrimidine-4(3H)-thione (576), pyrimidine4(3H)-thione (577), quinoline-2(1H)-thione (578), and pyridine2(1H)-thione (579), into the corresponding $N$-thietan-3-yl- $\alpha$-oxo nitrogen-containing heterocycles 583-587 with chloromethyloxirane (142a) as an alkylation reagent. For the reaction process, the reaction of 1,9-dihydro- $6 H$-purine-6-thione (575a) and chloromethyloxirane (142a) first generated the $S$-alkylated intermediate $\mathbf{5 8 0}$ in the presence of sodium bicarbonate. After the treatment with $\mathrm{NaOH}$, the intermediate $\mathbf{5 8 0}$ converted into tricyclic intermediates $\mathbf{5 8 1}$ and $\mathbf{5 8 2}$, which finally produced the $N$-thietan-3-yl product 583a in more than $99 \%$ yield in methanolic sodium methoxide through a rearrangement [173] (Scheme 132).

Recently, the nickel-catalyzed reductive thiolation of unactivated alkyl bromides and thiosulfonates was developed to synthesize thioethers. The method could also be applied in the synthesis of thietane derivatives. Such as, thietan-3-yl benzoate (590) was prepared through the nickel-catalyzed intramolecular reductive thiolation of $S$-(3-bromo-2benzoyloxypropyl)benzenesulfonothioate (588) [174] (Scheme 133).

The thiophilic ring-opening reaction of 3,3-bis(trifluoromethyl)5-butoxy-1,2-dithiolane (591) proceeded with the treatment of the nucleophile $\mathrm{CF}_{3} \mathrm{SiMe}_{3}$ to generate 2,2-bis(trifluoromethyl)4-butoxythietane (374d) as an intermediate. The latter compound further reacted with another molecule of $\mathrm{CF}_{3} \mathrm{SiMe}_{3}$ to afford a mixture of 2,2-bis(trifluoromethyl)-4-butoxythietane (374d) and (1-butoxy-4,4-difluoro-3-(trifluoromethyl)but-3-en$1-y 1)($ trifluoromethyl)sulfane (592) in a ratio of 60:20 [175] (Scheme 134).

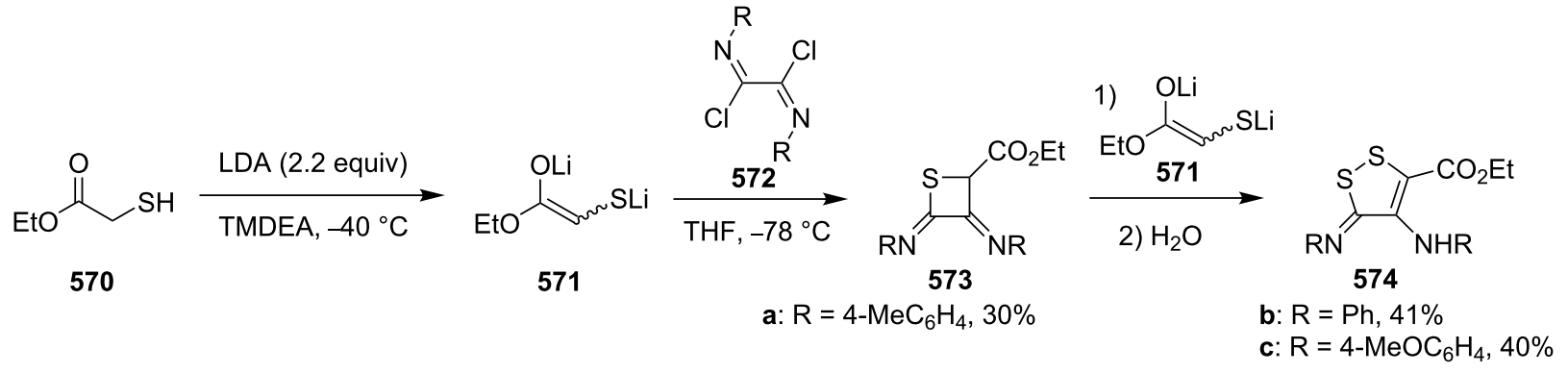




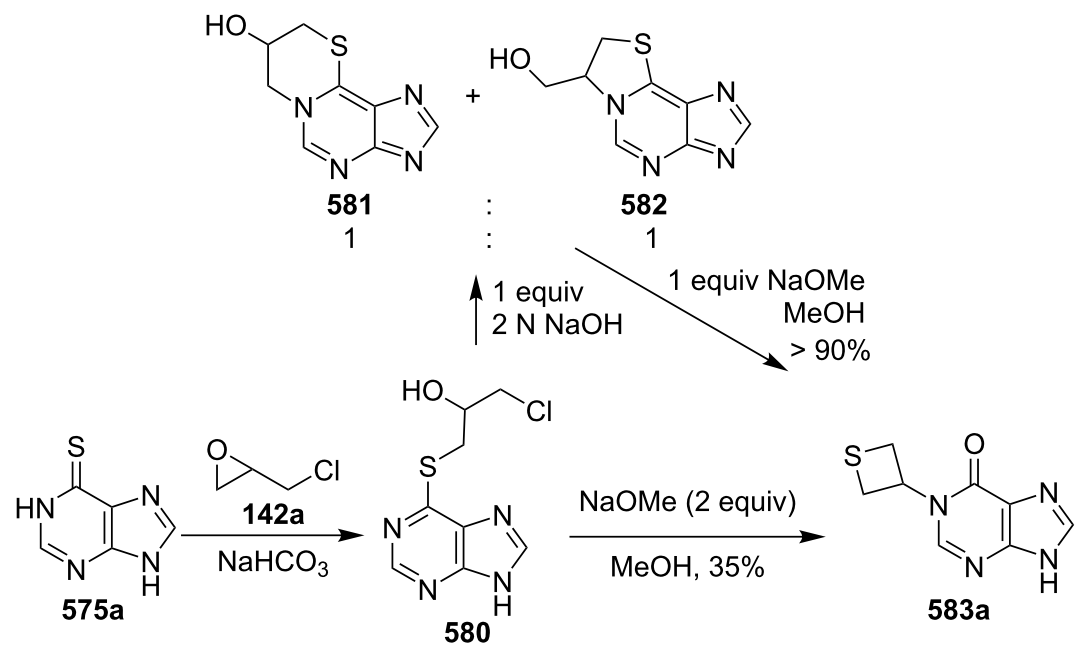

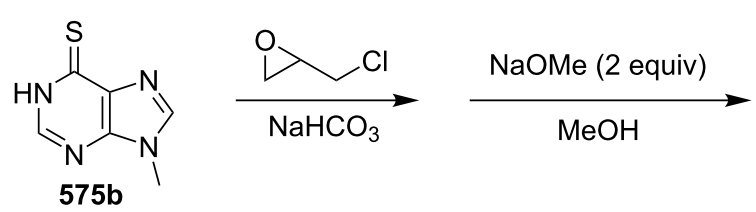<smiles>Cn1cnc2c(=O)n(C3CSC3)cnc21</smiles>

583b $2.5 \%$<smiles>S=c1[nH]cnc2[nH]ncc12</smiles><smiles>CC(C)(C)[C@H](Cl)CC1CO1</smiles>

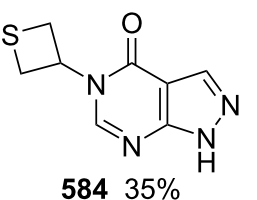<smiles>S=c1ccnc[nH]1</smiles><smiles>O=C(O)N1CC1C[N+](=O)[O-]</smiles><smiles>COC(OC)[C@H]1C[C@@H](n2cnccc2=O)CS1</smiles><smiles>O=c1ccnc[nH]1</smiles>

577<smiles>S=c1ccc2ccccc2[nH]1</smiles>

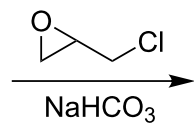<smiles>COC(=O)OCCCCCO</smiles>

578

$5855 \%$<smiles>S=c1cccc[nH]1</smiles>

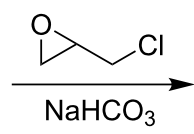

$\underset{\mathrm{MeOH}}{\stackrel{\text { NaOMe (2 equiv) }}{\longrightarrow}}$<smiles>O=c1ccc2ccccc2n1C1CSC1</smiles>

$58641 \%$<smiles>O=c1ccccn1C1CSC1</smiles>

$58758 \%$
The reaction of enamine $\mathbf{5 9 3}$ and methanesulfonyl chloride in the presence of triethylamine generated 3-amino-2-proylthietane 1,1-dioxide 594. After the methylation with MeI and Hofmann elimination, 2-propyl-2H-thiete 1,1-dioxide (595) was obtained. Compound $\mathbf{5 9 5}$ was converted into 2-propylthietane (597) after hydrogenation and reduction [176] (Scheme 135).
It is well known that cyclobutane-1,3-dithiones undergo ring rearrangement and isomerization into thietane-2-thiones in the presence of bases [177,178]. 2,2,4,4-Tetramethylcyclobutane1,3-dithione (598) generated 3,3-dimethyl-4-(propan-2ylidene)thietane-2-thione (602) in the presence of triethylamine. It further reacted with the fluorinated nitrile imine $\mathbf{5 9 9}$ derived 


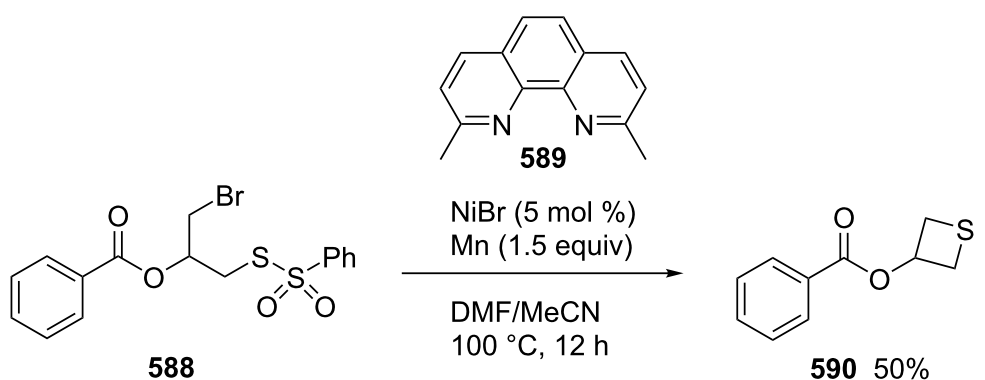

Scheme 133: Synthesis of thietan-3-yl benzoate (590) via the nickel-catalyzed intramolecular reductive thiolation of $S$-(3-bromo-2-benzoyloxypropyl) benzenesulfonothioate $\mathbf{5 8 8}$.<smiles>CC(C)OC1CC(C(F)(F)F)(C(F)(F)F)SS1</smiles>

591

\section{$\mathrm{CF}_{3} \mathrm{SiMe}_{3, \mathrm{KF}}$}<smiles></smiles>

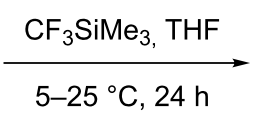

60

$\mathrm{BuO}$

374d

$\mathrm{BuO}$<smiles>OC(CC(=C[18OH])C(F)(F)F)C(F)(F)F</smiles>

Scheme 134: Synthesis of 2,2-bis(trifluoromethyl)thietane from 3,3bis(trifluoromethyl)-1,2-dithiolane.

from trifluoroacetaldehyde phenylhydrazonoyl bromide in the presence of triethylamine to give 1,8-dithia-5,6-diazaspiro[3.4] oct-6-ene 603, the spiro thietane-1,3,4-thiadiazolidine derivative, through a [2+3] cycloaddition [179] (Scheme 136).

In 2006, a Russian group attempted to prepare thietane (605) from 1-bromo-3-chloropropane (604) and sulfur in the presence of hydrazine hydrate and $\mathrm{KOH}$. The yield depended on the ratio of $\mathrm{KOH}: \mathrm{S}$. When the ratio was $1: 2$, thietane (605) was obtained in $26 \%$ yield, however, polymeric $-\left(\mathrm{SCH}_{2} \mathrm{CH}_{2} \mathrm{CH}_{2} \mathrm{~S}\right)_{n}-(\mathbf{6 0 7})$ was the major product in 65\% yield [180] (Scheme 137).

\section{Conclusion}

Thietanes are one class of important aliphatic four-membered thiaheterocycles. They are not only crucial pharmaceutical cores

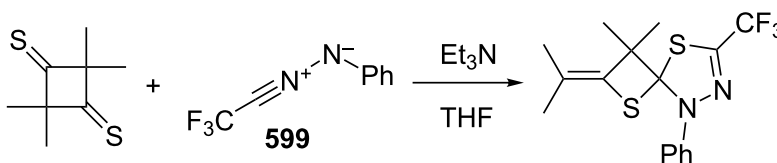

598

$60341 \%$<smiles>C=CNCC</smiles><smiles>FC(F)(F)C#[N+]N[Pb]</smiles>

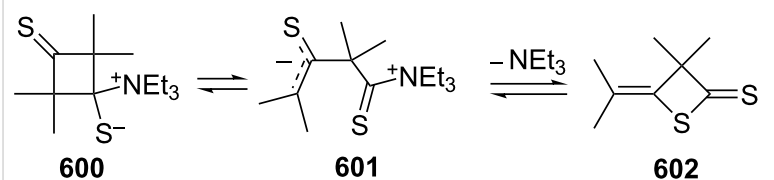

Scheme 136: Synthesis of spirothietane 603 via the [2+3] cycloaddition of 2,2,4,4-tetramethylcyclobutane-1,3-dithione and nitrile imine.

$$
\begin{aligned}
& \mathrm{Br} \underbrace{}_{604} \mathrm{Cl}+\mathrm{S} \frac{\mathrm{H}_{2} \mathrm{NNH}_{2} \cdot \mathrm{H}_{2} \mathrm{O}}{\mathrm{KOH}}
\end{aligned}
$$

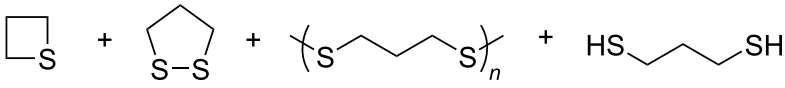

$$
\begin{aligned}
& \begin{array}{llll}
605 & 606 & 607 & 608
\end{array} \\
& \begin{array}{llll}
26 \% & 4 \% & 65 \% & 5 \%
\end{array}
\end{aligned}
$$

Scheme 137: Synthesis of thietane (605) from 1-bromo-3-chloropropane and sulfur.

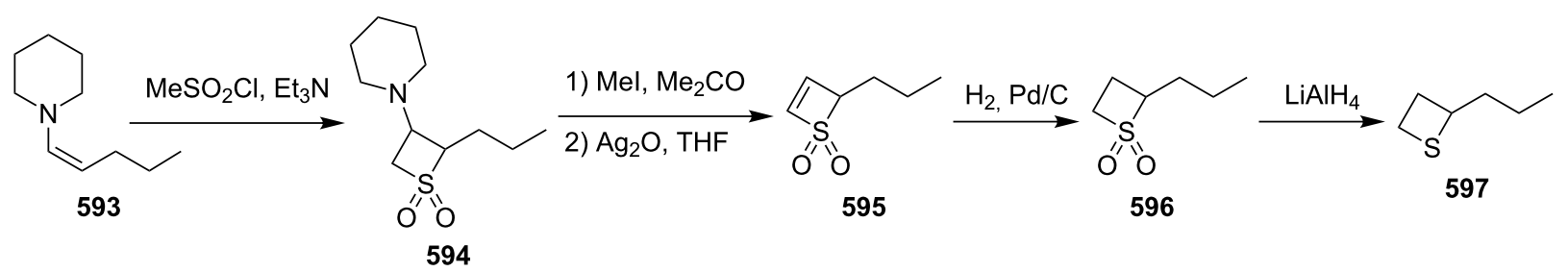


and structural motifs of some biological compounds, but also useful and versatile synthetic intermediates in organic chemistry. Various synthetic methods of thietanes have been developed to date. They mainly included the inter- and intramolecular nucleophilic thioetherifications and photochemical $[2+2]$ cycloadditions of thiocarbonyl compounds with olefins, the ring expansions of aliphatic three-membered heterocycles and ring contractions of aliphatic five- and six-membered thiaheterocycles, the nucleophilic cyclizations, and some miscellaneous methods. Abundant synthetic methods are available for the preparation of different substituted thietanes, respectively. Although various cyclic thioetherification strategies have been applied in the synthesis of biologically important thietanose nucleosides and sulfur analogues of docetaxel and 7-deoxydocetaxel till now, it can be believed that some newly developed synthetic strategies will show wide applications in the preparation of sulfur-containing biologically active compounds and organic materials in the near future.

\section{Funding}

The project was supported by the National Natural Science Foundation of China (Nos. 21572017 and 21772010).

\section{ORCID ${ }^{\circledR}$ iDs}

Jiaxi Xu - https://orcid.org/0000-0002-9039-4933

\section{References}

1. Crump, D. R. J. Chem. Ecol. 1980, 6, 341-347. doi:10.1007/bf01402912

2. Crump, D. R. J. Chem. Ecol. 1980, 6, 837-844. doi:10.1007/bf00990407

3. Nishizono, N.; Koike, N.; Yamagata, Y.; Fujii, S.; Matsuda, A. Tetrahedron Lett. 1996, 37, 7569-7572. doi:10.1016/0040-4039(96)01719-4

4. Nishizono, N.; Akama, Y.; Agata, M.; Sugo, M.; Yamaguchi, Y.; Oda, K. Tetrahedron 2011, 67, 358-363. doi:10.1016/j.tet.2010.11.038

5. Roy, A.; Achari, B.; Mandal, S. B. Tetrahedron Lett. 2006, 47, 3875-3879. doi:10.1016/j.tetlet.2006.03.175

6. Mercklé,, L.; Dubois, J.; Place, E.; Thoret, S.; Guéritte, F.; Guénard, D.; Poupat, C.; Ahond, A.; Potier, P. J. Org. Chem. 2001, 66, 5058-5065. doi:10.1021/jo015539+

7. Ohuchida, S.; Hamanaka, N.; Hayashi, M. Tetrahedron 1983, 39, 4269-4272. doi:10.1016/s0040-4020(01)88650-6

8. Renold, P.; Zambach, W.; Maienfisch, P.; Muehlebach, M. Insecticidal compounds. PCT Patent Application, WO 2009/080250 A2, July 9 , 2009.

9. Brennan, T. M.; Hendrick, M. E. U.S. Patent 4,411,925, Oct 25, 1983.

10. Xu, W.; Xu, J. X. Curr. Org. Synth. 2016, 13, 73-81. doi:10.2174/1570179412999150723153005

11. Xu, J. X. Top. Heterocycl. Chem. 2016, 41, 311-362. doi:10.1007/7081_2015_157

12. Sander, M. Chem. Rev. 1966, 66, 341-353. doi:10.1021/cr60241a005

13. Parrick, J.; Mehta, L. K. Prog. Heterocycl. Chem. 1995, 7, 64-81. doi:10.1016/s0959-6380(06)80006-1
14. Carreira, E. M.; Fessard, T. C. Chem. Rev. 2014, 114, 8257-8322. doi:10.1021/cr500127b

15. Sakamoto, M.; Nishio, T. Heterocycles 2003, 59, 399-427. doi:10.3987/rev-02-sr1

16. Sakamoto, M.; Takahashi, M.; Hokari, N.; Fujita, T.; Watanabe, S. J. Org. Chem. 1994, 59, 3131-3134. doi:10.1021/jo00090a034

17. Nishio, T. J. Chem. Soc., Perkin Trans. 1 1995, 561-568. doi:10.1039/p19950000561

18. Padwa, A.; Jacquez, M. N.; Schmidt, A. Org. Lett. 2001, 3, 1781-1783. doi:10.1021/ol0159975

19. Petrov, V. A.; Marshall, W. J. J. Fluorine Chem. 2009, 130, 780-787. doi:10.1016/j.jfluchem.2009.06.011

20. Miller, J. A.; Pugh, A. W.; Ullah, G. M. Nucleosides, Nucleotides Nucleic Acids 2000, 19, 1475-1486. doi:10.1080/15257770008033855

21. Er, E.; Margaretha, P. Helv. Chim. Acta 1992, 75, 2265-2269. doi:10.1002/hlca.19920750712

22. Dong, J.; Xu, J. Org. Biomol. Chem. 2017, 15, 836-844. doi:10.1039/c6ob02387h

23. Dong, J.; Du, H.; Xu, J. J. Org. Chem. 2019, 84, 10724-10739. doi:10.1021/acs.joc.9b01152

24. Das, P.; Njardarson, J. T. Eur. J. Org. Chem. 2016, 4249-4259. doi:10.1002/ejoc.201600312

25. Miyauchi, H.; Chiba, S.; Fukamizu, K.; Ando, K.; Narasaka, K. Tetrahedron 2007, 63, 5940-5953. doi:10.1016/j.tet.2007.02.116

26. Chalyk, B. A.; Butko, M. V.; Yanshyna, O. O.; Gavrilenko, K. S.; Druzhenko, T. V.; Mykhailiuk, P. K. Chem. - Eur. J. 2017, 23, 16782-16786. doi:10.1002/chem.201702362

27. Chalyk, B. A.; Isakov, A. A.; Butko, M. V.; Hrebeniuk, K. V.; Savych, O. V.; Kucher, O. V.; Gavrilenko, K. S.; Druzhenko, T. V.; Yarmolchuk, V. S.; Zozulya, S.; Mykhailiuk, P. K. Eur. J. Org. Chem. 2017, 4530-4542. doi:10.1002/ejoc.201700536

28. Deng, H.; Jia, R.; Yang, W.-L.; Yu, X.; Deng, W.-P. Chem. Commun. 2019, 55, 7346-7349. doi:10.1039/c9cc03589c

29. Hashem, A. I.; El-Hussieny, M.; Abd-El-Maksoud, M. A.; Maigali, S. S.; Mansour, S. T.; Soliman, F. M. Phosphorus, Sulfur Silicon Relat. Elem. 2018, 193, 1-9. doi:10.1080/10426507.2017.1370467

30. Lassalas, P.; Oukoloff, K.; Makani, V.; James, M.; Tran, V.; Yao, Y.; Huang, L.; Vijayendran, K.; Monti, L.; Trojanowski, J. Q.; Lee, V. M.-Y.; Kozlowski, M. C.; Smith, A. B., III; Brunden, K. R.; Ballatore, C. ACS Med. Chem. Lett. 2017, 8, 864-868. doi:10.1021/acsmedchemlett.7b00212

31. Greb, A.; Poh, J.-S.; Greed, S.; Battilocchio, C.; Pasau, P.; Blakemore, D. C.; Ley, S. V. Angew. Chem., Int. Ed. 2017, 56, 16602-16605. doi:10.1002/anie.201710445

32. Černý, J. V.; Poláček, J. Collect. Czech. Chem. Commun. 1966, 31 , 1831-1838. doi:10.1135/cccc19661831

33. Nishizono, N.; Sugo, M.; Machida, M.; Oda, K. Tetrahedron 2007, 63, 11622-11625. doi:10.1016/j.tet.2007.09.002

34. Lu, P.; Herrmann, A. T.; Zakarian, A. J. Org. Chem. 2015, 80, 7581-7589. doi:10.1021/acs.joc.5b01177

35. Burkhard, J. A.; Wagner, B.; Fischer, H.; Schuler, F.; Müller, K.; Carreira, E. M. Angew. Chem., Int. Ed. 2010, 49, 3524-3527. doi:10.1002/anie.200907108 
36. Borst, M. L. G.; Ouairy, C. M. J.; Fokkema, S. C.; Cecchi, A.; Kerckhoffs, J. M. C. A.; de Boer, V. L.; van den Boogaard, P. J.; Bus, R. F.; Ebens, R.; van der Hulst, R.; Knol, J.; Libbers, R.; Lion, Z. M.; Settels, B. W.; de Wever, E.; Attia, K. A.; Sinnema, P.-J.; de Gooijer, J. M.; Harkema, K.; Hazewinkel, M.; Snijder, S.; Pouwer, K. ACS Comb. Sci. 2018, 20, 335-343. doi:10.1021/acscombsci.7b00150

37. Lu, Y.; Wang, J.; Guo, J.; Tang, Y.; Zhang, S.; Tao, J.; Xiong, L.; Li, X.; Luo, J. Heterocycl. Commun. 2015, 21, 1-4. doi:10.1515/hc-2014-0210

38. Hazelard, D.; Compain, P. Org. Biomol. Chem. 2017, 15, 3806-3827. doi:10.1039/c7ob00386b

39. Ichikawa, E.; Yamamura, S.; Kato, K. Tetrahedron Lett. 1999, 40, 7385-7388. doi:10.1016/s0040-4039(99)01515-4

40. Maity, J. K.; Ghosh, R.; Drew, M. G. B.; Achari, B.; Mandal, S. B. J. Org. Chem. 2008, 73, 4305-4308. doi:10.1021/jo8002826

41. De Carvalho, G. S. G.; Fourrey, J.-L.; Dodd, R. H.; Da Silva, A. D. Tetrahedron Lett. 2009, 50, 463-466. doi:10.1016/j.tetlet.2008.11.039

42. Gonzalez-Lopez de Turiso, F.; Shin, Y.; Brown, M.; Cardozo, M.; Chen, Y.; Fong, D.; Hao, X.; He, X.; Henne, K.; Hu, Y.-L.; Johnson, M. G.; Kohn, T.; Lohman, J.; McBride, H. J.; McGee, L. R.; Medina, J. C.; Metz, D.; Miner, K.; Mohn, D.; Pattaropong, V.; Seganish, J.; Simard, J. L.; Wannberg, S.; Whittington, D. A.; Yu, G.; Cushing, T. D. J. Med. Chem. 2012, 55, 7667-7685. doi:10.1021/jm300679u

43. Lacharity, J. J.; Fournier, J.; Lu, P.; Mailyan, A. K.; Herrmann, A. T.; Zakarian, A. J. Am. Chem. Soc. 2017, 139, 13272-13275. doi:10.1021/jacs.7b07685

44. Burkhard, J. A.; Guerot, C.; Knust, H.; Evans, M. R.; Carreira, E. M. Org. Lett. 2010, 12, 1944-1947. doi:10.1021/ol1003302

45. Ikemizu, D.; Matsuyama, A.; Takemura, K.; Mitsunobu, O. Synlett 1997, 1247-1248. doi:10.1055/s-1997-1032

46. Korotkikh, N. I.; Aslanov, A. F.; Raenko, G. F.; Shvaika, O. P. Russ. J. Org. Chem. 1999, 35, 730-740.

47. Downer, J. D.; Colchester, J. E. J. Chem. Soc. 1965, 1528-1529.

48. Miljković, D.; Popsavin, V.; Harangi, J. Tetrahedron 1985, 41, 2737-2743. doi:10.1016/s0040-4020(01)96374-4

49. Cubero, I. I.; Plaza Lopez-Espinosa, M. T.; de Buruaga Molina, A. S. Carbohydr. Res. 1996, 280, 145-150. doi:10.1016/0008-6215(95)00282-0

50. Adiwidjaja, G.; Brunck, J.-S.; Polchow, K.; Voss, J. Carbohydr. Res. 2000, 325, 237-244. doi:10.1016/s0008-6215(00)00009-4

51. Schulze, O.; Voss, J.; Adiwidjaja, G.; Olbrich, F. Carbohydr. Res. 2004, 339, 1787-1802. doi:10.1016/j.carres.2004.04.020

52. Polchow, K.; Voss, J. Phosphorus, Sulfur Silicon Relat. Elem. 2005, 180, 1755-1768. doi:10.1080/104265090508424

53. Choo, H.; Chen, X.; Yadav, V.; Wang, J.; Schinazi, R. F.; Chu, C. K. J. Med. Chem. 2006, 49, 1635-1647. doi:10.1021/jm050912h

54. Yoshimura, Y.; Asami, K.; Imamichi, T.; Okuda, T.; Shiraki, K.; Takahata, H. J. Org. Chem. 2010, 75, 4161-4171. doi:10.1021/jo100556u

55. Otzen, D.; Voss, J.; Adiwidjaja, G. Phosphorus, Sulfur Silicon Relat. Elem. 2006, 181, 1249-1270. doi:10.1080/10426500500326545

56. Abbott, F. S.; Haya, K. Can. J. Chem. 1978, 56, 71-79. doi:10.1139/v78-012

57. Kozikowski, A. P.; Fauq, A. H. Synlett 1991, 783-784. doi:10.1055/s-1991-20873

58. Karikomi, M.; Narabu, S.-i.; Yoshida, M.; Toda, T. Chem. Lett. 1992, 21, 1655-1658. doi:10.1246/cl.1992.1655
59. Gunatilaka, A. A. L.; Ramdayal, F. D.; Sarragiotto, M. H.; Kingston, D. G. I.; Sackett, D. L.; Hamel, E. J. Org. Chem. 1999, 64, 2694-2703. doi:10.1021/jo982095h

60. Payré, C.; Al Mourabit, A.; Mercklé, L.; Ahond, A.; Poupat, C.; Potier, P. Tetrahedron Lett. 2000, 41, 4891-4894. doi:10.1016/s0040-4039(00)00727-9

61. Gay, J.; Scherowsky, G. Synth. Commun. 1995, 25, 2665-2672. doi:10.1080/00397919508011813

62. Sureshkumar, D.; Koutha, S.; Ganesh, V.; Chandrasekaran, S. J. Org. Chem. 2010, 75, 5533-5541. doi:10.1021/jo100640w

63. Ohno, A.; Ohnishi, Y.; Tsuchihashi, G. J. Am. Chem. Soc. 1969, 91 , 5038-5045. doi:10.1021/ja01046a018

64. Gotthardt, H.; Nieberl, S. Chem. Ber. 1978, 111, 1471-1474. doi:10.1002/cber.19781110425

65. Visser, R. G.; Bos, H. J. T. Tetrahedron Lett. 1979, 20, 4857-4858. doi:10.1016/s0040-4039(01)86732-0

66. Kamphuis, J.; Grootenhuis, P. D. J.; Ruijter, A. P.; Visser, R. G.; Bos, H. J. T. Isr. J. Chem. 1985, 26, 120-130. doi:10.1002/ijch.198500081

67. Hofstra, G.; Kamphuis, J.; Bos, H. J. T. Tetrahedron Lett. 1984, 25 , 873-876. doi:10.1016/s0040-4039(01)80050-2

68. Coyle, J. D.; Rapley, P. A. Tetrahedron Lett. 1984, 25, 2247-2248. doi:10.1016/s0040-4039(01)80223-9

69. Jenner, G.; Papadopoulos, M. Tetrahedron Lett. 1985, 26, 725-726. doi:10.1016/s0040-4039(00)89119-4

70. Machida, M.; Oda, K.; Yoshida, E.; Kanaoka, Y. J. Org. Chem. 1985, 50, 1681-1688. doi:10.1021/jo00210a023

71. Machida, M.; Oda, K.; Yoshida, E.; Kanaoka, Y. Tetrahedron 1986, 42, 4691-4699. doi:10.1016/s0040-4020(01)82050-0

72. Oda, K.; Machida, M.; Kanaoka, Y. Synthesis 1986, 768-770. doi:10.1055/s-1986-31772

73. Coyle, J. D.; Rapley, P. A. J. Chem. Soc., Perkin Trans. 1 1986, 2273-2278. doi:10.1039/p19860002273

74. Ooms, P.; Hartmann, W. Tetrahedron Lett. 1987, 28, 2701-2704. doi:10.1016/s0040-4039(00)96185-9

75. Nishio, T. J. Chem. Soc., Perkin Trans. 1 1987, 1225-1228. doi:10.1039/p19870001225

76. Takechi, H.; Machida, M.; Kanaoka, Y. Chem. Pharm. Bull. 1989, 37, 1431-1433. doi:10.1248/cpb.37.1431

77. Rao, V. P.; Ramamurthy, V. J. Org. Chem. 1988, 53, 332-339. doi:10.1021/jo00237a021

78. Devanathan, S.; Ramamurthy, V. J. Org. Chem. 1988, 53, 741-744. doi:10.1021/jo00239a007

79. Oda, K.; Machida, M.; Kanaoka, Y. Heterocycles 1988, 27, 2417-2422. doi:10.3987/com-88-4649

80. Nishio, T.; Okuda, N.; Omote, Y. J. Chem. Soc., Perkin Trans. 1 1988, 1663-1668. doi:10.1039/p19880001663

81. Nishio, T. J. Chem. Soc., Perkin Trans. 1 1999, 1151-1152. doi:10.1039/a900699k

82. Nishio, T.; lida, I.; Sugiyama, K. J. Chem. Soc., Perkin Trans. 12000 , 3039-3046. doi:10.1039/b002548h

83. Nishio, T.; Shiwa, K.; Sakamoto, M. Helv. Chim. Acta 2002, 85, 2383-2393. doi:10.1002/1522-2675(200208)85:8<2383::aid-hlca2383>3.0.co;2-e

84. Nishio, T.; Shiwa, K.; Sakamoto, M. Helv. Chim. Acta 2003, 86, 3255-3264. doi:10.1002/hlca.200390266

85. Takechi, H.; Machida, M.; Kanaoka, Y. Synthesis 1992, 778-782. doi:10.1055/s-1992-26225

86. Takechi, H.; Takahashi, H.; Machida, M. J. Heterocycl. Chem. 2005 , 42, 201-207. doi:10.1002/jhet.5570420204 
87. Bonini, B. F.; Franchini, M. C.; Fochi, M.; Mazzanti, G.; Ricci, A.; Zani, P.; Zwanenburg, P. J. Chem. Soc., Perkin Trans. 1 1995, 2039-2044. doi:10.1039/p19950002039

88. Sakamoto, M.; Shigekura, M.; Saito, A.; Ohtake, T.; Mino, T.; Fujita, T. Chem. Commun. 2003, 2218-2219. doi:10.1039/b304435a

89. Friedel, M. G.; Cichon, M. K.; Carell, T. Org. Biomol. Chem. 2005, 3, 1937-1941. doi:10.1039/b503205a

90. Nakadaira, Y.; Ohkura, Y.; Kyushin, S.; Ohashi, M.; Sakurai, H.; Ueno, K.; Kanouchi, S. Tetrahedron Lett. 1992, 33, 4013-4016. doi:10.1016/0040-4039(92)88088-m

91. Machida, M.; Oda, K.; Kanaoka, Y. Chem. Pharm. Bull. 1985, 33, 3552-3554. doi:10.1248/cpb.33.3552

92. Oda, K.; Machida, M.; Aoe, K.; Nishibata, Y.; Sato, Y.; Kanaoka, Y. Chem. Pharm. Bull. 1986, 34, 1411-1414. doi:10.1248/cpb.34.1411

93. Wipf, P.; Heimgartner, H. Helv. Chim. Acta 1987, 70, 992-994. doi:10.1002/hlca.19870700409

94. Oda, K.; Machida, M.; Kanaoka, Y. Chem. Pharm. Bull. 1992, 40, 585-587. doi:10.1248/cpb.40.585

95. Padwa, A.; Jacquez, M. N.; Schmidt, A. J. Org. Chem. 2004, 69, 33-45. doi:10.1021/j0035127w

96. Sakamoto, M.; Yanase, T.; Fujita, T.; Watanabe, S.; Aoyama, H.; Omote, Y. J. Chem. Soc., Perkin Trans. 1 1991, 403-407. doi:10.1039/p19910000403

97. Sakamoto, M.; Hokari, N.; Takahashi, M.; Fujita, T.; Watanabe, S.; lida, I.; Nishio, T. J. Am. Chem. Soc. 1993, 115, 818. doi:10.1021/ja00055a080

98. Sakamoto, M.; Takahashi, M.; Mino, T.; Fujita, T. Tetrahedron 2001, 57, 6713-6719. doi:10.1016/s0040-4020(01)00619-6

99. Petrov, V. A.; Krespan, C. G.; Marshall, W. J. Fluorine Chem. 2005, 126, 1332-1341. doi:10.1016/j.jfluchem.2005.07.001

100.Petrov, V. A.; Marshall, W. J. Fluorine Chem. 2012, 143, 220-225. doi:10.1016/j.jluchem.2012.06.031

101.Petrov, V. A.; Marshall, W. J. Fluorine Chem. 2015, 179, 56-63. doi:10.1016/j.jfluchem.2015.04.003

102.L'abbé, G.; Dekerk, J.-P.; Declercq, J.-P.; Germain, G.; Van Meerssche, M. Tetrahedron Lett. 1979, 20, 3213-3216. doi:10.1016/s0040-4039(01)95365-1

103. Bestmann, H. J.; Siegel, B.; Schmid, G. Chem. Lett. 1986, 15 , 1529-1530. doi:10.1246/cl.1986.1529

104.Yang, H.-B.; Yuan, Y.-C.; Wei, Y.; Shi, M. Chem. Commun. 2015, 51, 6430-6433. doi:10.1039/c5cc01313e

105. Tomashevskii, A. A.; Sokolov, V. V.; Potekhin, A. A. Russ. J. Org. Chem. 2003, 39, 226-234. doi:10.1023/a:1025592320130

106. Allakhverdiev, M. A.; Akperov, N. A.; Farzaliev, V. M.; Zeinalov, G. A.; Agaeva, M. N. Zh. Prikl. Khim. (S.-Peterburg, Russ. Fed.) 1988, 61, 1441.

107. Allakhverdiev, M. A.; Akperov, N. A.; Farzaliev, V. M.; Gasanov, B. R.; Goryachev, V. V. Khim. Geterotsikl. Soedin. 1988, 1619.

108. Cassayre, J. Y.; Godineau, E.; Boussemghoune, M. A.; Smits, H. PCT Patent Appllication WO 2013/007582 A2, Jan 17, 2013.

109. Klen, E. E.; Khaliullin, F. A.; Iskhakova, G. F. Russ. J. Org. Chem. 2005, 41, 1847-1848. doi:10.1007/s11178-006-0047-3

110.Sokolov, V. V.; Butkevich, A. N.; Yuskovets, V. N.; Tomashevskii, A. A.; Potekhin, A. A. Russ. J. Org. Chem. 2005, 41, 1023-1035. doi:10.1007/s11178-005-0288-6

111.Butkevich, A. N.; Sokolov, V. V.; Tomashevskii, A. A.; Potekhin, A. A. Russ. J. Org. Chem. 2006, 42, 1244-1245. doi: $10.1134 / \mathrm{s} 1070428006080276$
112.Butkevich, A. N.; Zibinsky, M.; Sokolov, V. V.; Tomashevskii, A. A. Chem. Heterocycl. Compd. 2012, 47, 1509-1515. doi:10.1007/s10593-012-0941-2

113. Kataev, V. A.; Meshcheryakova, S. A.; Lazarev, V. V.; Kuznetsov, V. V. Russ. J. Org. Chem. 2013, 49, 743-745. doi:10.1134/s1070428013050199

114. Khaliullin, F. A.; Klen, E. E. Russ. J. Org. Chem. 2009, 45, 135-138. doi:10.1134/s1070428009010187

115. Ongoka, P.; Mauzé, B.; Miginiac, L. Synthesis 1985, 1069-1070. doi:10.1055/s-1985-31432

116. Okuma, K.; Tanaka, Y.; Kaji, S.; Ohta, H. J. Org. Chem. 1983, 48, 5133-5134. doi:10.1021/jo00173a072

117. Butova, E. D.; Barabash, A. V.; Petrova, A. A.; Kleiner, C. M.; Schreiner, P. R.; Fokin, A. A. J. Org. Chem. 2010, 75, 6229-6235. doi:10.1021/j0101330p

118. Jamieson, M. L.; Hume, P. A.; Furkert, D. P.; Brimble, M. A. Org. Lett. 2016, 18, 468-471. doi:10.1021/acs.orglett.5b03514

119. Vaultier, M.; Danion-Bougot, R.; Danion, D.; Hamelin, J.; Carrie, R. J. Org. Chem. 1975, 40, 2990-2992. doi:10.1021/jo00908a043

120. Nadir, U. K.; Sharma, R. L.; Koul, V. K. Tetrahedron 1989, 45 , 1851-1858. doi:10.1016/s0040-4020(01)80051-X

121. Huang, J. X.; Wang, F.; Du, D. M.; Xu, J. X. Synthesis 2005, 2122-2128. doi:10.1055/s-2005-869994

122. Huang, J. X.; Du, D. M.; Xu, J. X. Synthesis 2006, 315-319. doi:10.1055/s-2005-924767

123. Chen, X.; Xu, J. Tetrahedron Lett. 2017, 58, 1651-1654. doi:10.1016/j.tetlet.2017.03.039

124.Zhou, C.; Xu, J. X. Prog. Chem. 2012, 24, 338-347.

125. Yu, H.; Cao, S. L.; Zhang, L. L.; Liu, G.; Xu, J. X. Synthesis 2009, 2205-2209. doi:10.1055/s-0029-1216816

126. Li, X. Y.; Xu, J. X. Tetrahedron 2011, 67, 1681-1688. doi:10.1016/j.tet.2010.12.063

127.Hu, L.; Zhu, H.; Du, D.-M.; Xu, J. J. Org. Chem. 2007, 72, 4543-4546. doi:10.1021/jo070470c

128. Li, X.; Yang, Z.; Xu, J. Curr. Org. Synth. 2013, 10, 169-177. doi:10.2174/1570179411310010009

129.Zhou, C.; Xu, J. X. Prog. Chem. 2011, 23, 174-189.

130. Ma, L. G.; Xu, J. X. Prog. Chem. 2004, 16, 220-235.

131. Li, S.; Chen, X.; Xu, J. Tetrahedron 2018, 74, 1613-1620. doi:10.1016/j.tet.2018.01.014

132. Dong, J.; Xu, J. New J. Chem. 2018, 42, 9037-9044. doi:10.1039/c8nj01117f

133.L'abbé, G.; Francis, A.; Dehaen, W.; Toppet, S. J. Chem. Soc., Chem. Commun. 1995, 67-68. doi:10.1039/c39950000067

134.L'Abbé, G.; Francis, A.; Dehaen, W.; Bosman, J. Bull. Soc. Chim. Belg. 1996, 105, 253-258. doi:10.1002/bscb.19961050507

135. L'abbe, G.; Dekerk, J. P.; Martens, C.; Toppet, S. J. Org. Chem. 1980, 45, 4366-4371. doi:10.1021/jo01310a020

136.Jeong, L. S.; Moon, H. R.; Yoo, S. J.; Lee, S. N.; Kim, H.-D.; Chun, M. W. Nucleosides Nucleotides 1999, 18, 571-572. doi:10.1080/15257779908041497

137. Okuma, K.; Tsubone, T.; Shigetomi, T.; Shioji, K.; Yokomori, Y. Heterocycles 2005, 65, 1553-1556. doi:10.3987/com-05-10396

138. Ueno, Y.; Yadav, L. D. S.; Okawara, M. Synthesis 1981, 547-548. doi:10.1055/s-1981-29521

139. Yadav, L. D. S.; Kapoor, R. Synthesis 2002, 1502-1504. doi:10.1055/s-2002-33337 
140. Myrboth, B.; Laloo, B. M.; Mizar, P. Curr. Org. Chem. 2011, 15, 647-656. doi:10.2174/138527211794519032

141. Yadav, L. D. S.; Garima, R. K. Synthesis 2009, 1055-1058. doi:10.1055/s-0028-1088119

142.Rai, A.; Yadav, L. D. S. Tetrahedron 2012, 68, 2459-2464. doi:10.1016/j.tet.2012.01.062

143. Robertson, F. J.; Wu, J. J. Am. Chem. Soc. 2012, 134, 2775-2780. doi:10.1021/ja210758n

144.Soós, T.; Bacsó, A.; Szigeti, M.; Varga, S. Synthesis 2016, 49, 429-439. doi:10.1055/s-0036-1588612

145.Soulère, L.; Sturm, J.-C.; Núñez-Vergara, L. J.; Hoffmann, P.; Périé, J. Tetrahedron 2001, 57, 7173-7180. doi:10.1016/s0040-4020(01)00694-9

146.Pattenden, G.; Shuker, A. J. Tetrahedron Lett. 1991, 32, 6625-6628. doi:10.1016/0040-4039(91)80239-3

147.Pattenden, G.; Shuker, A. J. J. Chem. Soc., Perkin Trans. 11992 , 1215-1221. doi:10.1039/p19920001215

148. Lee, A. H. F.; Chan, A. S. C.; Li, T. Tetrahedron 2003, 59, 833-839. doi:10.1016/s0040-4020(02)01600-9

149. Keerthi, K.; Rajapakse, A.; Sun, D.; Gates, K. S. Bioorg. Med. Chem. 2013, 21, 235-241. doi:10.1016/j.bmc.2012.10.021

150.Liu, T.; Ma, M.; Ge, H.-M.; Yang, C.; Cleveland, J.; Shen, B. Bioorg. Med. Chem. Lett. 2015, 25, 4899-4902. doi:10.1016/j.bmcl.2015.05.078

151.Chaput, J.-P.; St-Pierre, S.; Tremblay, A. Mini-Rev. Med. Chem. 2007, 7, 3-10. doi:10.2174/138955707779317849

152. Aubry, S.; Aubert, G.; Cresteil, T.; Crich, D. Org. Biomol. Chem. 2012, 10, 2629-2632. doi:10.1039/c2ob06976h

153.Lei, M.-Y.; Fukamizu, K.; Xiao, Y.-J.; Liu, W.-M.; Twiddy, S.; Chiba, S.; Ando, K.; Narasaka, K. Tetrahedron Lett. 2008, 49, 4125-4129. doi:10.1016/j.tetlet.2008.04.127

154.Lei, M.-Y.; Xiao, Y.-J.; Liu, W.-M.; Fukamizu, K.; Chiba, S.; Ando, K.; Narasaka, K. Tetrahedron 2009, 65, 6888-6902. doi:10.1016/j.tet.2009.06.078

155.Zhao, Q.; Li, L.; Fang, Y.; Sun, D.; Li, C. J. Org. Chem. 2009, 74, 459-462. doi:10.1021/j0802235e

156.Sanin, A. V.; Nenajdenko, V. G.; Kuz'min, V. S.; Balenkova, E. S. J. Org. Chem. 1996, 61, 1986-1989. doi:10.1021/jo951351c

157. Uenishi, J.; Motoyama, M.; Kimura, Y.; Yonemitsu, O. Heterocycles 1998, 47, 439-451. doi:10.3987/com-97-s(n)67

158. Bonini, B. F.; Franchini, M. C.; Fochi, M.; Mangini, S.; Mazzanti, G.; Ricci, A. Eur. J. Org. Chem. 2000, 2391-2399. doi:10.1002/1099-0690(200007)2000:13<2391::aid-ejoc2391>3.0.co;2 $-\mathrm{m}$

159. Tarasova, O. A.; Brandsma, L.; Nedolya, N. A.; Ushakov, I. A.; Dmitrieva, G. V.; Koroteeva, T. V. Russ. J. Org. Chem. 2004, 40, 131-132. doi:10.1023/b:rujo.0000034923.10292.65

160. Tarasova, O. A.; Brandsma, L.; Nedolya, N. A.; Albanov, A. I.; Klyba, L. B.; Trofimov, B. A. Russ. J. Org. Chem. 2004, 40, 753-754. doi:10.1023/b:rujo.0000043727.09029.24

161.Ozaki, S.; Matsui, E.; Saiki, T.; Yoshinaga, H.; Ohmori, H. Tetrahedron Lett. 1998, 39, 8121-8124. doi:10.1016/s0040-4039(98)01802-4

162.Sakamoto, M.; Ishida, T.; Fujita, T.; Watanabe, S. J. Org. Chem. 1992, 57, 2419-2422. doi:10.1021/jo00034a040

163.Dondoni, A.; Battaglia, A.; Giorgianni, P. J. Org. Chem. 1980, 45, 3766-3773. doi:10.1021/jo01307a009

164. Mulzer, J.; Kermann, T. Angew. Chem., Int. Ed. Engl. 1980, 19, 466-468. doi:10.1002/anie.198004661
165.Schaumann, E.; Möller, M.; Adiwidjaja, G. Chem. Ber. 1988, 121, 689-699. doi:10.1002/cber.19881210416

166. Mulzer, J.; Kerkmann, T. Angew. Chem. 1980, 92, 470-471. doi:10.1002/ange.19800920613

167. Bestmann, H. J.; Schmid, G.; Sandmeier, D.; Geismann, C. Tetrahedron Lett. 1980, 21, 2401-2404. doi:10.1016/s0040-4039(00)93160-5

168. Coyle, J. P.; Rapley, P. A.; Kamphuis, J.; Bos, H. J. T. J. Chem. Soc., Perkin Trans. 1 1985, 1957-1959. doi:10.1039/p19850001957

169. Yoon, K. S.; Lee, S. J.; Kim, K. Heterocycles 1996, 43, 1211-1221. doi:10.3987/com-96-7417

170. Bestmann, H. J. Angew. Chem., Int. Ed. Engl. 1977, 16, 349-364. doi:10.1002/anie. 197703491

171.L'Abbé, G.; Huybrechts, L.; Declercq, J.-P.; Germain, G.; van Meerssche, M. J. Chem. Soc., Chem. Commun. 1979, 160-161. doi:10.1039/c39790000160

172.Langer, P.; Döring, M. Chem. Commun. 1999, 2439-2440. doi:10.1039/a906913e

173. Press, J. B.; McNally, J. J.; Hajos, Z. G.; Sawyers, R. A. J. Org. Chem. 1992, 57, 6335-6339. doi:10.1021/jo00049a052

174. Fang, Y.; Rogge, T.; Ackermann, L.; Wang, S.-Y.; Ji, S.-J. Nat. Commun. 2018, 9, 2240. doi:10.1038/s41467-018-04646-2

175. Petrov, V. J. Fluorine Chem. 2018, 212, 1-4. doi:10.1016/j.jfluchem.2018.05.004

176. Woolhouse, A. D.; Gainsford, G. J.; Crump, D. R. J. Heterocycl. Chem. 1993, 30, 873-880. doi:10.1002/jhet.5570300405

177. Muthuramu, K.; Sundari, B.; Ramamurthy, V. Tetrahedron 1983, 39 2719-2723. doi:10.1016/s0040-4020(01)91983-0

178. Mloston, G.; Prakash, G. K. S.; Olah, G. A.; Heimgartner, H. Helv. Chim. Acta 2002, 85, 1644-1658. doi:10.1002/1522-2675(200206)85:6<1644::aid-hlca1644>3.0.co;2-8

179. Utecht, G.; Sioma, J.; Jasiński, M.; Mlostoń, G. J. Fluorine Chem. 2017, 201, 68-75. doi:10.1016/j.jfluchem.2017.07.014

180. Russavskaya, N. V.; Levanova, E. P.; Klyba, L. V.; Zhanchipova, E. R.; Grabel'nykh, V. A.; Sukhomazova, E. N.; Albanov, A. I.; Kochervin, N. A.; Deryagina, E. N. Russ. J. Gen. Chem. 2006, 76, 156-157. doi:10.1134/s1070363206010300

\section{License and Terms}

This is an Open Access article under the terms of the Creative Commons Attribution License (http://creativecommons.org/licenses/by/4.0). Please note that the reuse, redistribution and reproduction in particular requires that the authors and source are credited.

The license is subject to the Beilstein Journal of Organic Chemistry terms and conditions: (https://www.beilstein-journals.org/bjoc)

The definitive version of this article is the electronic one which can be found at: doi: $10.3762 /$ bjoc. 16.116 